\title{
Upgrading of Ethanol to $n$-Butanol via a Ruthenium Catalyst in Aqueous Solution
}

\author{
Tarah A. DiBenedetto, William D. Jones* \\ Department of Chemistry, University of Rochester, Rochester, NY 14627 \\ jones@chem.rochester.edu \\ Supporting Information
}

\section{Table of Contents}

1. General information

2. Synthesis

3. Reaction setup

4. Optimization of workup

5. General reaction set-up and workup

6. Reaction optimization

7. GC Data

8. IR Data

9. Examination of aqueous phase of the reaction

10. References

S-76 


\section{S1. General information}

\section{S1.1 Reagents}

\section{$\underline{\text { Metal Complexes }}$}

Unless otherwise noted, all organometallic compounds were prepared and handled under a nitrogen atmosphere using standard Schlenk and glovebox techniques.

\section{Catalysts}

$\left[\left(\eta^{6}-p\right.\right.$-cymene $) \mathrm{RuCl}\left(6,6^{\prime}\right.$-dihydroxy-2,2'-bipyridine $\left.)\right] \mathrm{Cl}$ was synthesized according to the literature procedure. ${ }^{1}$

\section{$\underline{\text { Solvents }}$}

Anhydrous diethyl ether and acetonitrile was obtained from an Innovative Technology PSMD-6 solvent purification system and the diethyl ether was degassed and stored in a nitrogen glovebox. Methanol was obtained from Fisher Scientific, freeze pump thawed and stored in a Schlenk flask. Deionized water was obtained from a Barnstead Nanopure water purification system and used without further purification. $\mathrm{D}_{2} \mathrm{O}$, and DMSO-d $6\left(\left(\mathrm{CD}_{3}\right)_{2} \mathrm{SO}\right)$ were purchased from Cambridge Isotopes and used without further purification.

\section{$\underline{\text { Other reagents }}$}

Reagents were used as received from the following sources: Reagents were used as received from the following sources: dichloro(p-cymene)ruthenium(II) dimer, crotonaldehyde, 1-hexanol, 2-hexanol, 2-ethyl-1-butanol, sodium methoxide, sodium ethoxide, sodium phenoxide, sodium tert-butoxide, Hunigs base, DBU (Sigma Aldrich); 6,6'-dihydroxy-2,2'-bipyridine (TCI); ethanol 200 proof, $n$-butanol, $n$-propanol, potassium hydroxide, sodium hydroxide, lithium hydroxide, triethylamine, basic alumina (Fisher 
Scientific); acetaldehyde, potassium tert-butoxide (Acros Organics); acidic alumina (M. Woelm Eschwege Germany); neutral alumina (Alfa Aesar); $\mathrm{C}_{18}$ silica (J.T. Baker).

\section{S1.2 Methods}

\section{NMR spectroscopy}

${ }^{1} \mathrm{H}$ NMR spectra were recorded on 400 and $500 \mathrm{MHz}$ Bruker Avance NMR instruments. NMR chemical shifts are reported in ppm and are referenced to the residual solvent peak $\left(\mathrm{CD}_{3}\right)_{2} \mathrm{SO}(\delta=2.50)$ and $\mathrm{D}_{2} \mathrm{O}(\delta=4.79)$. Coupling constants $(J)$ are reported in Hertz. $\underline{\mathrm{GC} \text { analysis }}$

GC chromatograms were recorded on a Shimadzu GC-2010 Plus instrument equipped with an AOC-20i auto injector and a DB-WaxETR column $(30 \mathrm{M} \times 0.25 \mathrm{~mm}$ ID $\times 0.5 \mu \mathrm{m})$. Column flow $=2 \mathrm{~mL} / \mathrm{min}$, injection temperature $225^{\circ} \mathrm{C}$, split ratio $20: 1$, pressure $20.3 \mathrm{psi}$, temperature program: $5 \mathrm{~min}$ at $50^{\circ} \mathrm{C}$, then increase at $15{ }^{\circ} \mathrm{C} / \mathrm{min}$ to $155^{\circ} \mathrm{C}$ and hold for 3 $\min$.

\section{$\underline{\text { GC-MS analysis }}$}

GC-MS spectra were recorded on a Shimadzu QP-5000 instrument equipped with a DBWaxETR column $(30 \mathrm{M} \times 0.25 \mathrm{~mm}$ ID $\times 0.25 \mu \mathrm{m}$ film $)$. Column flow $=1.3 \mathrm{~mL} / \mathrm{min}$, injection temperature $225^{\circ} \mathrm{C}$, split ratio $21: 1$, temperature program: 5 min at $50{ }^{\circ} \mathrm{C}$, then increase at $15{ }^{\circ} \mathrm{C} / \mathrm{min}$ to $155^{\circ} \mathrm{C}$ and hold for $3 \mathrm{~min}$.

\section{$\underline{\text { Elemental analysis }}$}

Elemental analyses were obtained from the CENTC Elemental Analysis Facility at the University of Rochester using a Perkin Elmer PerkinElmer 2400 Series II Analyzer. 


\section{S2. Synthesis}

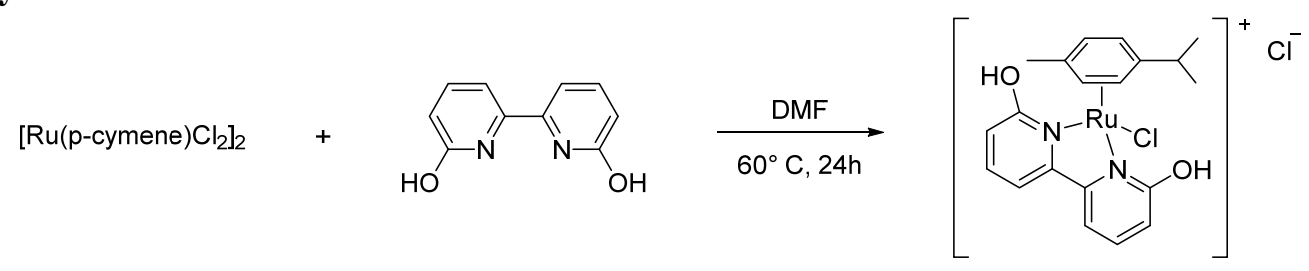

Synthesis of $\left[\left(\eta^{6}-p\right.\right.$-cymene $) \operatorname{RuCl}\left(6,6^{\prime}\right.$-dihydroxy-2,2'-bipyridine $\left.)\right] \mathrm{Cl}\left[\mathrm{Ru}\left(\mathrm{bipy}^{\mathrm{OH}}\right)\right]$ : In

a glove box an oven-dried 50mL Schlenk flask was charged with 6,6'-dihydroxy-2,2'bipyridine (0.408 mmol, 0.50 equiv), dichloro( $p$-cymene)ruthenium(II) dimer $(0.815$ mmol, 1.00 equiv) and freeze pump thaw degassed DMF $(10.0 \mathrm{~mL})$. The reaction was sealed and removed from the glove box and placed in a $60{ }^{\circ} \mathrm{C}$ oil bath for $24 \mathrm{~h}$. The reaction was then cooled to room temperature and concentrated on a vacuum line to afford a bright orange solid. The bright orange solid was dissolved in a minimal amount of freeze pump thaw degassed methanol (2-5 mL) and precipitated out with excess diethyl ether (20-50 $\mathrm{mL}$ ). Once the semi-dry orange product was obtained either steps A or B were followed.

A: The Schlenk flask was sealed and brought into the glove box, the orange solid was placed in a glass frit and washed with diethyl ether $(50 \mathrm{~mL})$ and dried on a vacuum line to afford product [Ru(bipy $\left.\left.{ }^{\mathbf{O H}}\right)\right](0.3637 \mathrm{~g}, 85 \%$ yield $)$. Elemental analysis calculated for $\mathrm{C}_{20} \mathrm{H}_{22} \mathrm{~N}_{2} \mathrm{O}_{2} \mathrm{RuCl}_{2}+1 \mathrm{CH}_{3} \mathrm{OH}$ (MW: $526.42 \mathrm{~g} / \mathrm{mol}$ ) Calculated: C: 47.91, H: 4.98, N: 5.32. Found C: 47.79, H: 4.91, N: 5.27.

B: The orange solid was removed from the Schlenk flask outside of the box and placed in a gravity filter and washed with diethyl either $(50 \mathrm{~mL})$ and dried on a vacuum line to afford product $\left[\mathbf{R u}\left(\mathbf{b i p y}^{\mathbf{O H}}\right)\right] \quad(0.318 \mathrm{~g}, \quad 79 \%$ yield $)$. Elemental analysis calculated for $\mathrm{C}_{20} \mathrm{H}_{22} \mathrm{~N}_{2} \mathrm{O}_{2} \mathrm{RuCl}_{2}$ (MW: $494.38 \mathrm{~g} / \mathrm{mol}$ ) Calculated: C: 48.59, H: 4.49, N: 5.67. Found C: 48.31, H: 4.41, N: 5.34 . 
Spectroscopic data matched the reported data ${ }^{1}{ }^{1} \mathrm{H}$ NMR (400 MHz, $\left(\left(\mathrm{CD}_{3}\right)_{2} \mathrm{SO}\right): \delta 7.93$ (m, 4H), $7.18(\mathrm{~d}, J=7.8 \mathrm{~Hz}, 2 \mathrm{H}), 6.16(\mathrm{~d}, J=6.0 \mathrm{~Hz}, 2 \mathrm{H}), 5.68(\mathrm{~d}, J=6.0 \mathrm{~Hz}, 2 \mathrm{H}), 2.41$ (m, 1H), $2.22(\mathrm{~s}, 3 \mathrm{H}), 0.86(\mathrm{~d}, J=7.0 \mathrm{~Hz}, 6 \mathrm{H})$.

\section{S3. Reaction setup}
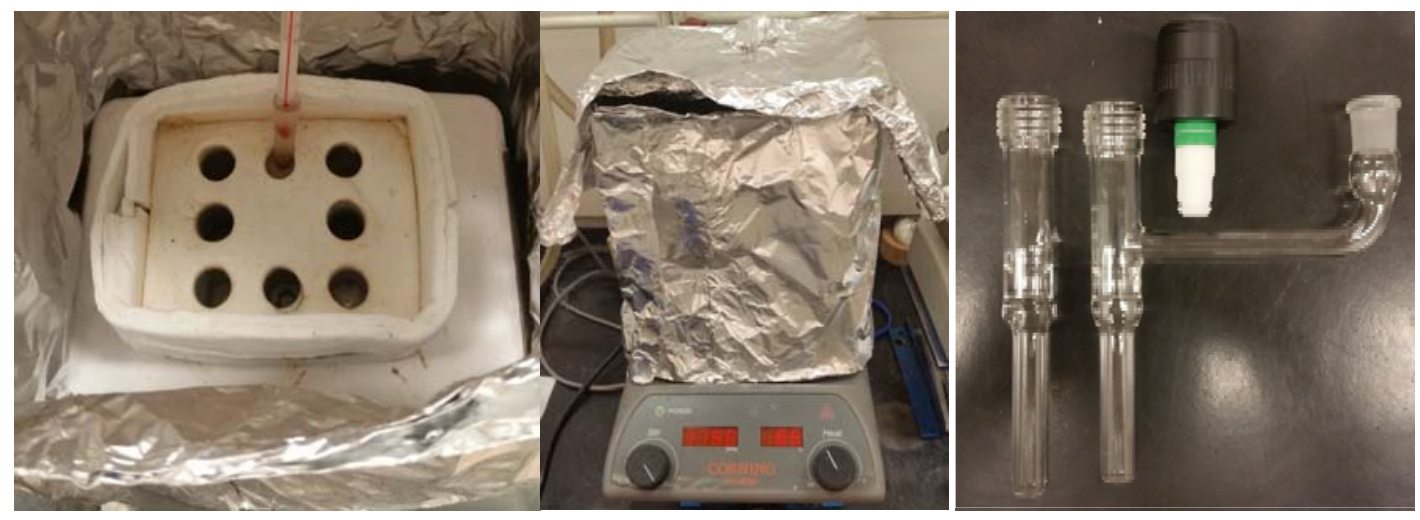

Reactions were conducted in Pyrex tubes $(6 \mathrm{~cm} \times 1 \mathrm{~cm})$ sealed with a Teflon valve. They were placed in a thermostated aluminum block heater at the indicated reaction temperature.

\section{S4. Optimization of workup}

This section describes several different workup procedures that proved unsatisfactory for quantitation. Section S5 describes the successful workup procedure.

\section{S4.1 Order of addition of internal standard}

For the optimization of the reaction workup, standard samples were used. A 1-dram vial was charged with 200 proof ethanol $1(58 \mu \mathrm{L}), n$-butanol 2 (46 $\mu \mathrm{L}), n$-propanol (internal standard, $10 \mu \mathrm{L})$ and petroleum ether $(2 \mathrm{~mL})$. The reactions were submitted to different workup conditions and analyzed by GC. Filtration: A $3 \mathrm{~cm}$ Pasteur pipette plug filled with celite. 
Table S1. Yields (\%) obtained with standard samples vs. order of addition of internal standard.

\begin{tabular}{|c|c|c|c|}
\hline Entry & Workup & $1^{b}$ & $2^{b}$ \\
\hline 1 & None. Run directly on GC & 101 & 98 \\
\hline 2 & Filter rxn through celite (internal Std. added after filtration) & 78 & 77 \\
\hline 3 & $\begin{array}{l}\text { Filter rxn through wet celite (internal Std. added after } \\
\text { filtration) }\end{array}$ & 79 & 81 \\
\hline 4 & $\begin{array}{l}\text { Filter rxn through wet celite (internal Std. added before } \\
\text { filtration) }\end{array}$ & 103 & 100 \\
\hline 5 & Filter rxn through celite (internal Std. added before filtration) & 103 & 103 \\
\hline 6 & $\begin{array}{l}\text { Filter rxn through celite using ether (internal Std. added before } \\
\text { filtration) }\end{array}$ & 105 & 102 \\
\hline
\end{tabular}

${ }^{\mathrm{b}} \mathrm{GC}(\%)$ yield vs $n$-propanol as the internal standard.

We observed running the standard sample directly on the GC recovered the starting materials within error of the GC measurement (entry 1). When adding the internal standard to the reaction after filtration through the celite plug we observed a loss in the recovery of both ethanol and butanol (Table $\mathrm{C} 1$, entry 2-3). Adding the internal standard before filtration resulted in the best recovery of starting materials (Table C1, 4-6). These results suggest that we lose a significant amount of material when using celite as a filtration material. If celite must be used the only way to account for the loss is to add the internal standard prior to filtration.

\section{S4.2 Acidic workup}

For the optimization of the reaction workup, standard samples were used. A 1-dram vial was charged with 200 proof ethanol $1(58 \mu \mathrm{L})$, n-butanol $2(46 \mu \mathrm{L}), n$-propanol (internal standard IS, $10 \mu \mathrm{L}), \mathrm{KOH}(0.0224 \mathrm{~g}), \mathrm{H}_{2} \mathrm{O}(0.3 \mathrm{~mL})$. The reactions were submitted to different workup conditions, using diethyl ether for the workup and analyzed by GC. Filtration: A $3 \mathrm{~cm}$ Pasteur pipette plug filled with celite. 
Table S2. Yields (\%) obtained with standard samples vs. order of addition of internal standard.

\begin{tabular}{|c|c|c|c|}
\hline Entry & Workup & $1^{b}$ & $2^{b}$ \\
\hline 1 & Acidify w/ $2 \% \mathrm{HCl}$, add IS, filter through celite & 59 & 118 \\
\hline 2 & $\begin{array}{c}\text { Neutralize with } 2 \mathrm{~mL} \text { aq. ammonium chloride, add IS, filter } \\
\text { through celite }\end{array}$ & 45 & 141 \\
\hline 3 & $\begin{array}{c}\text { Acidify } \mathrm{w} / 2 \% \mathrm{HCl} \text {, add IS, extract }(3 \times 1 \mathrm{~mL}) \mathrm{w} / \text { ether, filter } \\
\text { each extraction through celite }\end{array}$ & 62 & 106 \\
\hline 4 & $\begin{array}{l}\text { Neutralize with } 2 \mathrm{~mL} \text { aq. ammonium chloride, add IS, extract } \\
(3 \mathrm{x} 1 \mathrm{~mL}) \mathrm{w} / \text { ether, filter each extraction through celite }\end{array}$ & 51 & 115 \\
\hline
\end{tabular}

${ }^{\mathrm{b}} \mathrm{GC}(\%)$ yield vs $n$-propanol as the internal standard

Workup entry 1: the reaction was acidified with $2 \% \mathrm{HCl}$ (until $\mathrm{pH}$ of 1-2 was reached), the internal standard was added, and the reaction was extracted with $2 \mathrm{~mL}$ diethyl ether and filtered through celite.

Workup entry 2: the reaction was neutralized with a saturated solution of ammonium chloride ( $2 \mathrm{~mL}$, reached a $\mathrm{pH}$ of 8$)$, internal standard was added, and the reaction was extracted with $2 \mathrm{~mL}$ diethyl either and filtered through celite.

Workup entry 3: the reaction was acidified with $2 \% \mathrm{HCl}$ (until $\mathrm{pH}$ of $1-2$ was reached), the internal standard was added, and the organics were extracted with diethyl ether $(3 \times 1$ $\mathrm{mL}$ ) and the extractions were filtered through celite.

Workup entry 4: the reaction was neutralized with a saturated solution of ammonium chloride $(2 \mathrm{~mL}$, reached a $\mathrm{pH}$ of 8$)$, internal standard was added, and the organics were extracted with diethyl ether $(3 \times 1 \mathrm{~mL})$ and the extractions were filtered through celite.

Conclusion: the inflated $n$-butanol yield is likely due to the fact that the internal standard is more soluble in water, making the full extraction difficult. Similarly, the high solubility 
of ethanol in water makes the full extraction of ethanol difficult, resulting in low ethanol recovery. More extractions are necessary.

\section{S4.3 Acidic workup with multiple extractions}

For the optimization of the reaction workup, standard samples were used. A 1-dram vial was charged with 200 proof ethanol $1(58 \mu \mathrm{L}), n$-butanol $2(46 \mu \mathrm{L}), n$-propanol (internal standard, $10 \mu \mathrm{L}), \mathrm{KOH}(0.0224 \mathrm{~g})$, and $\mathrm{H}_{2} \mathrm{O}(0.3 \mathrm{~mL})$. The reactions were submitted to the same workup conditions to determine the reproducibility the reaction. Filtration: A $3 \mathrm{~cm}$ Pasteur pipette plug filled with celite

Workup entry 1-6: the reaction was acidified with $0.54 \mathrm{~mL}$ of $2 \% \mathrm{HCl}$ solution to achieve a $\mathrm{pH}$ of 2 . The internal standard was then added, and the organics were extracted with diethyl ether (4 x $1 \mathrm{~mL})$ and filtered through celite.

Table S3. Workup with multiple extractions

\begin{tabular}{c|cc}
\hline $\boldsymbol{E n t r y}$ & $\boldsymbol{1}^{\boldsymbol{b}}$ & $\boldsymbol{2}^{\boldsymbol{b}}$ \\
\hline 1 & 71 & 102 \\
2 & 70 & 102 \\
3 & 70 & 105 \\
4 & 70 & 103 \\
5 & 74 & 107 \\
6 & 67 & 107 \\
\hline${ }^{\mathrm{b}} \mathrm{GC}(\%)$ yield vs & n-propanol as the internal standard
\end{tabular}

Conclusions: We observed that the extractions, while they are not able to fully extract the ethanol or the $n$-propanol, are consistent with the amount of ethanol and $n$-butanol that can be extracted.

When doing extractions with actual crude reactions, the catalyst will stay in the aqueous layer as long as the reaction is acidified. 


\section{S4.4 Filtration material}

In attempts to move away from extractions to a workup method that does not show loss of starting materials, we tried various filtration media. For the optimization of the reaction workup, standard samples were used. A 1-dram vial was charged with 200 proof ethanol 1 $(58 \mu \mathrm{L}), n$-butanol $2(46 \mu \mathrm{L})$ and petroleum ether $(2 \mathrm{~mL})$. The reactions were submitted to different workup conditions, then $n$-propanol (internal standard, $10 \mu \mathrm{L}$ ) was added and the reactions were analyzed by GC.

Table S4. Filtration material screen

\begin{tabular}{c|ccc}
\hline \multicolumn{1}{c}{ Entry } & Filtration material & $\boldsymbol{1}^{\boldsymbol{b}}$ & $\boldsymbol{2}^{\boldsymbol{b}}$ \\
\hline 1 & Glass wool plug & 99 & 101 \\
2 & Glass filter paper & 99 & 100 \\
3 & Cotton plug & 97 & 99 \\
4 & Hydrophilic syringe filter & 95 & 97 \\
5 & Hydrophobic syringe filter & 94 & 98 \\
6 & Celite (3cm) plugged with cotton & 94 & 98 \\
\hline
\end{tabular}

${ }^{\mathrm{b}} \mathrm{GC}(\%)$ yield vs $n$-propanol as the internal standard

Glass fiber filter paper: grade 934-AH, $2.4 \mathrm{~cm}$, VWR catalog \# 28496-773

Workup entry 1-6: the reaction was filtered through each respective plug and the plugs were washed with diethyl ether $(2 \mathrm{~mL})$, internal standard was then added and the reactions were analyzed by GC.

Conclusion: The glass filter paper showed the best overall retention of starting material, but when using this method in crude reactions, it was not enough to remove the catalyst. This method had to be used in conjunction with the acidic workup and extractions. 


\section{S4.5 Acidic workup with crude reactions and further solvent optimization}

Workup of crude reaction: the reaction was cooled to room temperature and $0.54 \mathrm{~mL}$ of $2 \% \mathrm{HCl}$ was added to the reaction vessel. The reaction was then filtered through a Pasteur pipette containing glass filter paper. The organics were then extracted with diethyl ether (4 x $1 \mathrm{~mL})$.

When using this method to determine the yield of $n$-butanol, some of the catalyst remained in the organic layer, making it impossible to analyze by GC (catalyst in the GC sample can cause an error of up to $5 \%$ in the yield).

Several other solvents were used to try and extract the organics without extracting the catalyst out of the aqueous layer. Below is a summary of the solvents that were used.

We did not want the solvent to extract any catalyst into the organic layer and we needed it to fully extract the $n$-butanol from the standard sample reactions. Unfortunately, pentane could only extract $64 \%$ of $n$-butanol from a standard sample, and benzene could only extract a maximum of $90 \%$-butanol. We did find that methyl-tert-butyl ether extracted $97 \%$ of $n$-butanol and left the catalyst in the aqueous layer when more acid was added. 
Table S5. Analysis of solvents in the extraction

\begin{tabular}{c|ccc}
\hline \multicolumn{1}{c}{ Solvent } & $\begin{array}{c}\text { Overlaps With } \\
\text { Peaks in GC? }\end{array}$ & $\begin{array}{c}\text { Extracts n-Butanol } \\
\text { Fully? }\end{array}$ & $\begin{array}{c}\text { Extracts } \\
\text { Catalyst? }\end{array}$ \\
\hline $\begin{array}{c}\text { Pentane } \\
\text { Petroleum Ether }\end{array}$ & NO & NO & NO \\
P-Xylene & NO & NO & NO \\
Toluene & YES & -- & NO \\
Benzene & YES & -- & NO \\
Ether & NO & NO & NO \\
THF & NO & YES & YES \\
Chloroform & -- & -- & YES \\
MTBE & -- & -- & YES \\
& NO & YES & NO
\end{tabular}

It turned out that in the crude reactions, more acid was necessary to achieve the desired $\mathrm{pH}$ of 2 . When we had a $\mathrm{pH}$ between 5-10, the catalyst would be extracted into the organic layer, but when additional acid was added, the catalyst remained in the aqueous layer. With this new result in mind, we again investigated the use of diethyl ether to extract the organics.

For the optimization of the reaction workup, standard samples were used. A 1-dram vial was charged with 200 proof ethanol 1, n-butanol 2, $\mathrm{KOH}(0.0224 \mathrm{~g})$, and $\mathrm{H}_{2} \mathrm{O}(0.3 \mathrm{~mL})$. The reactions were then acidified with $0.2 \mathrm{~mL}$ of $10 \% \mathrm{HCl}$ (used $10 \%$ now so we could use less water overall), filtered through a Pasteur pipette glass filter plug, and the organics were extracted with diethyl ether $(5 \times 1 \mathrm{~mL})$. The organics were collected and $n$-propanol (internal standard $10 \mu \mathrm{L}$ ) was added as an internal standard before analysis by GC. 
Table S6. Analysis of standard samples reactions with ether extractions

\begin{tabular}{c|cccc}
\hline $\boldsymbol{E n}$ Eny & Ethanol $\boldsymbol{\mu L}$ & $\boldsymbol{n}$-Butanol $\boldsymbol{\mu L}$ & $\boldsymbol{1}^{\boldsymbol{b}}$ & $\boldsymbol{2}^{\boldsymbol{b}}$ \\
\hline 1 & 58 & 46 & 82 & 100 \\
2 & 44 & 37 & 79 & 100 \\
3 & 29 & 28 & 82 & 100 \\
4 & 15 & 18 & 81 & 99 \\
5 & 9 & 9 & 79 & 98 \\
\hline
\end{tabular}

${ }^{\mathrm{b}} \mathrm{GC}(\%)$ yield vs $n$-propanol as the internal standard

Conclusion: while we were able to achieve recovery of $n$-butanol in the sample reactions and yield of $n$-butanol in the crude reactions, the recovery of ethanol could not be determined by GC analysis alone, because ethanol could not be fully extracted from the aqueous layers. Attempts were made to analyze the remaining ethanol in the aqueous layer using NMR yields, but this proved to be challenging and we decided not to move forward with this method.

\section{S4.6 Vacuum transfer}

In the glovebox, a 1-dram vial was charged with [Ru(bipy $\left.\left.{ }^{\mathbf{O H}}\right)\right](0.01 \mathrm{mmol}, 1 \mathrm{~mol} \%)$, and potassium hydroxide $(0.5 \mathrm{mmol}, 0.5$ equiv, $50 \mathrm{~mol} \%)$. The vial was capped with a septum and removed from the glovebox. Once outside the glovebox, $\mathrm{D}_{2} \mathrm{O}(0.2 \mathrm{~mL})$ was added to the vessel via a plastic syringe, 200 proof ethanol (1mmol, 1 equiv) was then added to the dram vial through the septa using an airtight glass syringe. The weight of ethanol was recorded, and the solution was transferred to a Schlenk flask. The dram vial was then washed with $\mathrm{D}_{2} \mathrm{O}(0.1 \mathrm{~mL})$ and the washings were added to the Schlenk flask. The flask was sealed and placed in a metal heating block at $80{ }^{\circ} \mathrm{C}$ for $24 \mathrm{~h}$. After $24 \mathrm{~h}$, the reaction was cooled to room temperature and vacuum transferred using a bridge to a new Schlenk 
flask. The reaction was diluted with $\mathrm{H}_{2} \mathrm{O}(5 \mathrm{~mL})$ and analyzed by $\mathrm{GC}$ using $n$-propanol (10 $\mu \mathrm{L})$ as the internal standard. It was determined that $59 \%$ of ethanol was recovered and $18 \%$

of $n$-butanol was produced, and no higher chain alcohols were observed in the GC. On a small scale, vacuum transfer is not a reliable quantitative method and this method does not allow higher chain alcohols to be analyzed due to their higher boiling points. We did not move forward with this method of analysis.

\section{S4.7 Filtrations with alumina and silica}

In the glovebox a 1-dram vial was charged with [Ru(bipy $\left.\left.{ }^{\mathbf{O H}}\right)\right](0.01 \mathrm{mmol}, 1 \mathrm{~mol} \%)$, and potassium hydroxide $(0.5 \mathrm{mmol}, 0.5$ equiv, $50 \mathrm{~mol} \%)$. The vial was capped with a septa and removed from the glovebox. Once outside the glovebox, $\mathrm{D}_{2} \mathrm{O}(0.3 \mathrm{~mL})$ was added to the vessel via a plastic syringe, 200 proof ethanol ( 1 mmol, 1 equiv) was then added to the dram vial through the septa using an airtight glass syringe. The weight of ethanol was recorded, and the solution was transferred to a Schlenk flask. The dram vial was then washed with $\mathrm{D}_{2} \mathrm{O}(0.1 \mathrm{~mL})$ and the washings were added to the Schlenk flask. The flask was sealed and placed in a metal heating block at $80{ }^{\circ} \mathrm{C}$ for $24 \mathrm{~h}$. The reaction was then used to test various filtration materials. 
Table S7. Qualitative analysis of alumina and silica filtration material

\begin{tabular}{|c|c|c|c|c|}
\hline Attempt & Filter & Color of filtrate & $p H$ & Conditions/Observations \\
\hline 1 & $\mathrm{C}_{18}$ silica plug & Orange & 14 & Filtered entire reaction \\
\hline 2 & $2^{\text {nd }} \mathrm{C}_{18}$ silica plug & Yellow & 14 & Filtered $0.1 \mathrm{~mL}$ of attempt 1 \\
\hline 3 & basic alumina & Yellow tint & 9 & Filtered $0.1 \mathrm{~mL}$ of attempt 1 \\
\hline 4 & $\begin{array}{l}\text { acidify reaction } \rightarrow \\
\text { filter } \mathrm{C}_{18} \text { silica plug }\end{array}$ & Yellow & 2 & Filtered $0.1 \mathrm{~mL}$ of attempt 1 \\
\hline 5 & $\begin{array}{l}\text { acidify reaction } \rightarrow \\
\text { filter alumina plug }\end{array}$ & $\begin{array}{l}\text { Yellow tint } \\
\text { clearer than } 4\end{array}$ & 2.5 & Filtered $0.1 \mathrm{~mL}$ of attempt 1 \\
\hline 6 & $\begin{array}{l}\text { Neutral Alumina } \\
5 \mathrm{~cm} \text { plug }\end{array}$ & Clear & 7 & $\begin{array}{c}\text { Filtered } 0.3 \mathrm{~mL} \text { of attempt } 1 \\
* * * \text { removes catalyst and } \\
\text { base } * *\end{array}$ \\
\hline
\end{tabular}

Filtering an entire reaction through the $5 \mathrm{~cm}$ of neutral alumina resulted in the catalyst and base being carried through into the filtrate, and using aliquots of the reaction led to poor recovery of ethanol and $n$-butanol. With these initial results in hand, we tested various combinations of filtration material and eluent. After testing various types of alumina (neutral, acidic, and basic), it was determined that only neutral alumina was sufficient in removing the base from the reaction. After running various test reactions, it was determined that $6.5 \mathrm{~cm}$ of neutral alumina (wet packed) was optimal to remove $\mathrm{KOH}(0.0224 \mathrm{~g})$ when the reaction was eluted with $5 \mathrm{~mL}$ of DI water. If the reaction was eluted with more than 5 $\mathrm{mL}$ of DI water, the base would be washed into the filtrate. Acetonitrile and various water acetonitrile eluents were also used, but they were unsuccessful in recovering the alcohols. Although the neutral alumina was able to remove the base, it was not able to remove the catalyst. Previously when using $\mathrm{C}_{18}$ silica (reverse phase), the catalyst went through the plug, but if the reaction is filtered through alumina to remove the base (solution is $\mathrm{pH}$ of 7 now) and then filtered through reverse phase silica, the catalyst sticks to the silica and is 
removed. Although alcohols should be readily eluted on reverse phase silica, this was not the case. Various eluent ratios were tried in order to recover most of the starting material and products. The optimized eluents for the reverse phase silica plug were $4 \mathrm{~mL}$ of deionized water, $2 \mathrm{~mL}$ 80:20 $\left(\mathrm{H}_{2} \mathrm{O}: \mathrm{MeCN}\right), 4 \mathrm{~mL}$ 50:50 $\left(\mathrm{H}_{2} \mathrm{O}: \mathrm{MeCN}\right), 4 \mathrm{~mL}$ 40:60 $\left(\mathrm{H}_{2} \mathrm{O}: \mathrm{MeCN}\right)$, and $3 \mathrm{~mL}$ of $\mathrm{MeCN}$. With the filtration optimized, we looked into the temperature at which the reactions were worked up and found that a tandem filtration at with the collection flask in a dry ice ethylene glycol bath was optimal.

\section{S5. General reaction set-up and workup}

In a glovebox, a Schlenk flask was charged with [Ru(bipy $\left.\left.{ }^{\mathbf{O H}}\right)\right](0.02 \mathrm{mmol}, 2.0 \mathrm{~mol} \%)$, and potassium tert-butoxide ( $0.6 \mathrm{mmol}, 0.6$ equiv). The Schlenk flask was then capped with a septum and removed from the glovebox. Once outside the glovebox, the vessel was opened and deionized water $(0.3 \mathrm{~mL})$ was added to the reaction using a $1 \mathrm{~mL}$ plastic syringe. 200 proof ethanol (1.0 mmol, 1.0 equiv) was then added to the reaction via an airtight glass syringe and the weight of ethanol was recorded. The Schlenk was sealed with a Teflon pin and was placed in a metal heating block at $80{ }^{\circ} \mathrm{C}$ for $18 \mathrm{~h}$. After $18 \mathrm{~h}$ the reaction was cooled to room temperature and worked up.

\section{Work up materials}

Glass fiber filter paper: grade 934-AH, 2.4 cm, VWR catalog \# 28496-773

Large pipette: Kimble 5-3/4" soda lime disposable glass monstr-pette pipette VWR catalog \# 50880-040 
Neutral alumina: Aluminum oxide, neutral, HPLC flash grade, 32-63 micron APS powder, Alfa Aesar

$C_{18}$ silica: Bakerbond Octadecyl $\left(\mathrm{C}_{18}\right), 40 \mu \mathrm{m}$ average particle diameter, J.T. Baker

Assembly of Alumina plug: A large pipette was plugged with glass fiber filter paper. The pipette was loaded with $6.5 \mathrm{~cm}$ of a slurry of neutral alumina in $\mathrm{DI}_{2} \mathrm{H}_{2} \mathrm{O}$.

Assembly of the $\mathbf{C}_{\mathbf{1 8}}$ plug: A large pipette was plugged with glass fiber filter paper. The pipette was dry loaded with $6 \mathrm{~cm}$ of $\mathrm{C}_{18}$ silica, then flushed with $1.5 \mathrm{ml}$ of $\mathrm{DI}_{2} \mathrm{O}$.

The reaction was allowed to cool to room temperature. The alumina plug and $\mathrm{C}_{18}$ silica plug were prepared, and the solvents and reaction vessel were cooled in an ice water bath. The collection flask was cooled in an ethylene glycol/dry ice bath $\left(-15^{\circ} \mathrm{C}\right.$ to $\left.-20^{\circ} \mathrm{C}\right)$. The filtration was set up according to the diagram below. The reaction was loaded into the alumina plug and washed with $5 \mathrm{~mL}$ of $\mathrm{DI}_{2} \mathrm{O}$ in portions. The eluent was manually forced through the alumina plug and silica plug sequentially after each portion. The $\mathrm{pH}$ of the residual eluent in the alumina plug was checked to ensure a $\mathrm{pH}$ of 7.

The $\mathrm{C}_{18}$ plug was then washed sequentially with $4 \mathrm{~mL}$ of $\mathrm{DI} \mathrm{H}_{2} \mathrm{O}$, followed by $2 \mathrm{~mL}$ 80:20 $\left(\mathrm{H}_{2} \mathrm{O}: \mathrm{MeCN}\right), 4 \mathrm{~mL}$ 50:50 ( $\left.\mathrm{H}_{2} \mathrm{O}: \mathrm{MeCN}\right), 4 \mathrm{~mL}$ 40:60 ( $\left.\mathrm{H}_{2} \mathrm{O}: \mathrm{MeCN}\right)$, and $3 \mathrm{~mL} \mathrm{MeCN}$, releasing pressure from the collection vessel after each wash. The reaction vessel was then capped with a septum and allowed to warm to room temperature. $n$-Propanol $(10 \mu \mathrm{L})$ was then added to the vessel via a micro syringe and the reaction was analyzed via GC. 
Figure S1. General filtration setup

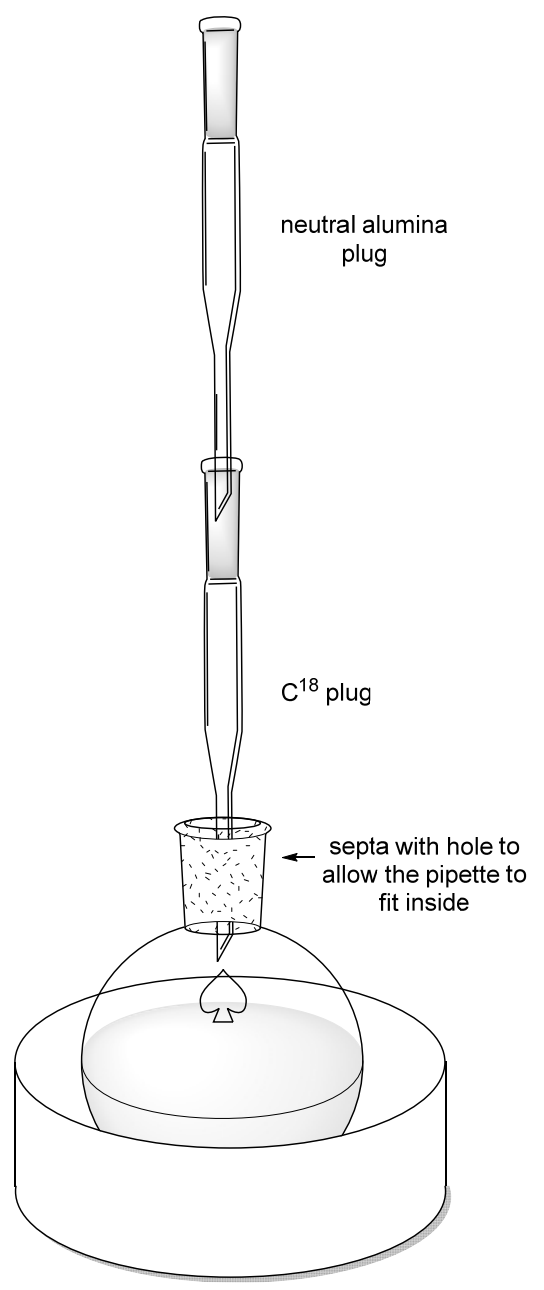




\section{S6. Reaction Optimizations}

Table S8. Investigation of the effect of catalyst loading on the conversion of ethanol

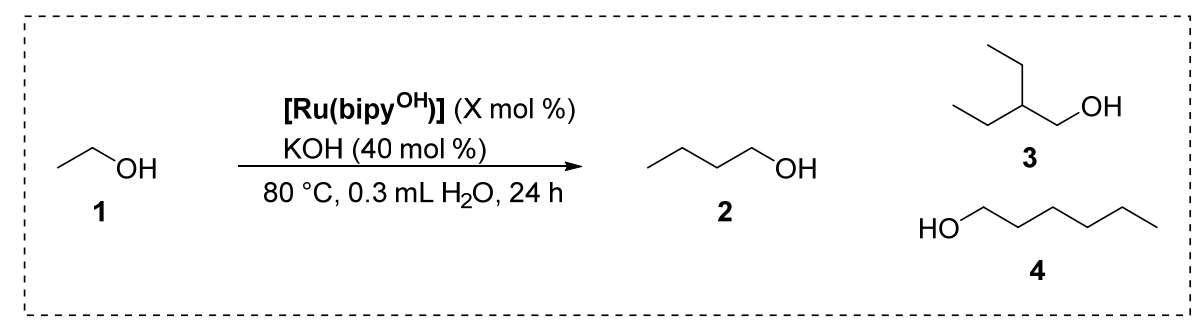

\begin{tabular}{c|cccccc}
\hline Entry & $\boldsymbol{X}$ mol \% & $\boldsymbol{1}^{\boldsymbol{a}}$ & $\boldsymbol{2}^{\boldsymbol{b}}$ & $\boldsymbol{3}^{\boldsymbol{b}}$ & $\boldsymbol{4}^{\boldsymbol{b}}$ & Selectivity $^{\boldsymbol{c}}$ \\
\hline 1 & 1 & 76 & 14 & 2 & 0.4 & 58 \\
2 & 1.5 & 66 & 18 & 4 & 1 & 53 \\
3 & 2 & 68 & 16 & 2 & 0.6 & 50 \\
4 & 2.5 & 66 & 17 & 3 & 0.7 & 50 \\
\hline
\end{tabular}

All reactions conducted on a $1 \mathrm{mmol}$ scale, ethanol (1 mmol, 1 equiv). ${ }^{a}$ amount of ethanol recovered, GC yield (\%) vs. $n$-propanol as the internal standard. ${ }^{b} \mathrm{GC}$ yield (\%) vs $n$-propanol as the internal standard. ${ }^{c}$ selectivity (\%) is reported for the formation of $n$-butanol vs. conversion of ethanol

Table S9. Time vs. the unselective formation of higher chain alcohols

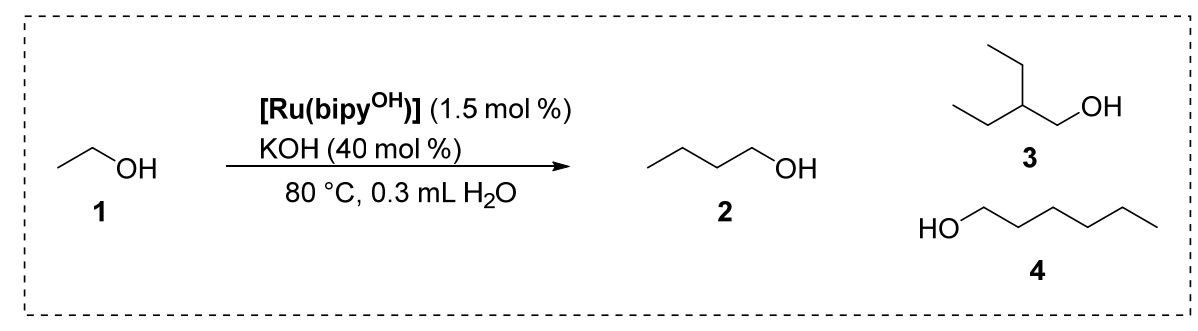

\begin{tabular}{c|cccccc}
\hline Entry & Time $^{(h)}$ & $\boldsymbol{1}^{\boldsymbol{a}}$ & $\boldsymbol{2}^{\boldsymbol{b}}$ & $\mathbf{3}^{\boldsymbol{b}}$ & $\boldsymbol{4}^{\boldsymbol{b}}$ & Selectivity $^{\boldsymbol{c}}$ \\
\hline 1 & 16 & 71 & 16 & 2 & 0.6 & 55 \\
2 & 18 & 67 & 18 & 3 & 0.6 & 55 \\
3 & 22 & 63 & 19 & 4 & 1 & 51 \\
\hline
\end{tabular}

All reactions conducted on a $1 \mathrm{mmol}$ scale, ethanol (1 mmol, 1 equiv). ${ }^{\text {a amount of }}$ ethanol recovered, $\mathrm{GC}$ yield (\%) vs. $n$-propanol as the internal standard. ${ }^{\mathrm{b}} \mathrm{GC}$ yield (\%) vs $n$-propanol as the internal standard. ${ }^{c}$ selectivity (\%) is reported for the formation of $n$-butanol vs. conversion of ethanol 
Table S10. Optimization of reaction conditions using potassium hydroxide

\begin{tabular}{|c|c|c|c|c|c|c|c|c|c|}
\hline \multirow[b]{2}{*}{ Entry } & $\overbrace{1} \mathrm{OH}$ & $\begin{array}{c}\text { [Ru(bip } \\
\mathrm{KOH}(\mathrm{Y} \\
80^{\circ} \mathrm{C},\end{array}$ & $\begin{array}{l}\left.\left.\mathrm{py}^{\mathrm{OH}}\right)\right](\mathrm{X} \mathrm{mo} \\
(\mathrm{mol} \%) \\
\mathrm{Z} \mathrm{mL} \mathrm{H} \mathrm{H}_{2} \mathrm{O}\end{array}$ & (\%) & 2 & & \multicolumn{2}{|c|}{4} & \\
\hline & $X(\mathrm{~mol} \%)$ & $Y(\mathrm{~mol} \%)$ & $Z(m L)$ & Time (h) & $1^{a}$ & $2^{b}$ & $3^{b}$ & $4^{b}$ & Selectivity \\
\hline 1 & 1.5 & 50 & 0.3 & 18 & 66 & 19 & 3 & 0.8 & 56 \\
\hline 2 & 1.5 & 55 & 0.3 & 18 & 64 & 17 & 4 & 0.9 & 47 \\
\hline 3 & 1.5 & 50 & 0.4 & 18 & 62 & 17 & 4 & 0.8 & 45 \\
\hline 4 & 1.5 & 50 & 0.5 & 18 & 75 & 12 & 2 & 0.3 & 48 \\
\hline 5 & 1.5 & 50 & 0.5 & 24 & 72 & 13 & 2 & 0.4 & 46 \\
\hline 6 & 1.5 & 50 & 0.55 & 24 & 69 & 13 & 2 & 0.4 & 42 \\
\hline 7 & 1.5 & 50 & 0.58 & 48 & 72 & 14 & 2 & 0.5 & 50 \\
\hline 8 & 2 & 50 & 0.58 & 48 & 69 & 14 & 2 & 0.5 & 45 \\
\hline 9 & 1.5 & 60 & 0.58 & 48 & 73 & 13 & 2 & 0.4 & 48 \\
\hline 10 & 2 & 60 & 0.58 & 48 & 67 & 16 & 3 & 0.7 & 48 \\
\hline
\end{tabular}

All reactions conducted on a $1 \mathrm{mmol}$ scale, ethanol ( $1 \mathrm{mmol}, 1$ equiv). ${ }^{\mathrm{a} a m o u n t}$ of ethanol recovered, GC yield (\%) vs. $n$-propanol as the internal standard. ${ }^{b} \mathrm{GC}$ yield (\%) vs $n$-propanol as the internal standard. ${ }^{{ }^{c}}$ selectivity (\%) is reported for the formation of $n$-butanol vs. conversion of ethanol

Table S11. Optimization of reaction conditions using sodium tert-butoxide

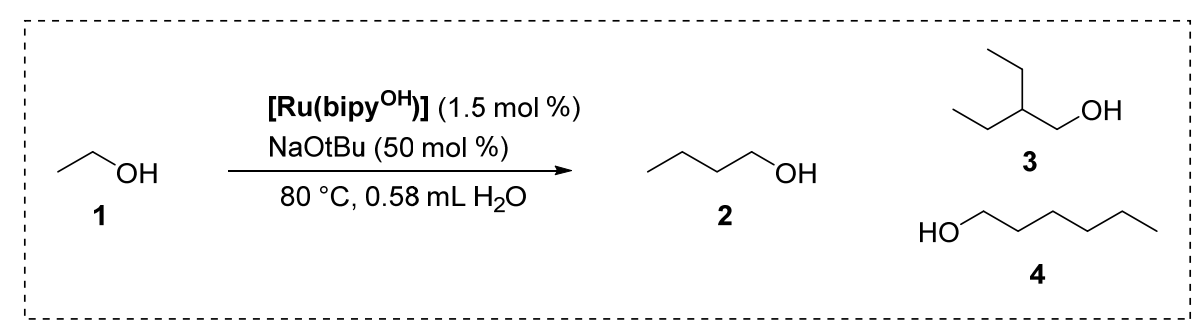

\begin{tabular}{c|cccccc}
\hline Entry & Time (h) & $\boldsymbol{1}^{\boldsymbol{a}}$ & $\boldsymbol{2}^{\boldsymbol{b}}$ & $\mathbf{3}^{\boldsymbol{b}}$ & $\mathbf{4}^{\boldsymbol{b}}$ & Selectivity $^{\boldsymbol{c}}$ \\
\hline 1 & 18 & 79 & 13 & 3 & 0.4 & 62 \\
2 & 48 & 71 & 14 & 3 & 0.8 & 48 \\
\hline
\end{tabular}

All reactions conducted on a $1 \mathrm{mmol}$ scale, ethanol (1 mmol, 1 equiv). ${ }^{\text {a amount of }}$ ethanol recovered, GC yield (\%) vs. $n$-propanol as the internal standard. ${ }^{b} \mathrm{GC}$ yield (\%) vs $n$-propanol as the internal standard. ${ }^{\circ}$ selectivity (\%) is reported for the formation of $n$-butanol vs. conversion of ethanol 


\section{S7. GC Data}

\section{S7.1 Standard samples}

uV

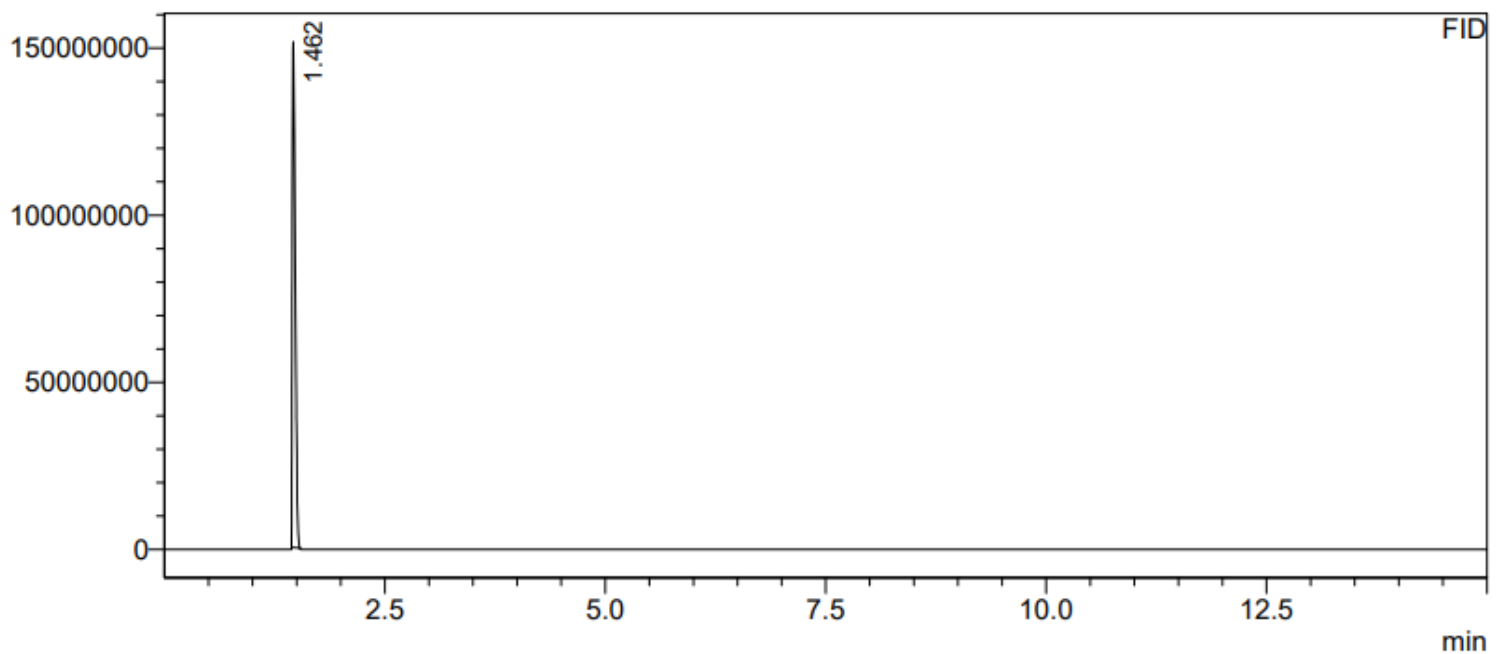

Figure S2. GC chromatogram of diethyl ether

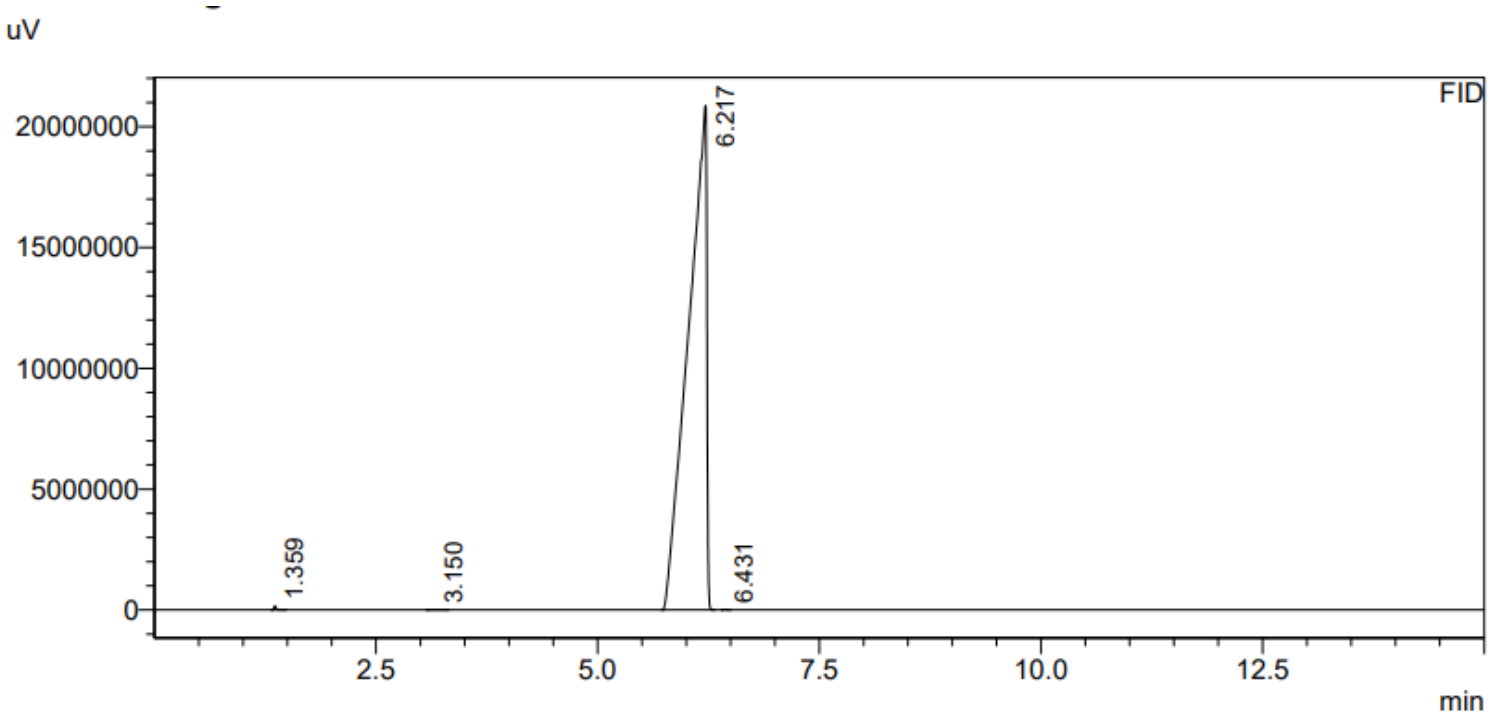




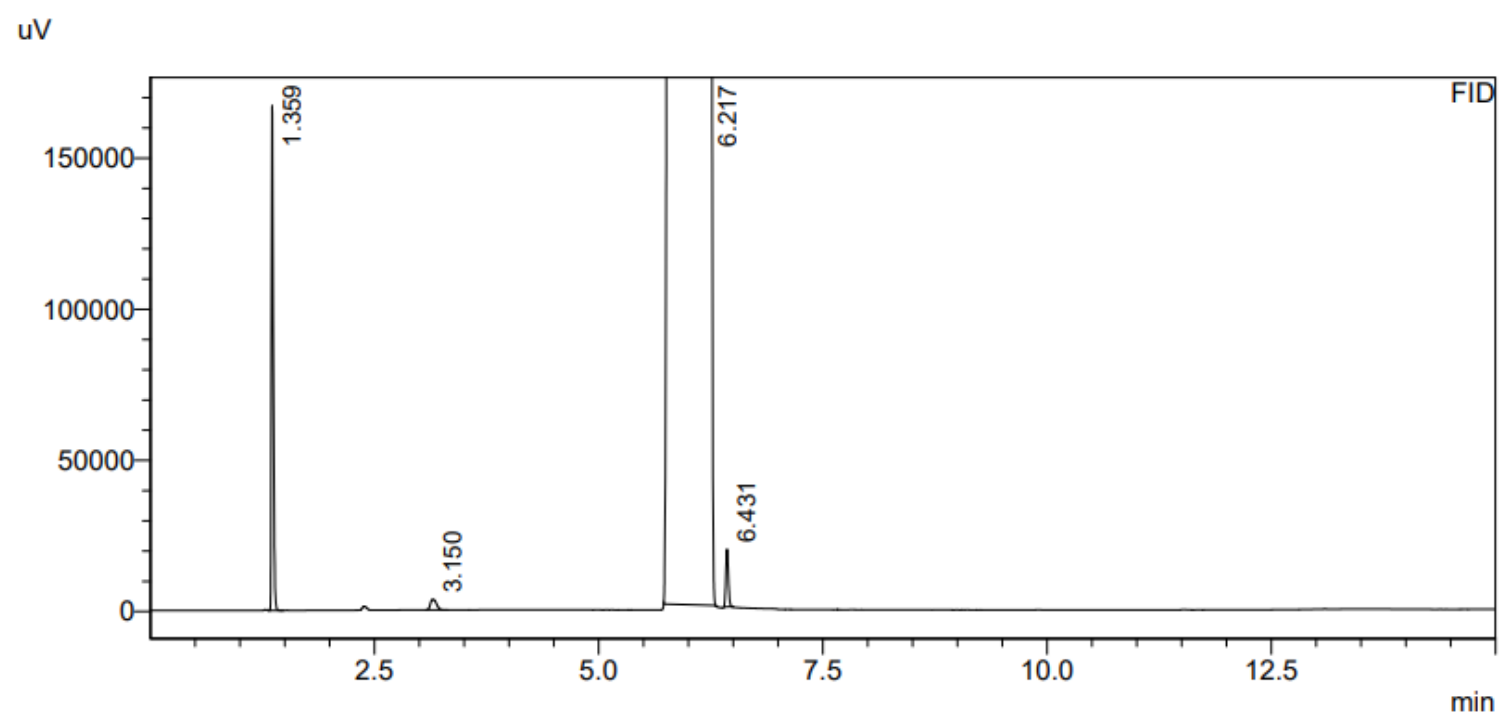

Figure S3. GC chromatograms of acetonitrile (retention time 6.217) in diethyl ether

$\mathrm{uV}$

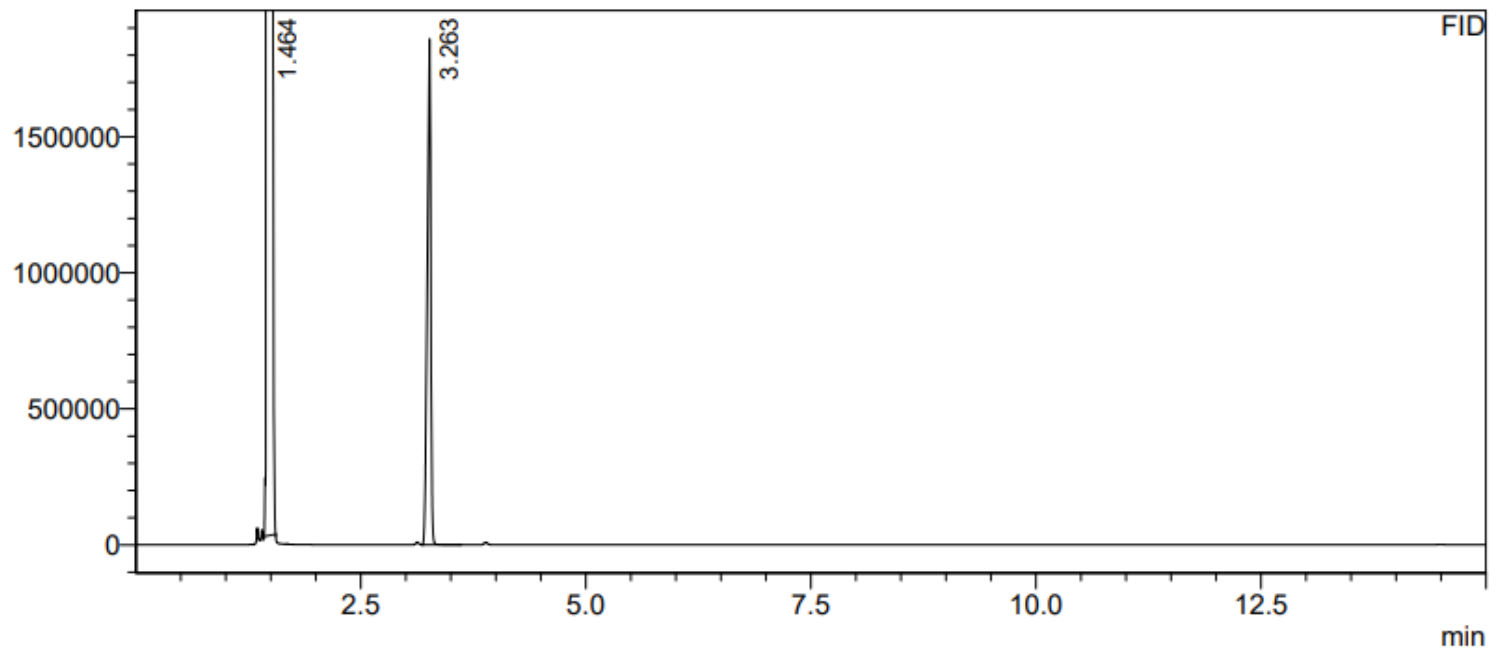

Figure S4. GC chromatogram of methanol (retention time 3.263) in diethyl ether 


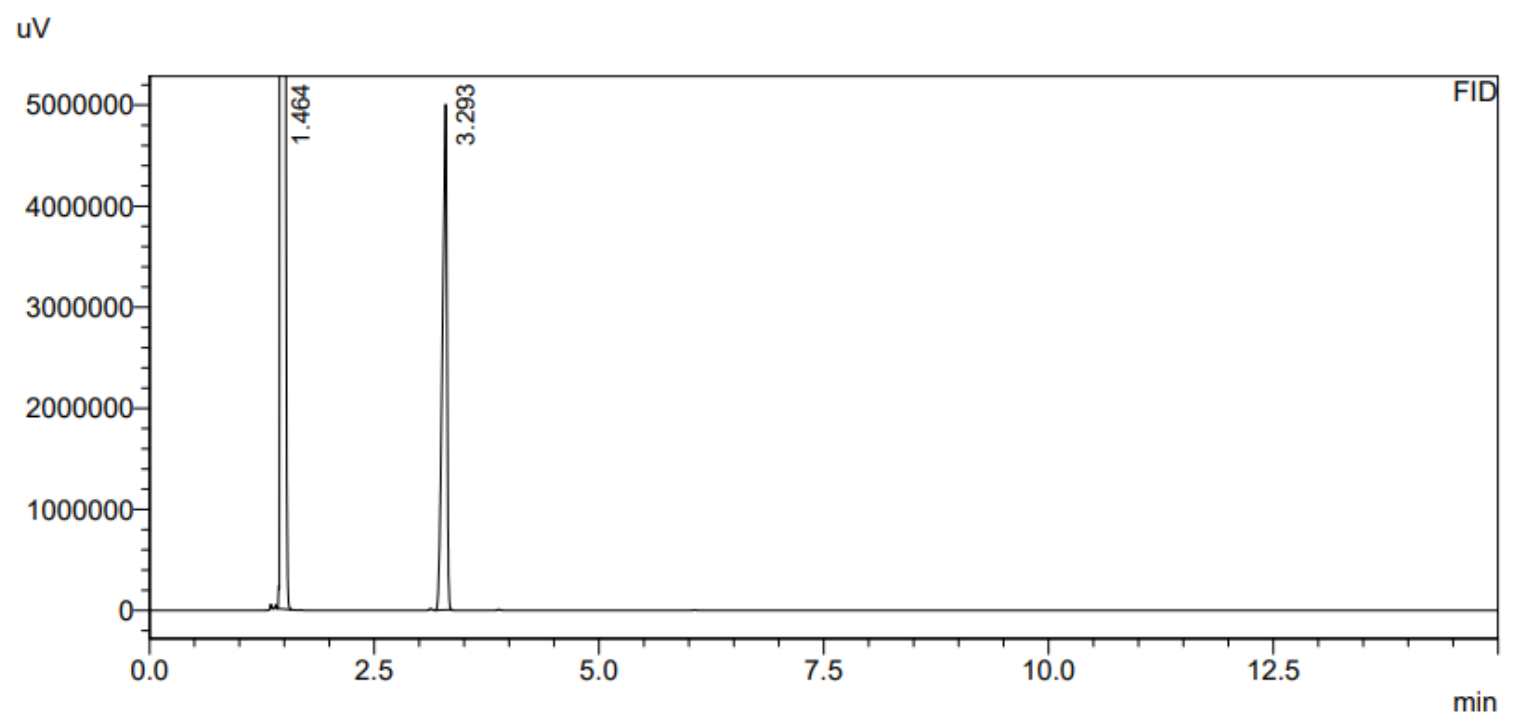

Figure S5. GC chromatogram of tert-butyl alcohol (retention time 3.293) in diethyl ether

uV

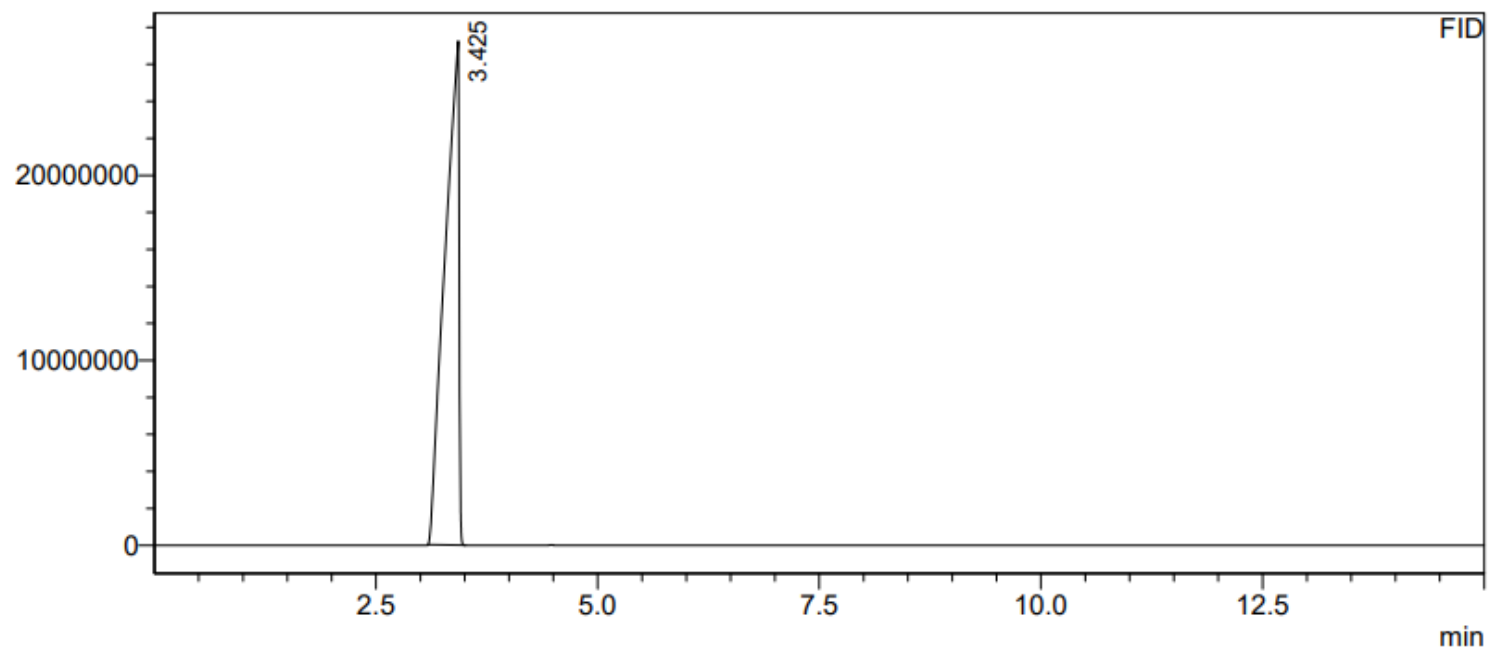

Figure S6. GC chromatogram of ethyl acetate (retention time 3.425) 
uV

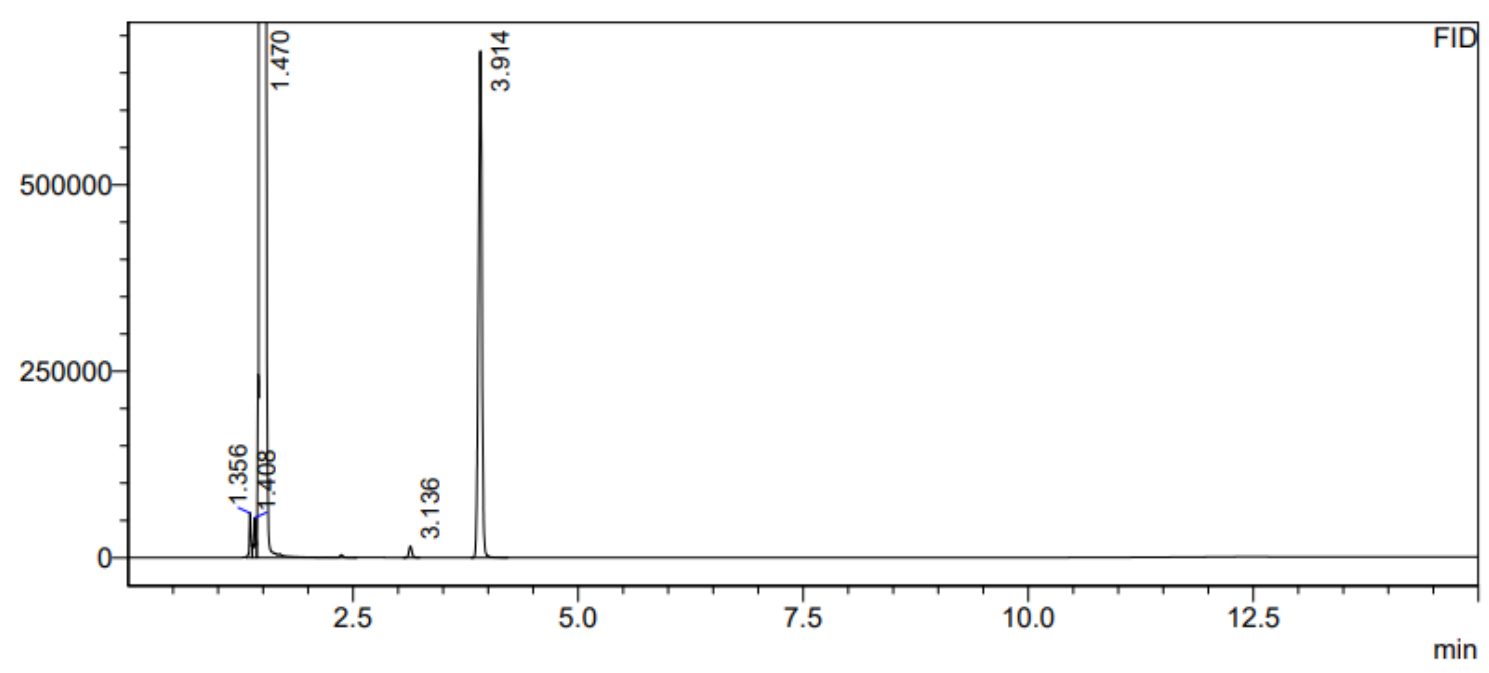

Figure S7. GC chromatogram of ethanol (retention time 3.914) in diethyl ether

uV

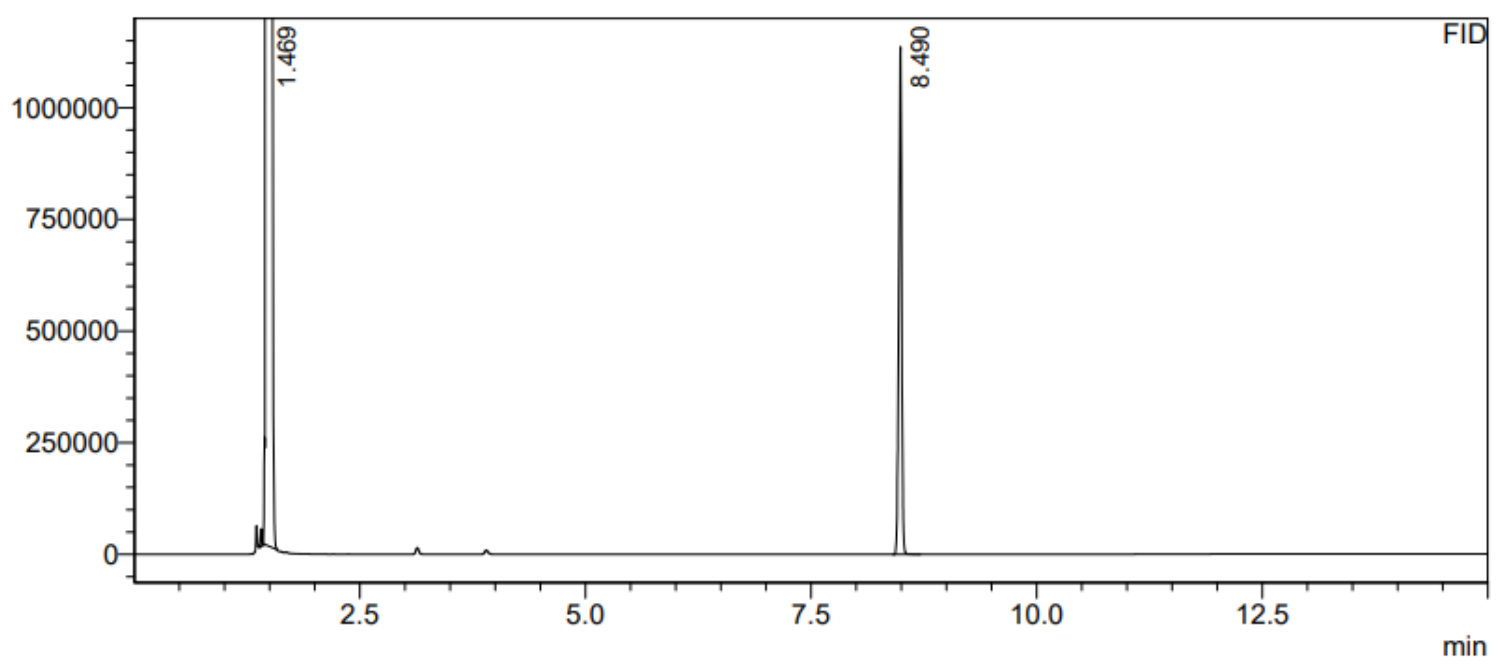

Figure S8. GC chromatogram of $n$-butanol (retention time 8.490) in diethyl ether 


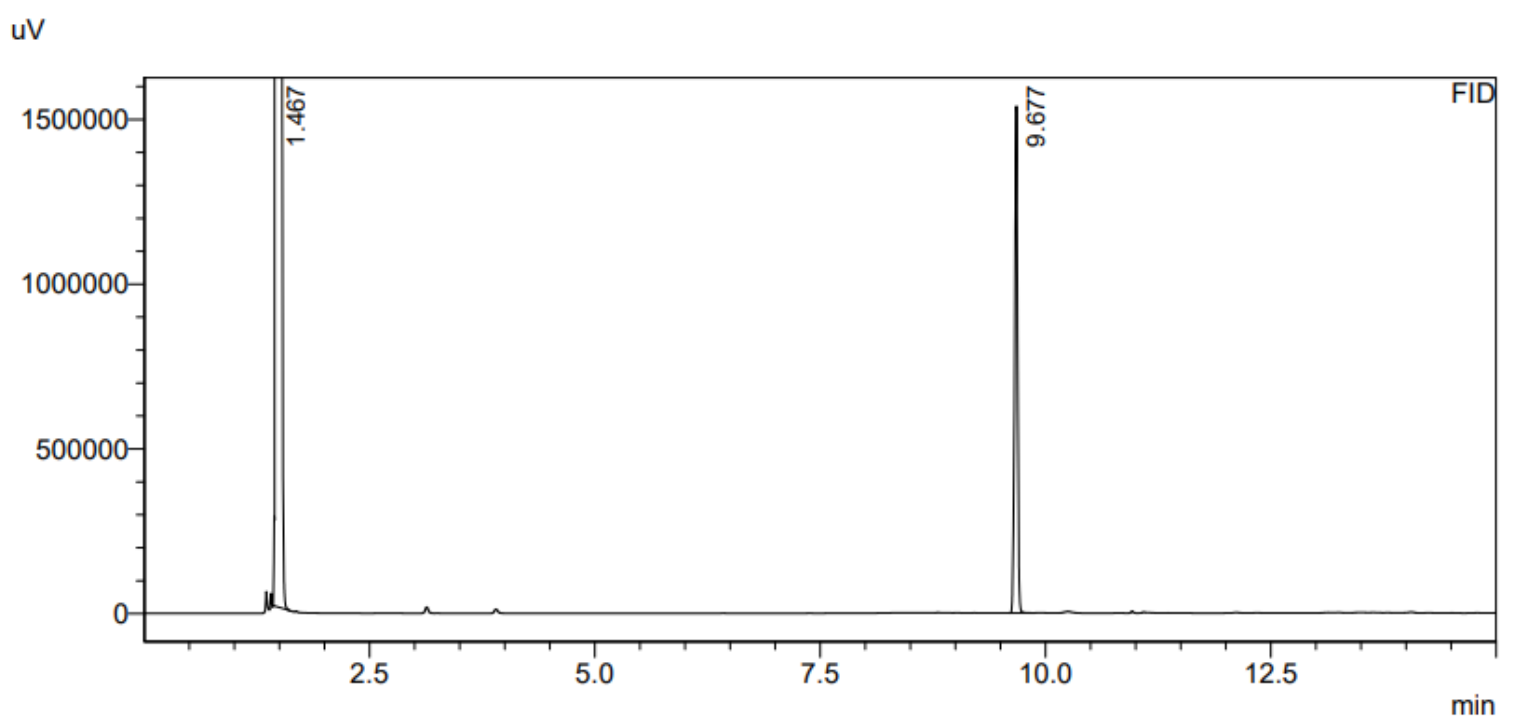

Figure S9. GC chromatogram of 2-hexanol (retention time 9.677) in diethyl ether

uV

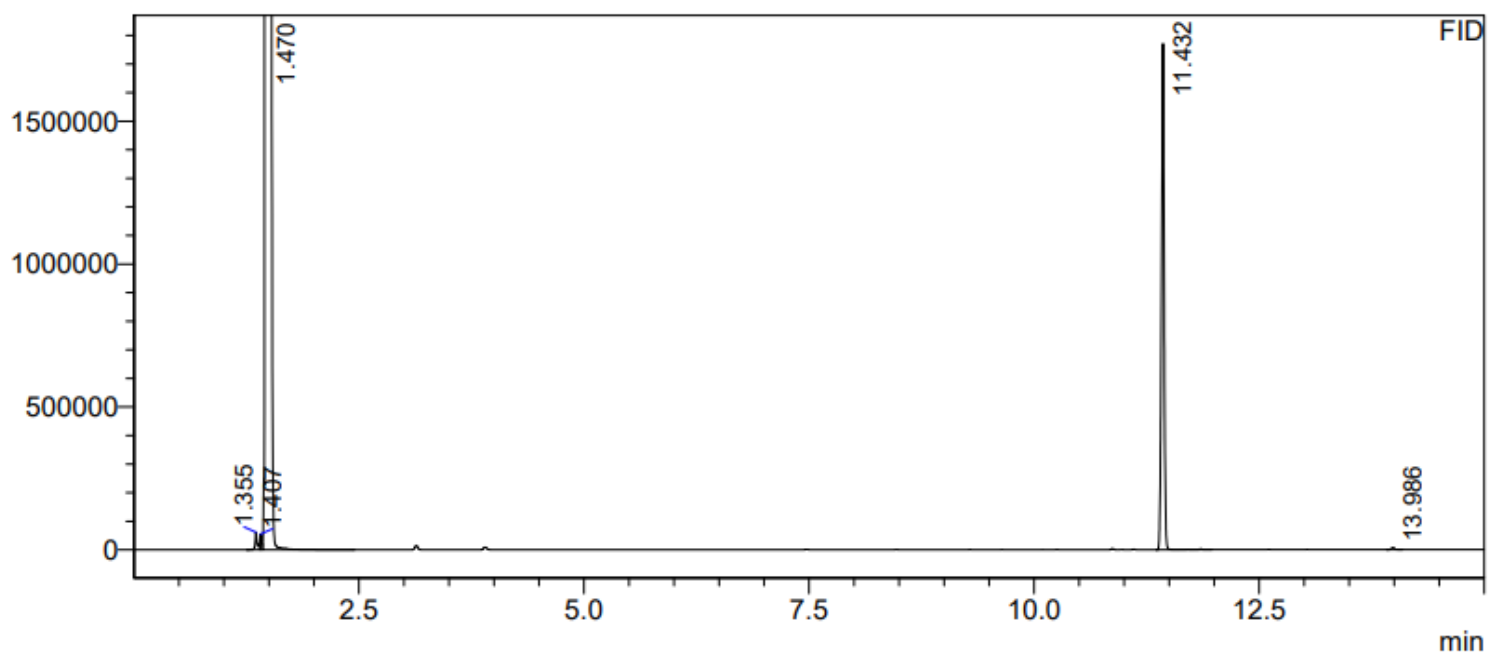

Figure S10. GC chromatogram of 1-hexanol (retention time 11.432) in diethyl ether 


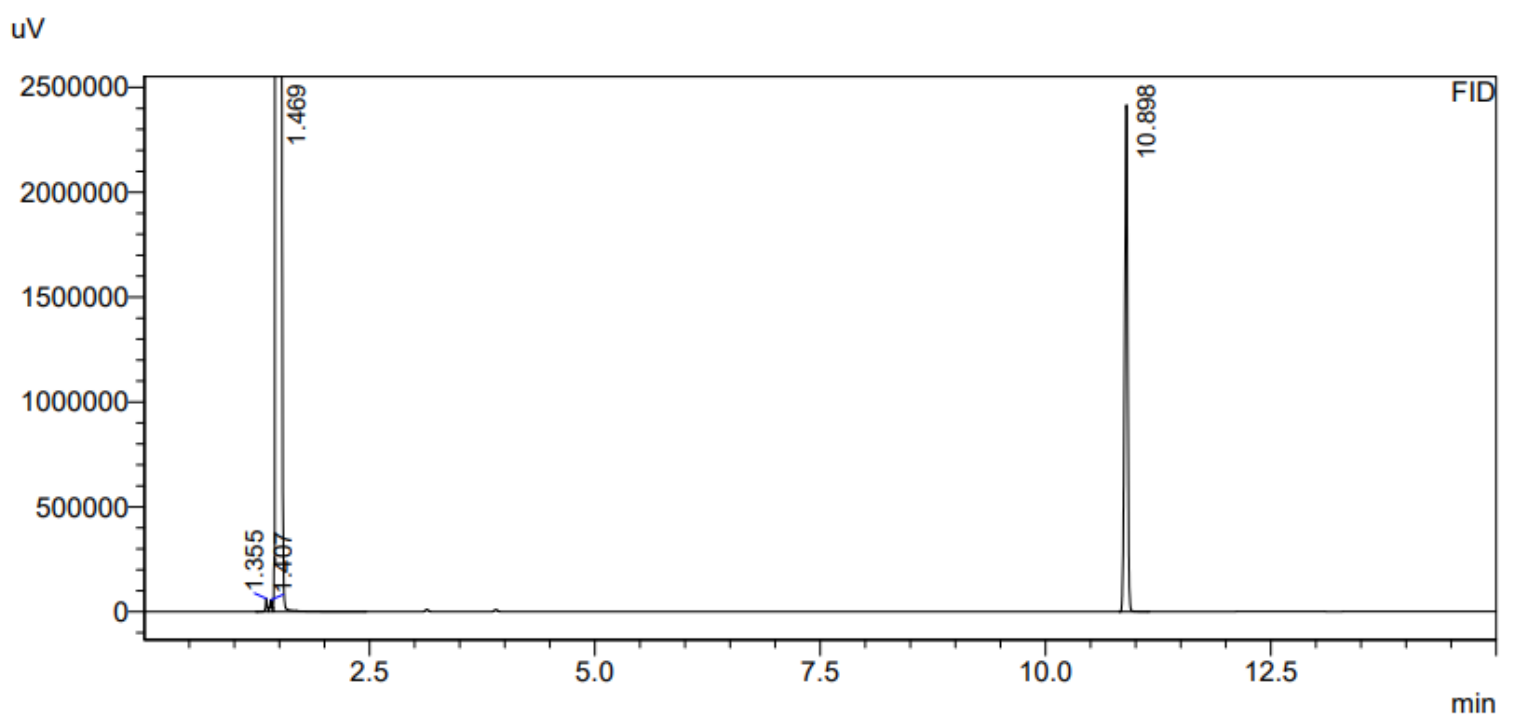

Figure S11. GC chromatogram of 2-ethyl-1-butanol (retention time 10.898) in diethyl ether

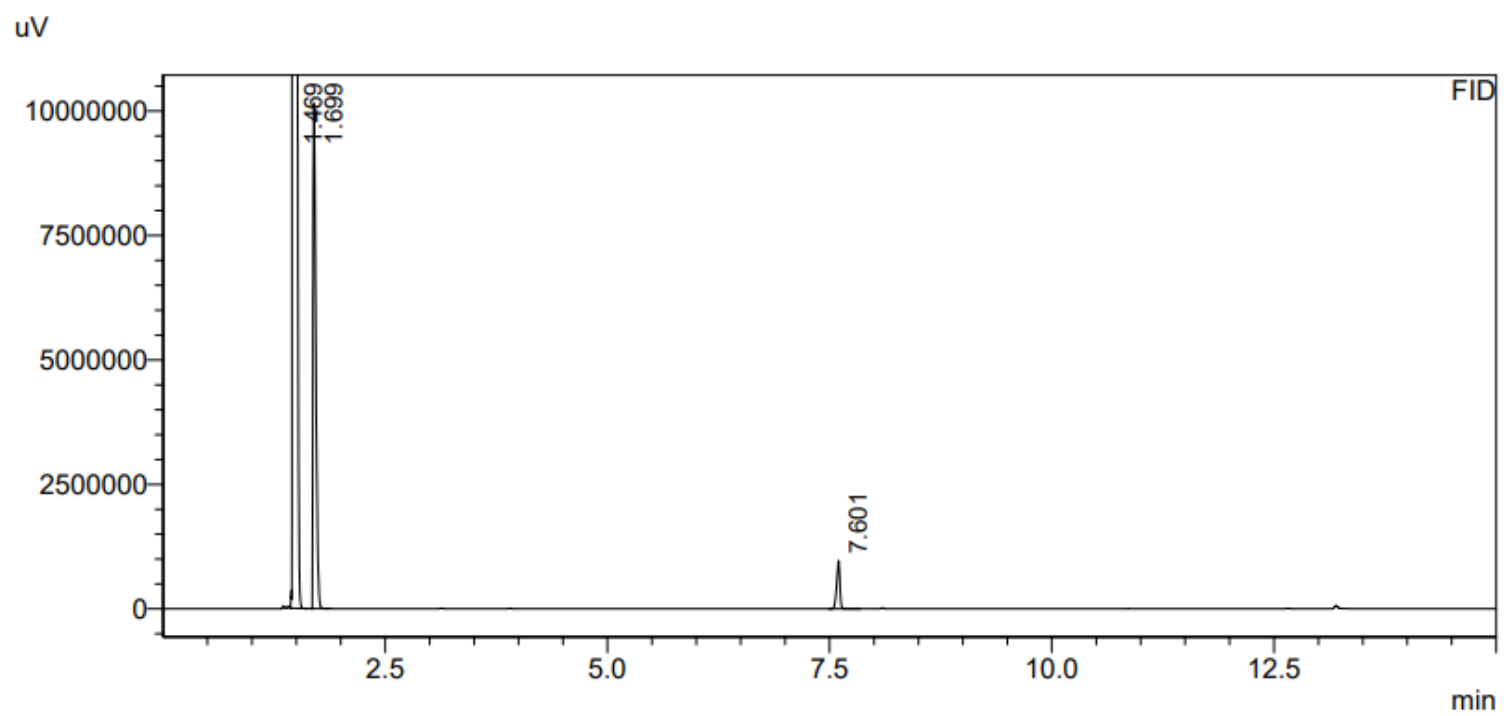

Figure S12. GC chromatogram of acetaldehyde (retention time 1.699) in diethyl ether 


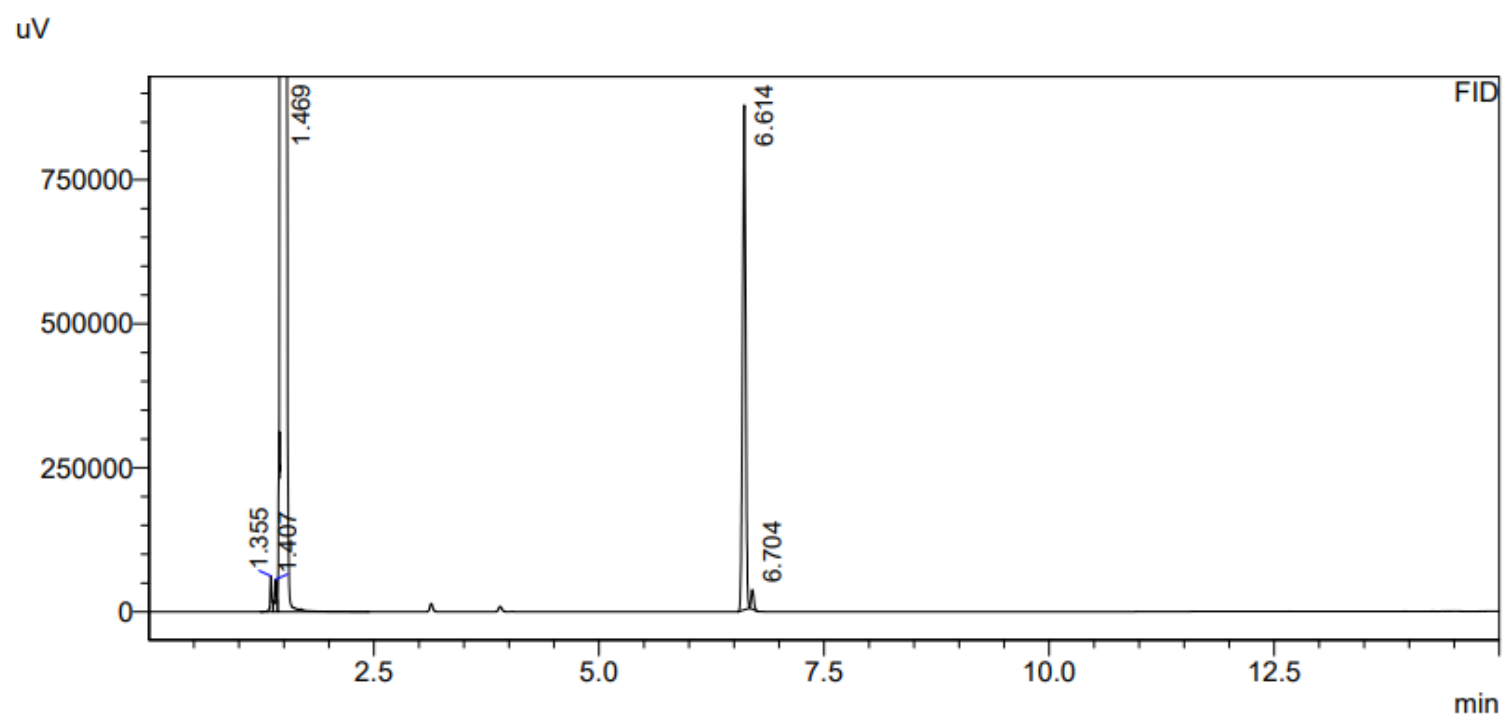

Figure S13. GC chromatogram of crotonaldehyde (retention time 6.614) in diethyl ether

uV

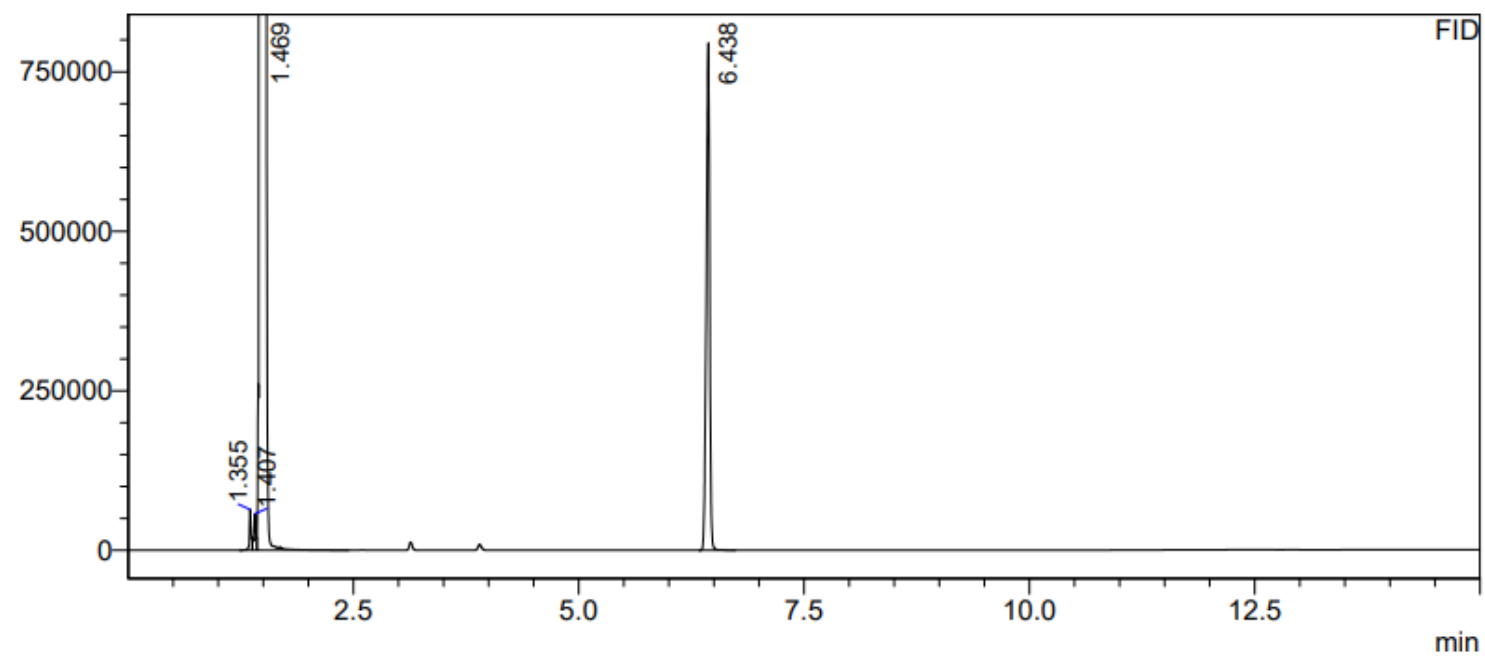

Figure S14. GC chromatogram of $n$-propanol (internal standard, retention time 6.438) in diethyl ether 


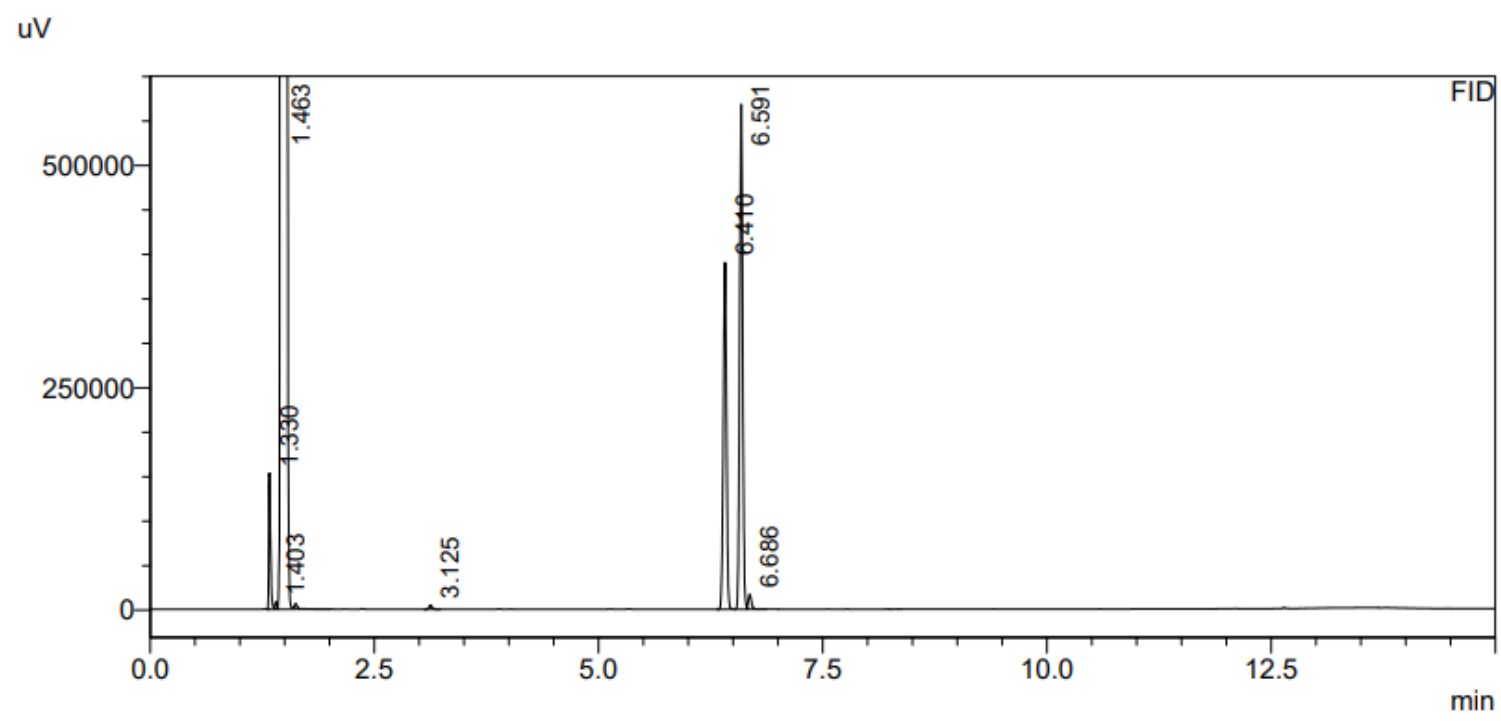

Figure S15. GC chromatogram of $n$-propanol (internal standard) and crotonaldehyde in diethyl ether 
Table S8, entry 1

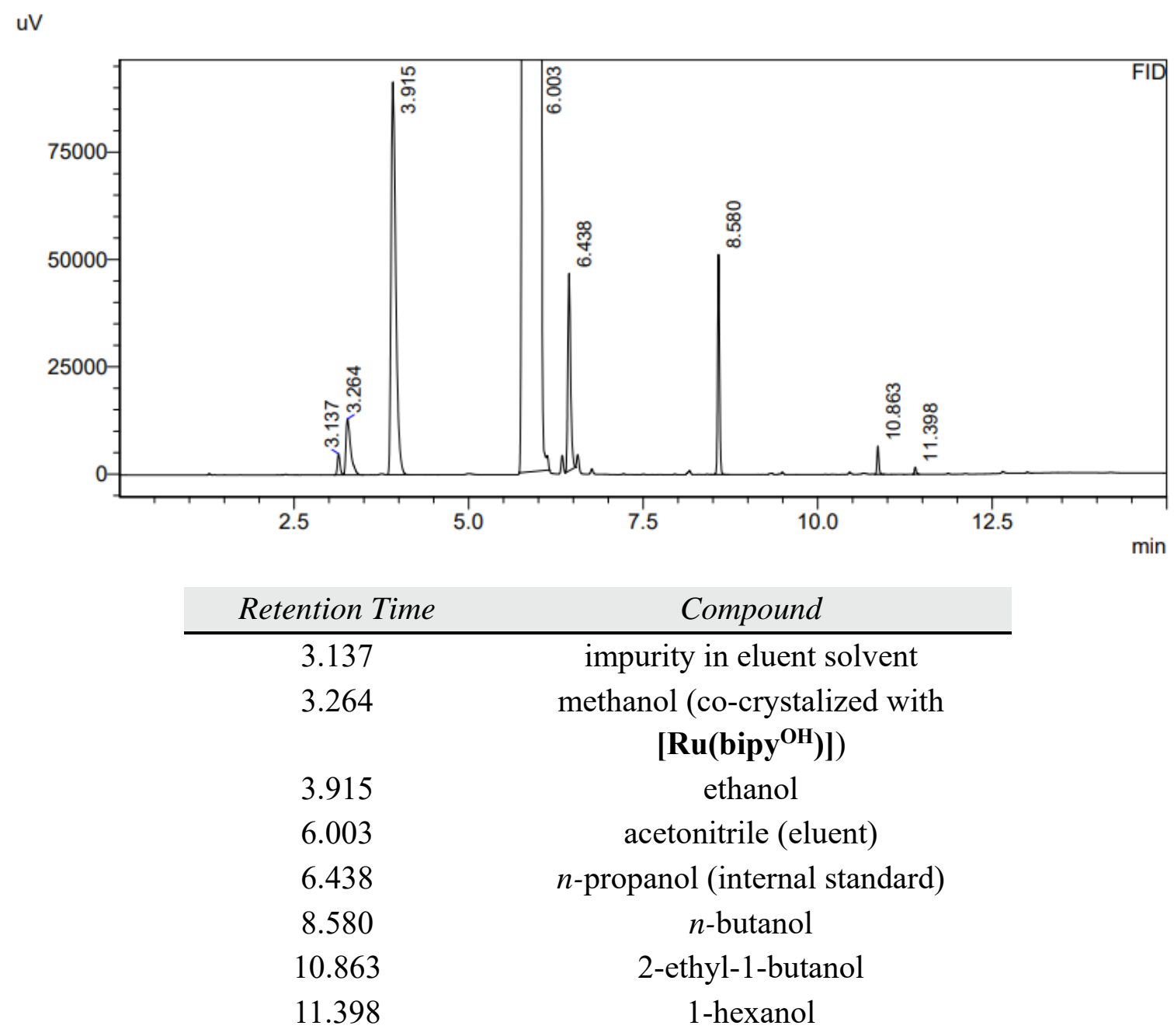

Figure S16. GC chromatogram and retention times of catalytic reaction table S8, entry 1 
Table S8, entry 2

uV

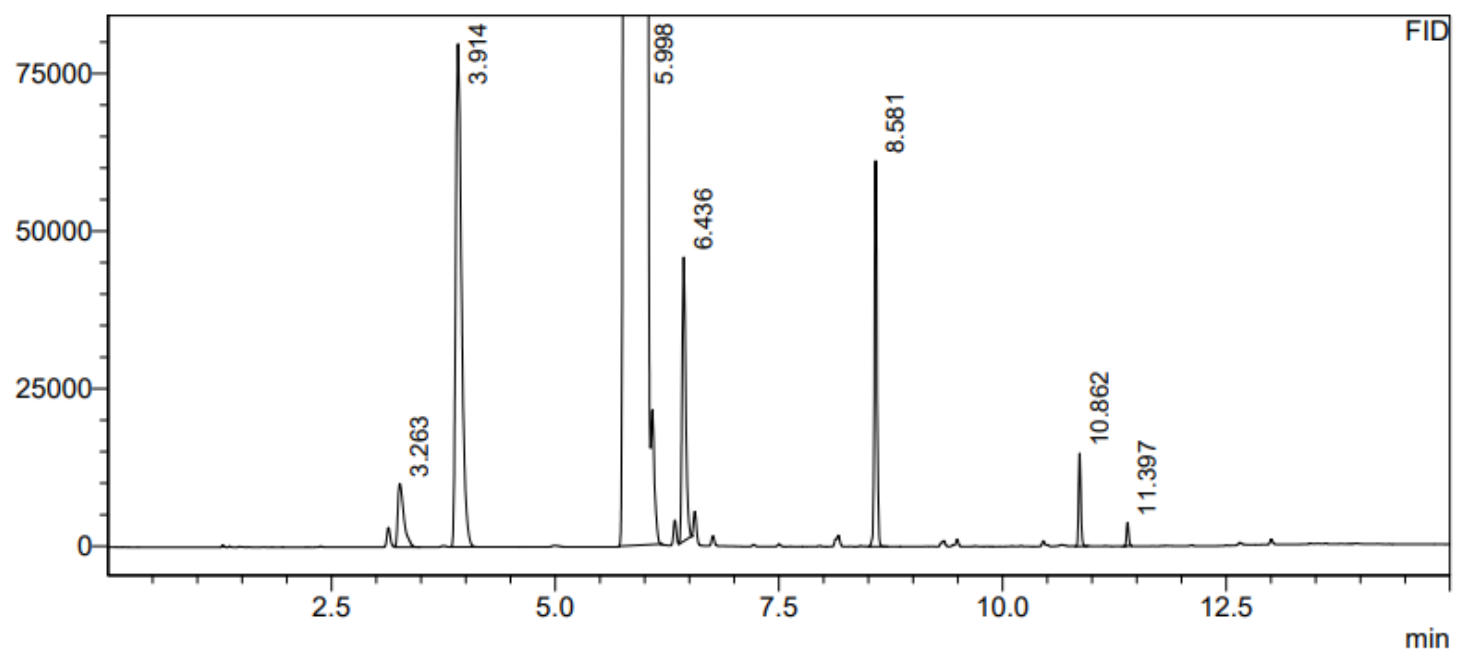

\begin{tabular}{cc} 
Retention Time & Compound \\
\hline 3.263 & $\begin{array}{c}\text { methanol (co-crystalized with } \\
{\left[\mathbf{R u}\left(\mathbf{b i p y} \mathbf{O H}^{\mathbf{O H}}\right)\right] \text { ) }}\end{array}$ \\
3.914 & ethanol \\
5.998 & acetonitrile (eluent) \\
6.436 & n-propanol (internal standard) \\
8.581 & $n$-butanol \\
10.862 & 2-ethyl-1-butanol \\
11.397 & 1-hexanol
\end{tabular}

Figure S17. GC chromatogram and retention times of catalytic reaction table S8, entry 2 
Table S8, entry 3

uV

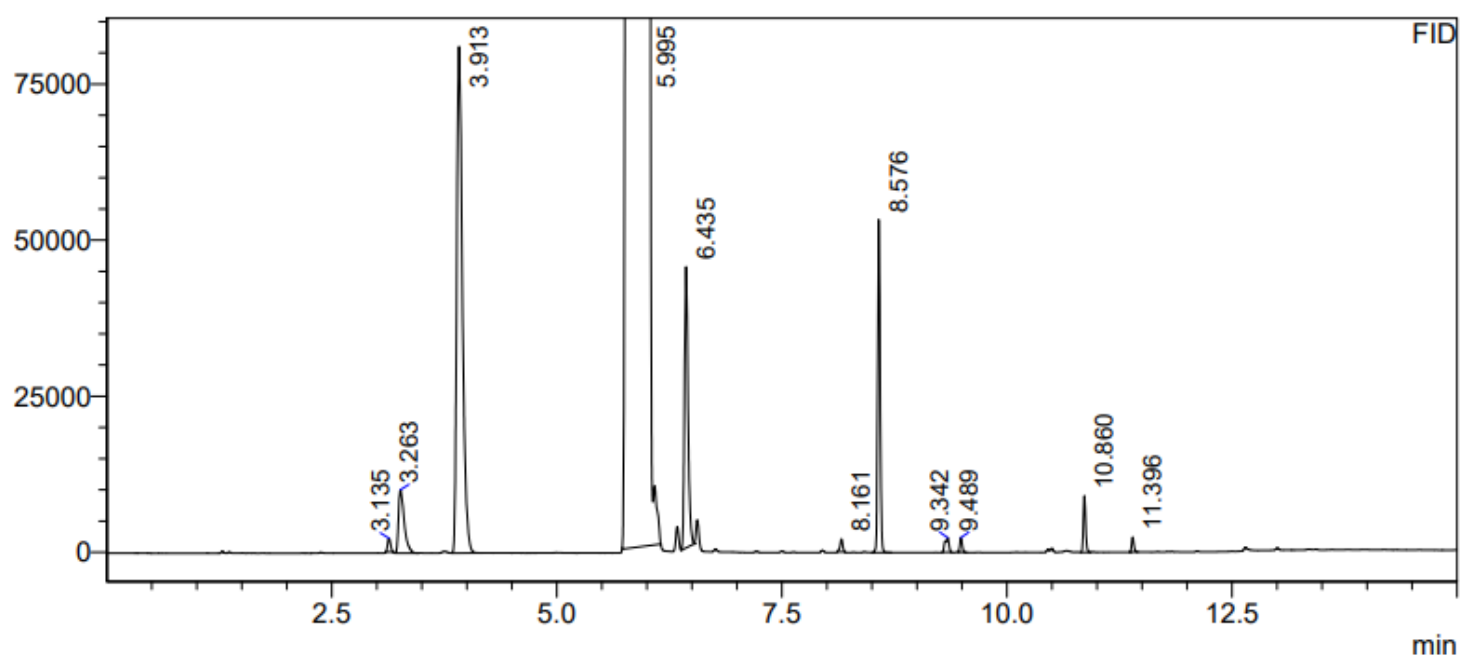

\begin{tabular}{cc} 
Retention Time & Compound \\
\hline 3.135 & $\left.\begin{array}{c}\text { impurity in eluent solvent } \\
\text { methanol (co-crystalized with } \\
{\left[\mathbf{R u}\left(\mathbf{b i p y} \mathbf{O H}^{\mathbf{O H}}\right)\right]}\end{array}\right)$ \\
3.913 & ethanol \\
5.995 & acetonitrile (eluent) \\
6.435 & n-propanol (internal standard) \\
8.161 & unknown \\
8.576 & n-butanol \\
9.342 & unknown \\
9.489 & unknown \\
10.860 & 2-ethyl-1-butanol \\
11.396 & 1-hexanol
\end{tabular}

Figure S18. GC chromatogram and retention times of catalytic reaction table S8, entry 3 
Table S8, entry 4

uV

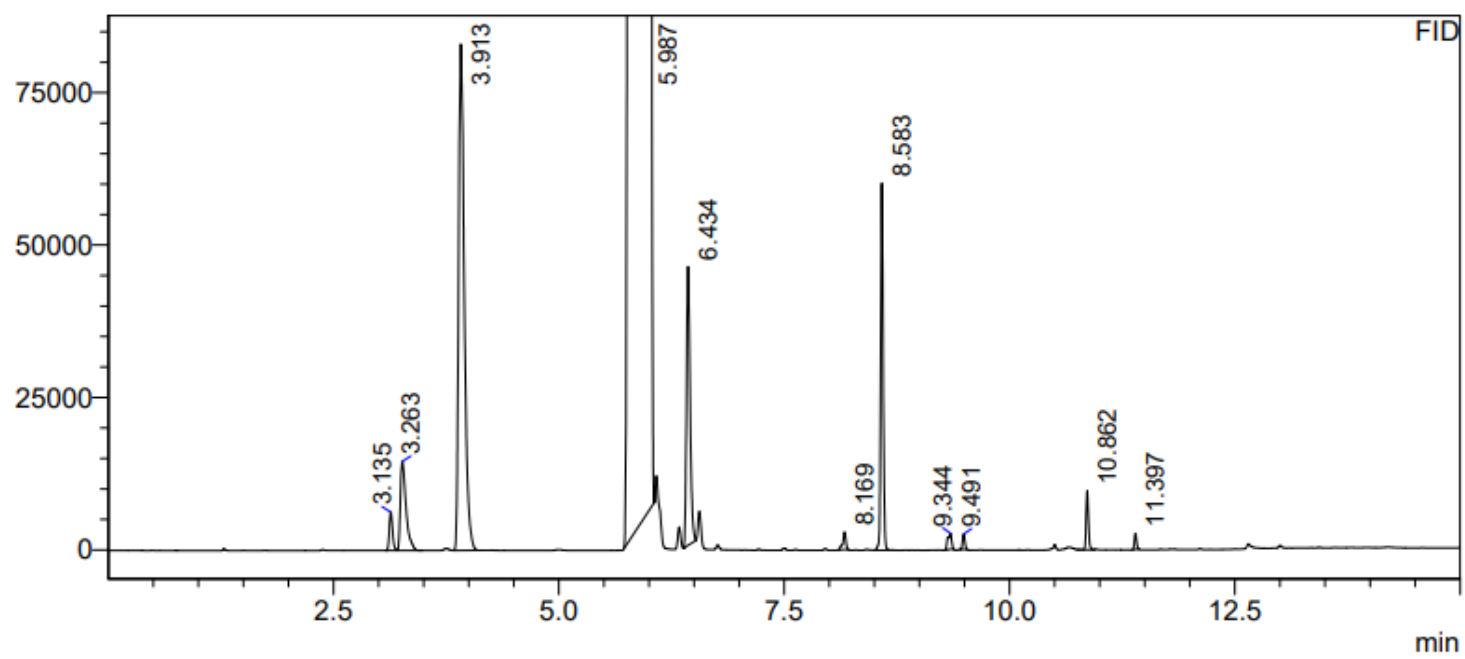

\begin{tabular}{cc} 
Retention Time & Compound \\
\hline 3.135 & $\left.\begin{array}{c}\text { impurity in eluent solvent } \\
\text { methanol (co-crystalized with } \\
{\left[\mathbf{R u}\left(\mathbf{b i p y} \mathbf{O H}^{\mathbf{C}}\right)\right]}\end{array}\right)$ \\
3.913 & ethanol \\
5.987 & acetonitrile (eluent) \\
6.434 & n-propanol (internal standard) \\
8.169 & unknown \\
8.583 & n-butanol \\
9.344 & unknown \\
9.491 & unknown \\
10.862 & 2-ethyl-1-butanol \\
11.397 & 1-hexanol
\end{tabular}

Figure S19. GC chromatogram and retention times of catalytic reaction table S8, entry 4 
Table S9, entry 1

uV

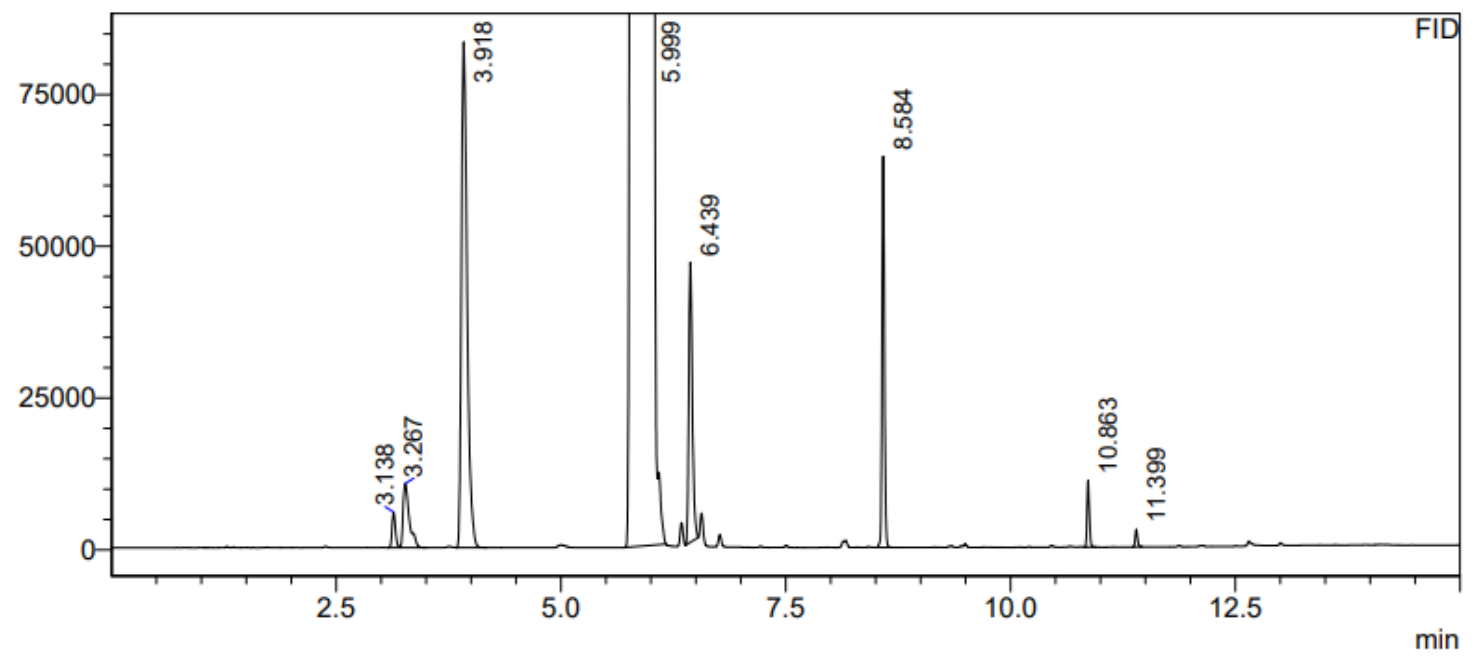

\begin{tabular}{cc} 
Retention Time & Compound \\
\hline 3.138 & impurity in eluent solvent \\
3.267 & $\left.\begin{array}{c}\text { methanol (co-crystalized with } \\
{\left[\mathbf{R u}\left(\mathbf{b i p y} \mathbf{O H}^{\mathbf{O}}\right)\right]}\end{array}\right)$ \\
3.918 & ethanol \\
5.999 & acetonitrile (eluent) \\
6.439 & $n$-propanol (internal standard) \\
8.584 & $n$-butanol \\
10.863 & 2-ethyl-1-butanol \\
11.399 & 1-hexanol
\end{tabular}

Figure S20. GC chromatogram and retention times of catalytic reaction table S9, entry 1 
Table S9, entry 2

uV

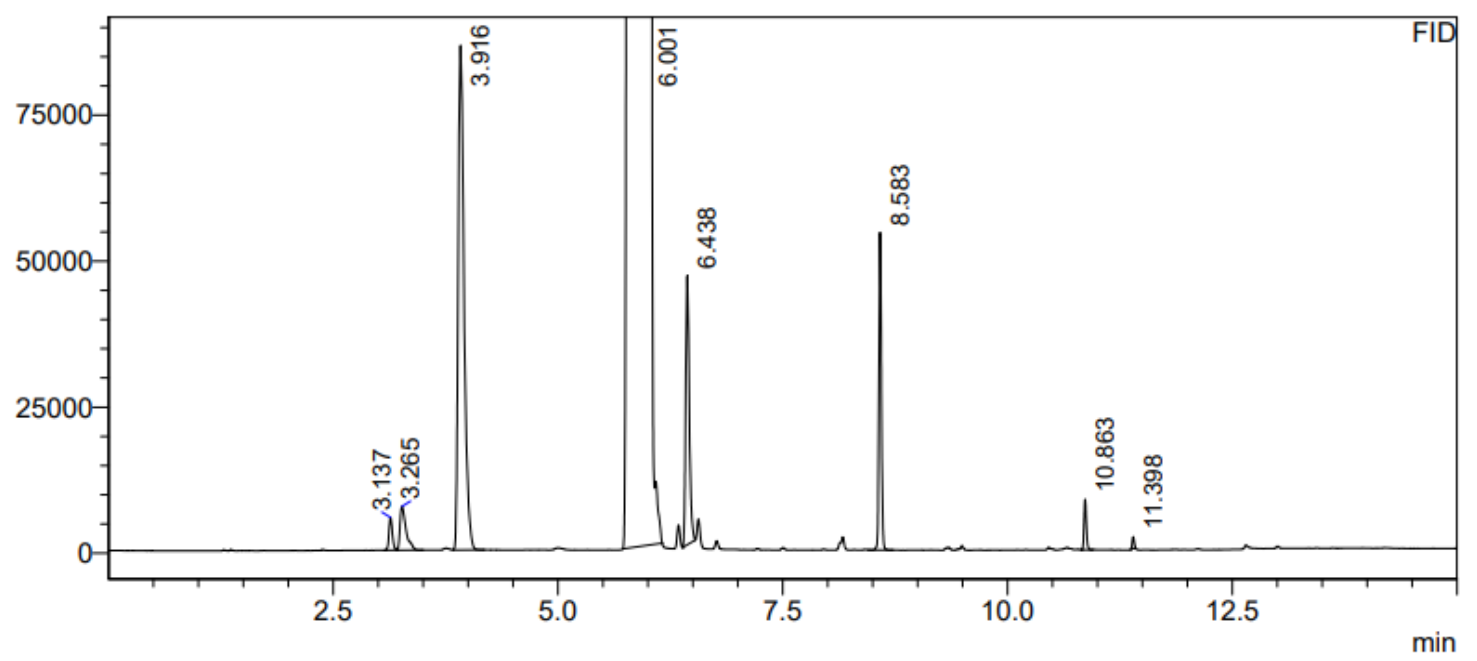

\begin{tabular}{cc} 
Retention Time & Compound \\
\hline 3.137 & $\left.\begin{array}{c}\text { impurity in eluent solvent } \\
\text { methanol (co-crystalized with } \\
\left.\left.\text { [Ru(bipy } \mathbf{O H}^{\mathbf{O H}}\right)\right]\end{array}\right)$ \\
3.265 & ethanol \\
6.001 & acetonitrile (eluent) \\
6.438 & n-propanol (internal standard) \\
8.583 & n-butanol \\
10.863 & 2-ethyl-1-butanol \\
11.398 & 1-hexanol
\end{tabular}

Figure S21. GC chromatogram and retention times of catalytic reaction table S9, entry 2 
Table S9, entry 3

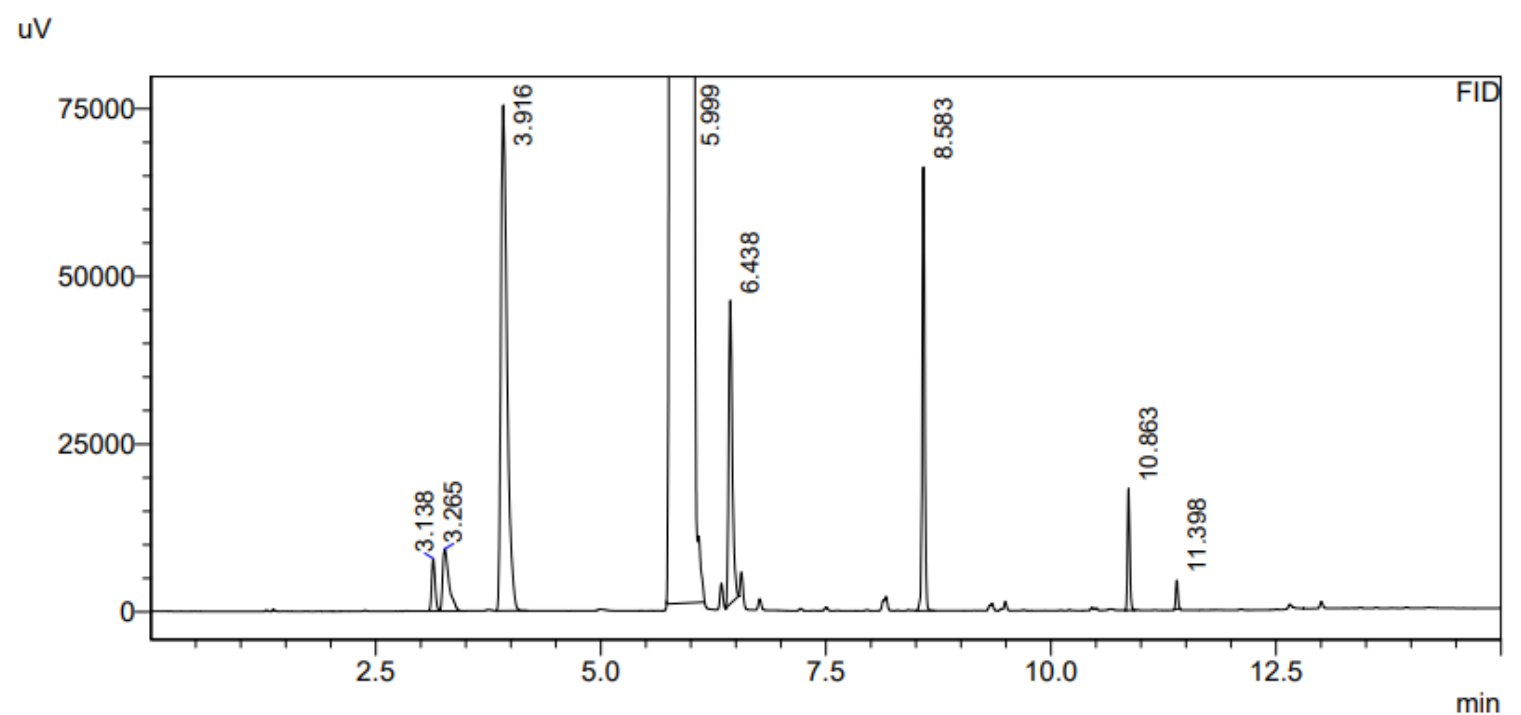

\begin{tabular}{cc} 
Retention Time & Compound \\
\hline 3.138 & $\begin{array}{c}\text { impurity in eluent solvent } \\
\text { methanol (co-crystalized with } \\
\left.\left.\text { [Ru(bipy } \mathbf{~}^{\mathbf{O H}}\right)\right] \text { ) }\end{array}$ \\
3.265 & ethanol \\
5.999 & acetonitrile (eluent) \\
6.438 & n-propanol (internal standard) \\
8.583 & n-butanol \\
10.863 & 2-ethyl-1-butanol \\
11.398 & 1-hexanol
\end{tabular}

Figure S22. GC chromatogram and retention times of catalytic reaction table S9, entry 3 
Table S10, entry 1

uV

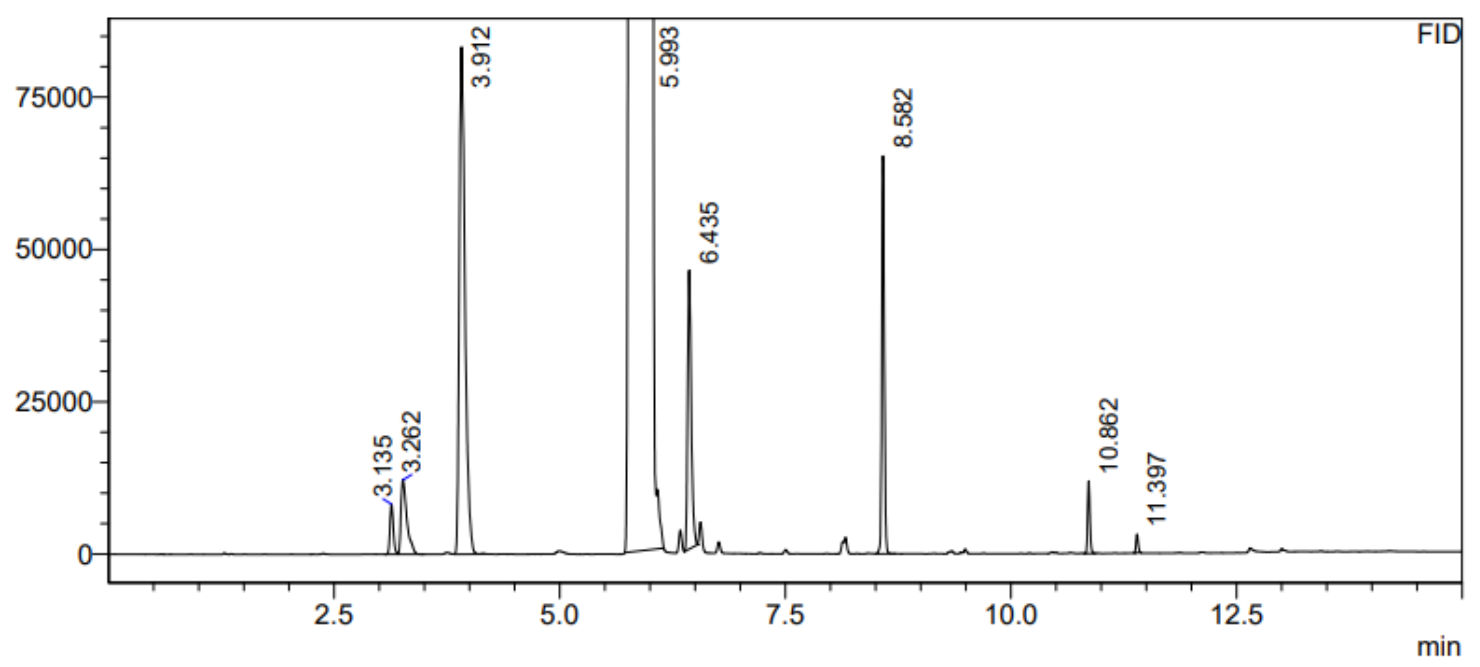

\begin{tabular}{cc} 
Retention Time & Compound \\
\hline 3.135 & $\left.\begin{array}{c}\text { impurity in eluent solvent } \\
\text { methanol (co-crystalized with } \\
\left.\left.\text { [Ru(bipy } \mathbf{O H}^{\mathbf{O H}}\right)\right]\end{array}\right)$ \\
3.962 & ethanol \\
5.993 & acetonitrile (eluent) \\
6.435 & n-propanol (internal standard) \\
8.582 & n-butanol \\
10.862 & 2-ethyl-1-butanol \\
11.397 & 1-hexanol
\end{tabular}

Figure S23. GC chromatogram and retention times of catalytic reaction table S10, entry 1 
Table S10, entry 2

uV

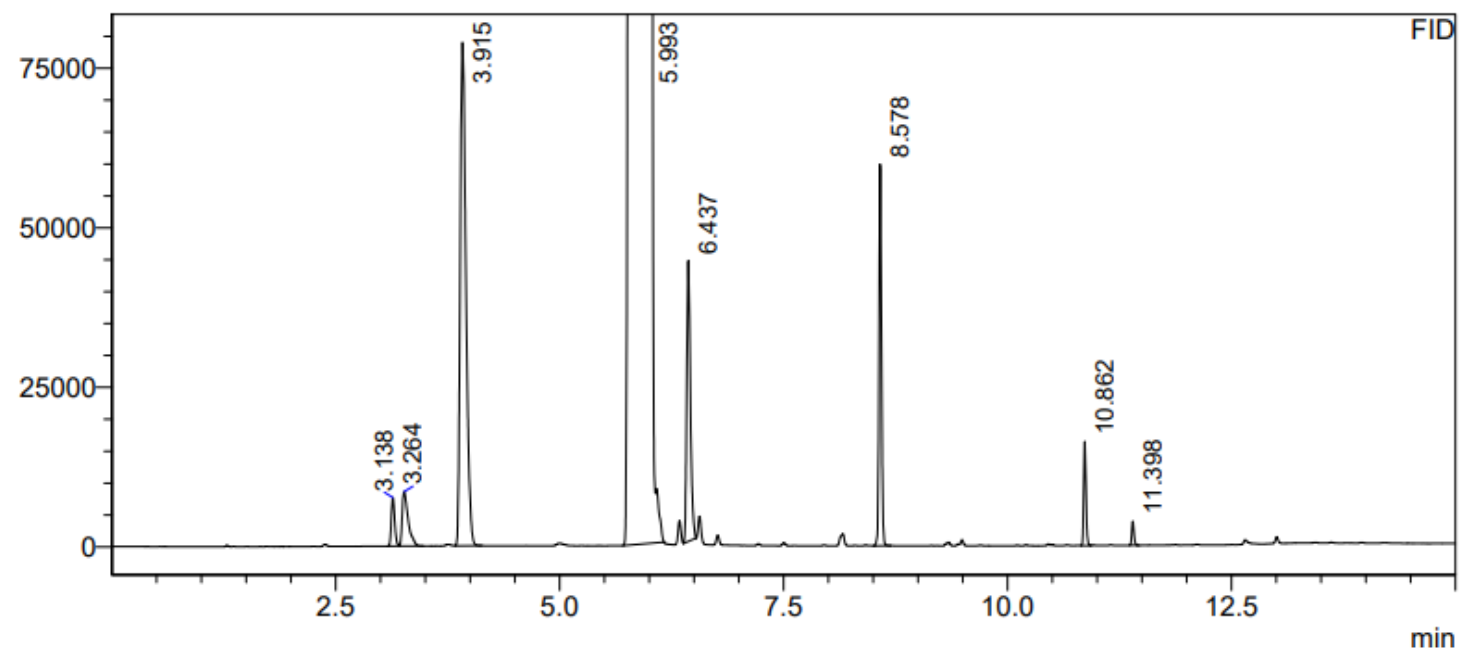

\begin{tabular}{cc} 
Retention Time & Compound \\
\hline 3.138 & $\begin{array}{c}\text { impurity in eluent solvent } \\
\text { methanol (co-crystalized with } \\
\left.\left.\text { [Ru(bipy }{ }^{\mathbf{O H}}\right)\right] \text { ) }\end{array}$ \\
3.264 & ethanol \\
5.993 & acetonitrile (eluent) \\
6.437 & n-propanol (internal standard) \\
8.578 & n-butanol \\
10.862 & 2-ethyl-1-butanol \\
11.398 & 1-hexanol
\end{tabular}

Figure S24. GC chromatogram and retention times of catalytic reaction table S10, entry 2 
Table S10, entry 3

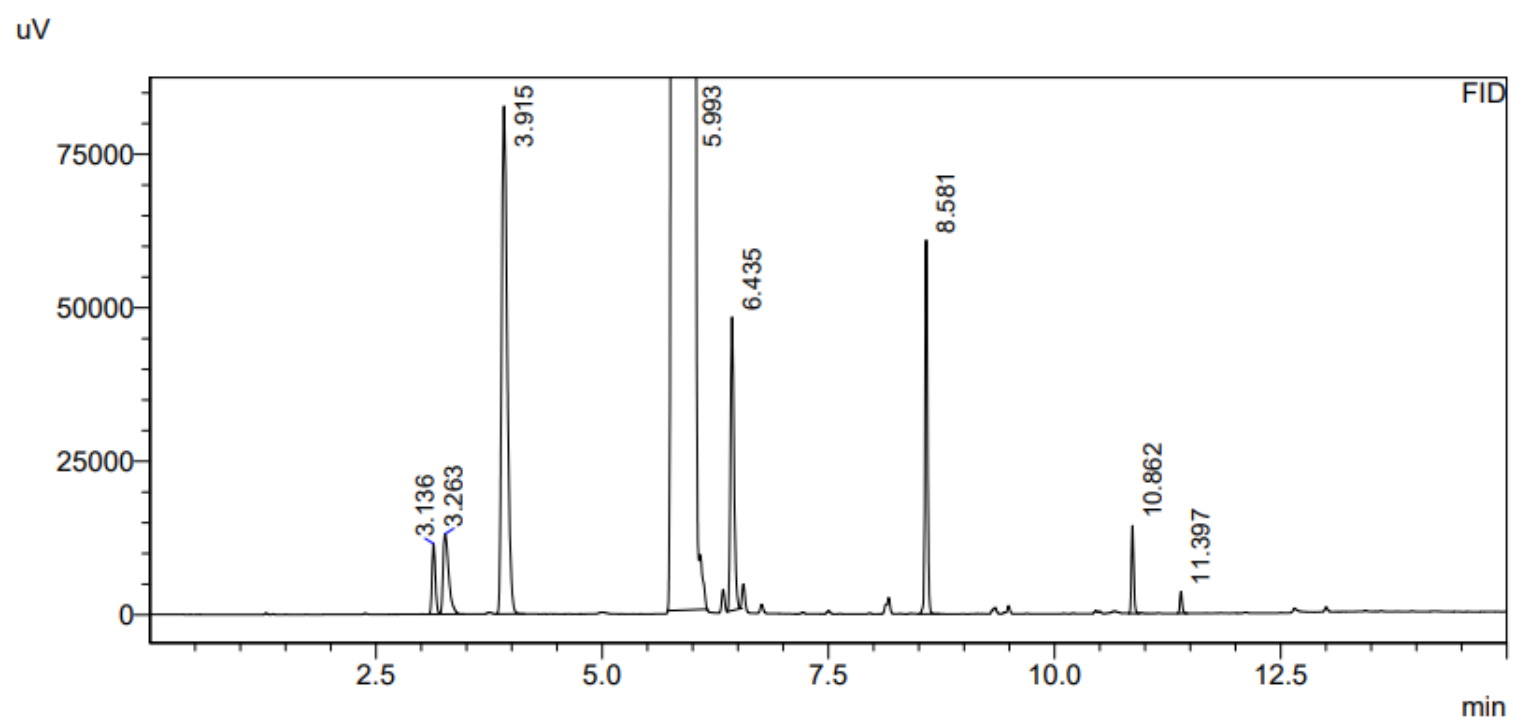

\begin{tabular}{cc} 
Retention Time & Compound \\
\hline 3.136 & $\begin{array}{c}\text { impurity in eluent solvent } \\
\text { methanol (co-crystalized with } \\
[\mathbf{R u}(\mathbf{b i p y} \mathbf{\text { OH}})])\end{array}$ \\
3.915 & ethanol \\
5.993 & acetonitrile (eluent) \\
6.435 & n-propanol (internal standard) \\
8.581 & $n$-butanol \\
10.862 & 2-ethyl-1-butanol \\
11.397 & 1-hexanol
\end{tabular}

Figure S25. GC chromatogram and retention times of catalytic reaction table S10, entry 3 
Table S10, entry 4

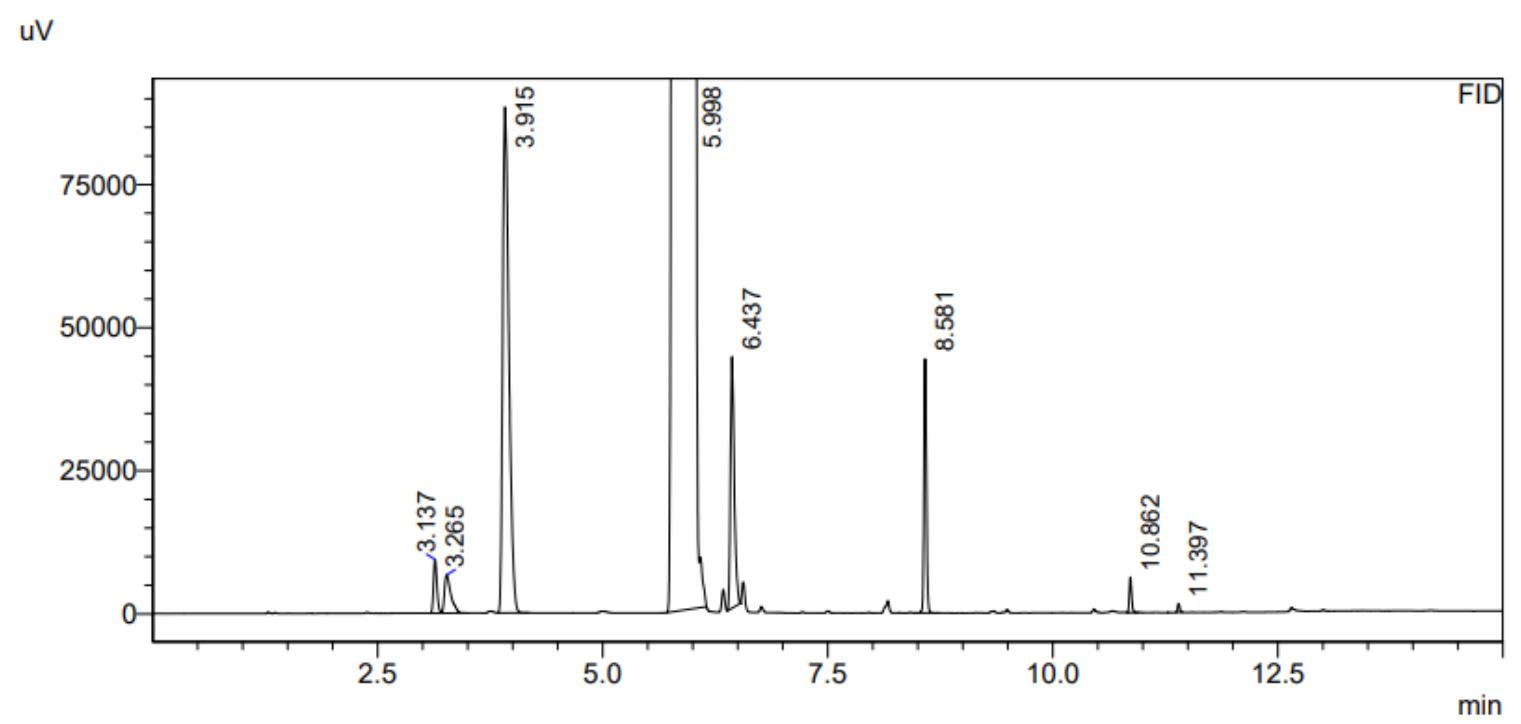

\begin{tabular}{cc} 
Retention Time & Compound \\
\hline 3.137 & $\begin{array}{c}\text { impurity in eluent solvent } \\
\text { methanol (co-crystalized with } \\
\text { [Ru(bipy } \mathbf{\text { OH}})] \text { ) }\end{array}$ \\
3.265 & ethanol \\
5.998 & acetonitrile (eluent) \\
6.437 & n-propanol (internal standard) \\
8.581 & n-butanol \\
10.862 & 2-ethyl-1-butanol \\
11.397 & 1-hexanol
\end{tabular}

Figure S26. GC chromatogram and retention times of catalytic reaction table S10, entry 4 
Table S10, entry 5

uV

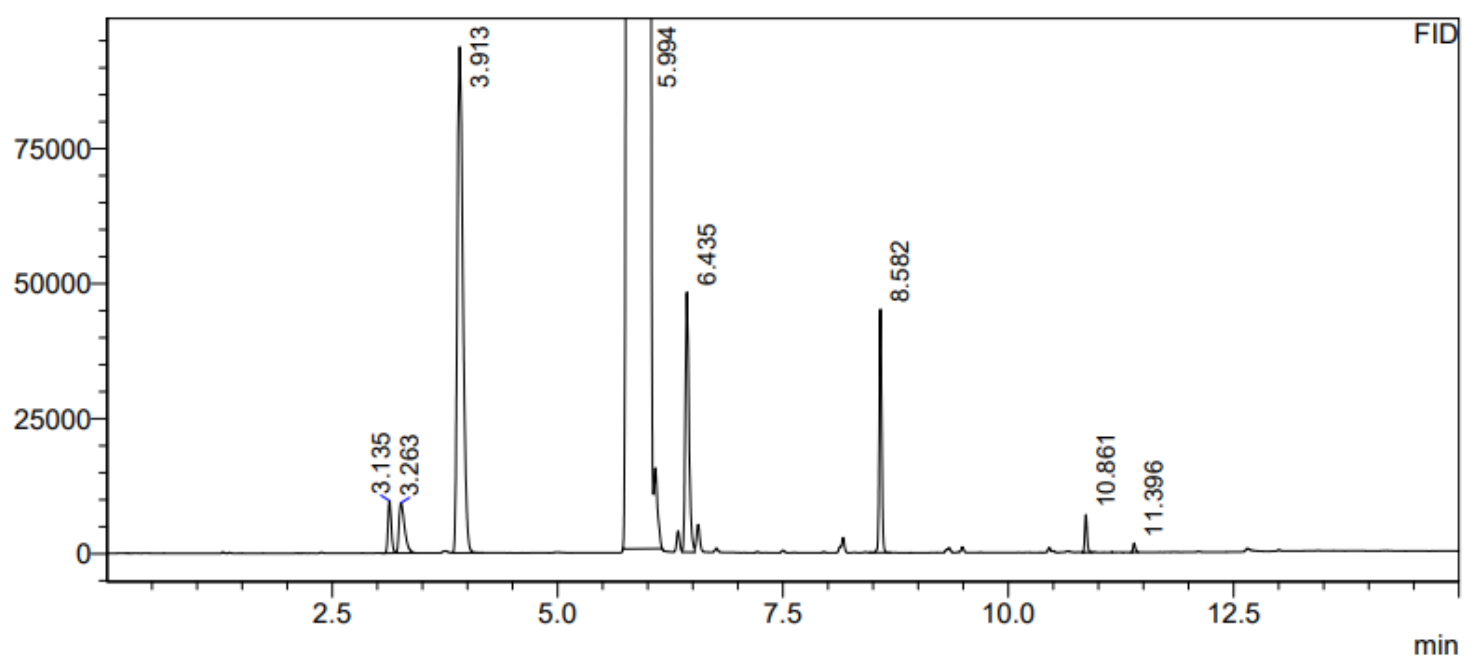

\begin{tabular}{cc} 
Retention Time & Compound \\
\hline 3.135 & $\begin{array}{c}\text { impurity in eluent solvent } \\
\text { methanol (co-crystalized with } \\
\left.\left[\mathbf{R u}\left(\mathbf{b i p y} \mathbf{O H}^{\mathbf{H}}\right)\right]\right)\end{array}$ \\
3.913 & ethanol \\
5.994 & acetonitrile (eluent) \\
6.435 & n-propanol (internal standard) \\
8.582 & $n$-butanol \\
10.861 & 2-ethyl-1-butanol \\
11.396 & 1-hexanol
\end{tabular}

Figure S27. GC chromatogram and retention times of catalytic reaction table S10, entry 5 
Table S10, entry 6

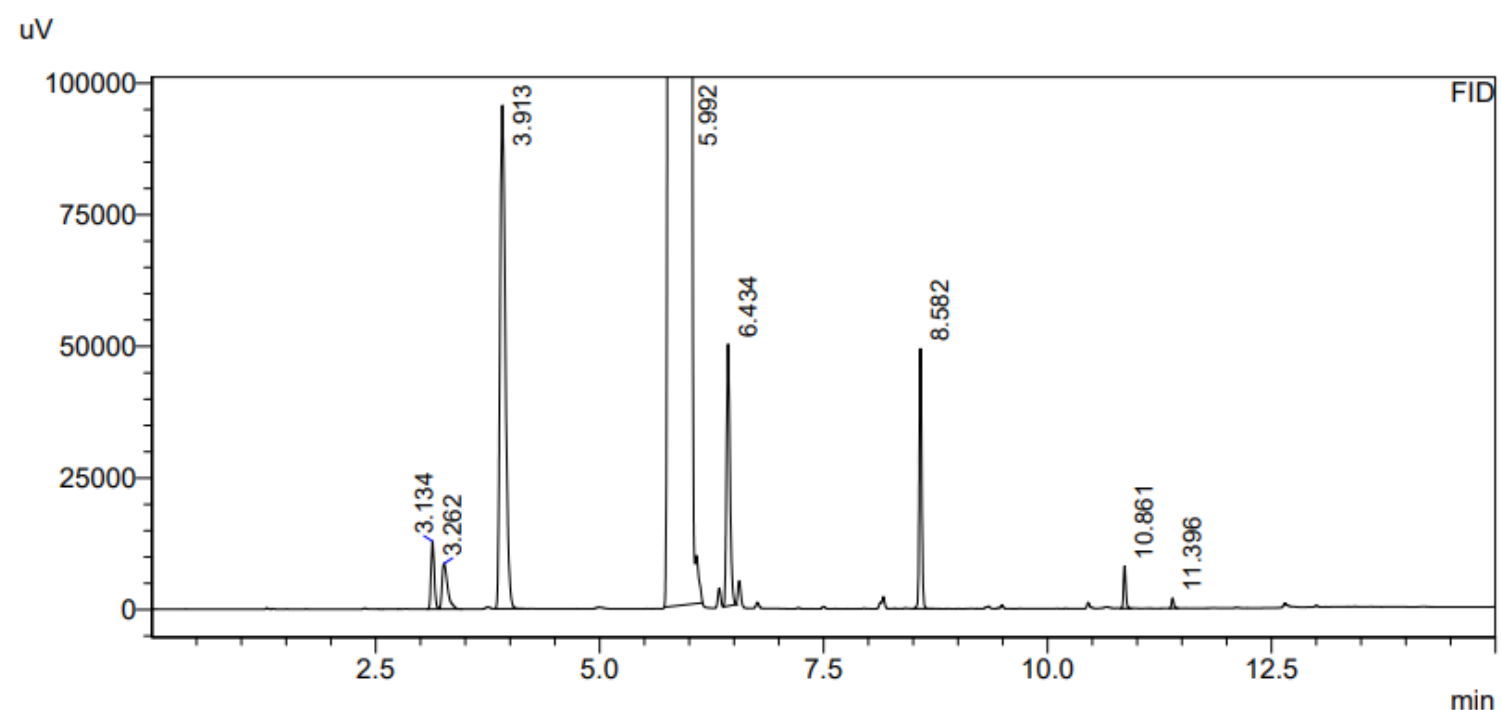

\begin{tabular}{cc} 
Retention Time & Compound \\
\hline 3.134 & impurity in eluent solvent \\
3.262 & $\left.\begin{array}{c}\text { methanol (co-crystalized with } \\
{\left[\mathbf{R u}\left(\mathbf{b i p y} \mathbf{O H}^{\mathbf{O}}\right)\right]}\end{array}\right)$ \\
3.913 & ethanol \\
5.992 & acetonitrile (eluent) \\
6.434 & $n$-propanol (internal standard) \\
8.582 & $n$-butanol \\
10.861 & 2-ethyl-1-butanol \\
11.396 & 1 -hexanol
\end{tabular}

Figure S28. GC chromatogram and retention times of catalytic reaction table S10, entry 6 
Table S10, entry 7

uV

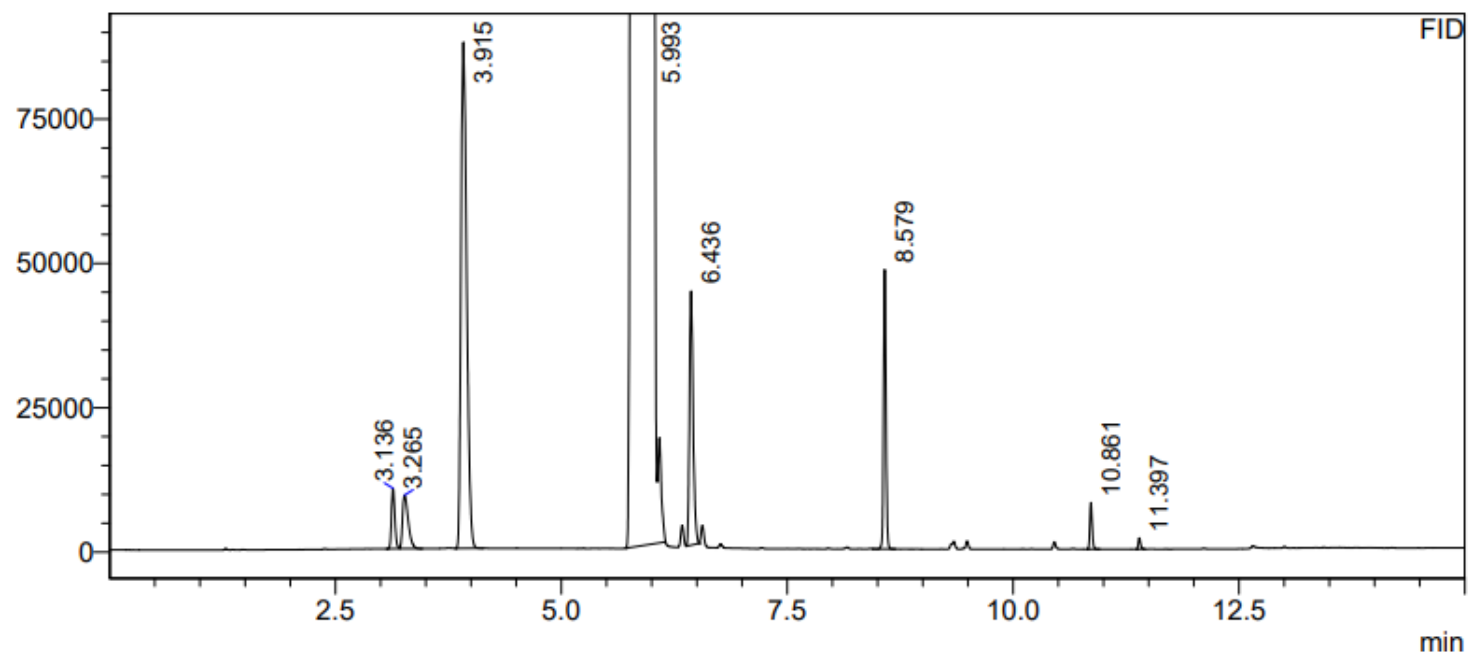

\begin{tabular}{cc} 
Retention Time & Compound \\
\hline 3.136 & $\begin{array}{c}\text { impurity in eluent solvent } \\
\text { methanol (co-crystalized with } \\
\left.\left.\text { [Ru(bipy } \mathbf{~}^{\mathbf{O H}}\right)\right] \text { ) }\end{array}$ \\
3.265 & ethanol \\
5.993 & acetonitrile (eluent) \\
6.436 & $n$-propanol (internal standard) \\
8.579 & $n$-butanol \\
10.861 & 2-ethyl-1-butanol \\
11.397 & $1-$-hexanol
\end{tabular}

Figure S29. GC chromatogram and retention times of catalytic reaction table S10, entry 7 
Table S10, entry 8

uV

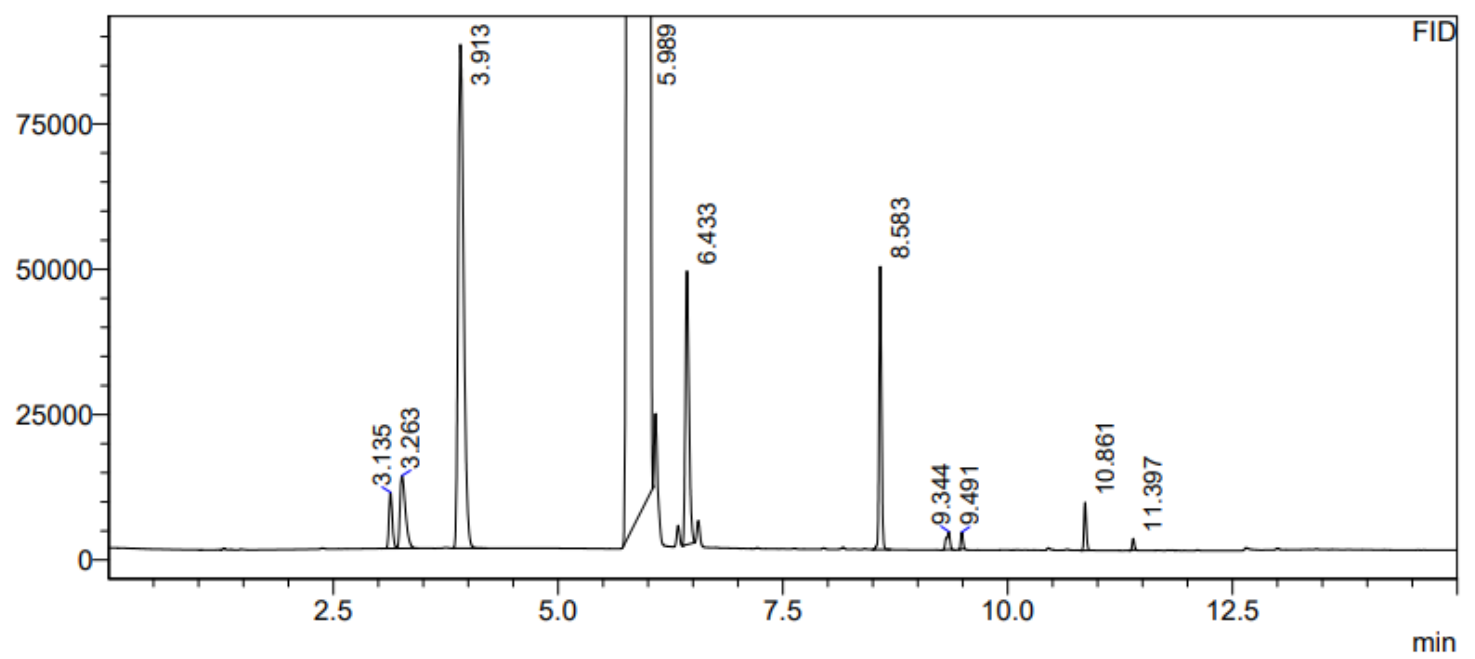

\begin{tabular}{|c|c|}
\hline Retention Time & Compound \\
\hline 3.135 & impurity in eluent solvent \\
\hline 3.263 & $\begin{array}{c}\text { methanol (co-crystalized with } \\
\left.\left[\mathbf{R u}\left(\mathbf{b i p y}^{\mathbf{O H}}\right)\right]\right)\end{array}$ \\
\hline 3.913 & ethanol \\
\hline 5.989 & acetonitrile (eluent) \\
\hline 6.433 & n-propanol (internal standard) \\
\hline 8.583 & $n$-butanol \\
\hline 9.344 & unknown \\
\hline 9.491 & unknown \\
\hline 10.861 & 2-ethyl-1-butanol \\
\hline 11.397 & 1-hexanol \\
\hline
\end{tabular}

Figure S30. GC chromatogram and retention times of catalytic reaction table S10, entry 8 
Table S10, entry 9

uV

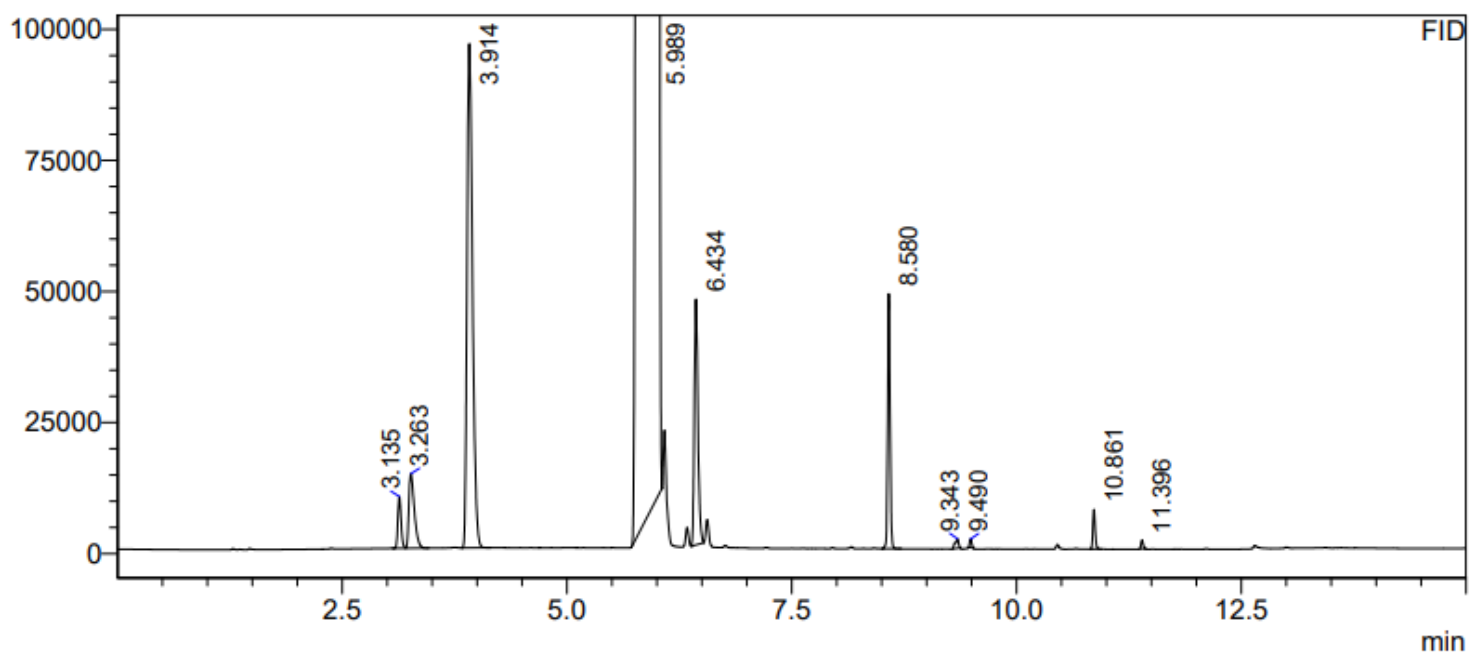

\begin{tabular}{|c|c|}
\hline Retention Time & Compound \\
\hline 3.135 & impurity in eluent solvent \\
\hline 3.263 & $\begin{array}{c}\text { methanol (co-crystalized with } \\
\left.\left[\mathbf{R u}\left(\mathbf{b i p y}^{\mathbf{O H}}\right)\right]\right)\end{array}$ \\
\hline 3.914 & ethanol \\
\hline 5.989 & acetonitrile (eluent) \\
\hline 6.434 & $n$-propanol (internal standard) \\
\hline 8.580 & $n$-butanol \\
\hline 9.343 & unknown \\
\hline 9.490 & unknown \\
\hline 10.861 & 2-ethyl-1-butanol \\
\hline 11.396 & 1-hexanol \\
\hline
\end{tabular}

Figure S31. GC chromatogram and retention times of catalytic reaction table S10, entry 9 
Table S10, entry 10

uV

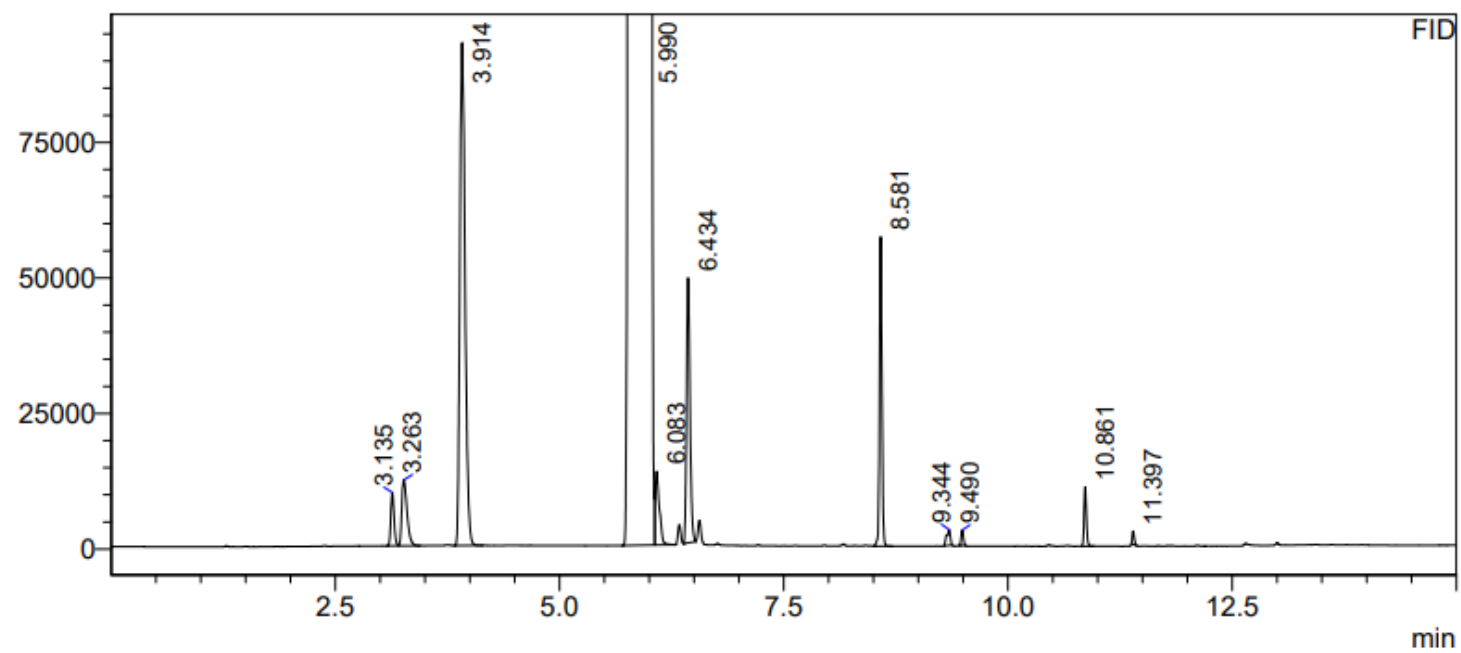

\begin{tabular}{cc} 
Retention Time & Compound \\
\hline 3.135 & $\left.\begin{array}{c}\text { impurity in eluent solvent } \\
\text { methanol (co-crystalized with } \\
{\left[\mathbf{R u}\left(\mathbf{b i p y} \mathbf{O H}^{\mathbf{H}}\right)\right]}\end{array}\right)$ \\
3.914 & ethanol \\
5.990 & acetonitrile (eluent) \\
6.083 & unknown \\
6.434 & n-propanol (internal standard) \\
8.581 & n-butanol \\
9.344 & unknown \\
9.490 & unknown \\
10.861 & 2-ethyl-1-butanol \\
11.397 & 1-hexanol
\end{tabular}

Figure S32. GC chromatogram and retention times of catalytic reaction table S10, entry 10 


\section{Table 2, entry 1}

uV

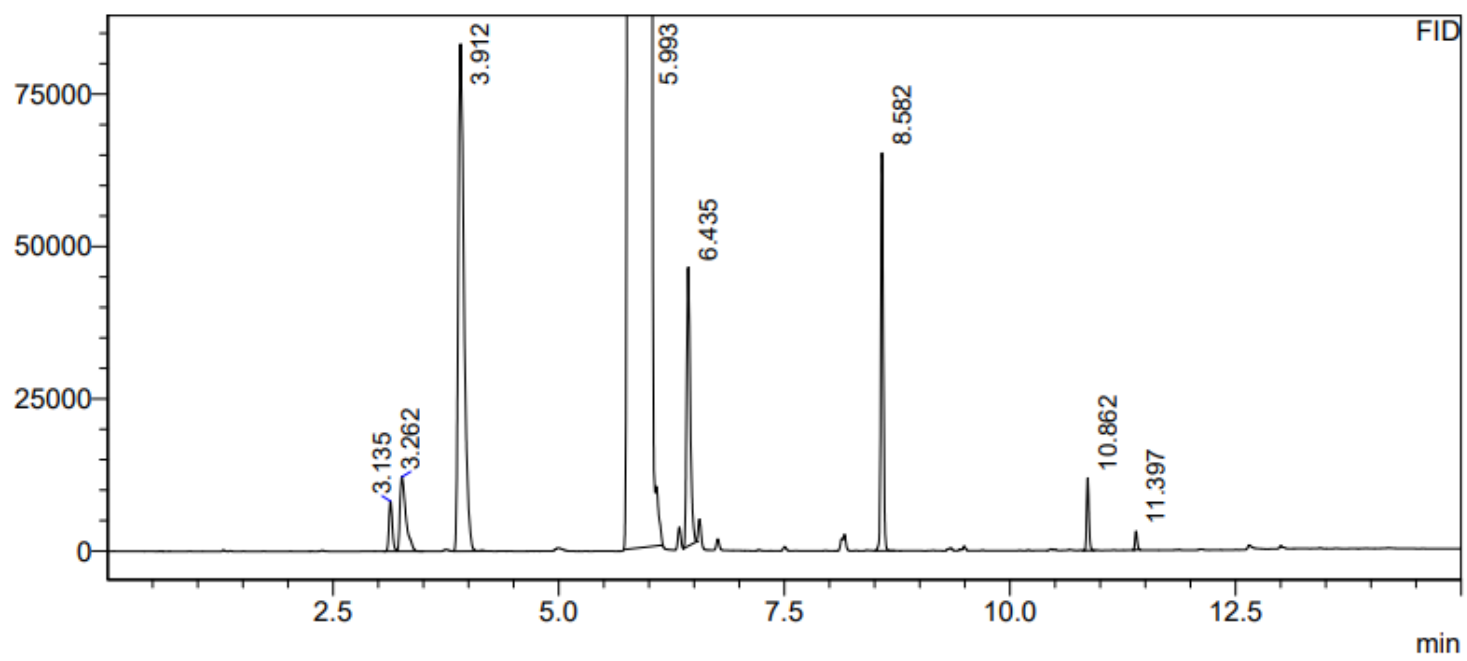

\begin{tabular}{cc} 
Retention Time & Compound \\
\hline 3.135 & $\left.\begin{array}{c}\text { impurity in eluent solvent } \\
\text { methanol (co-crystalized with } \\
\left.\left.\text { [Ru(bipy } \mathbf{O H}^{\mathbf{O H}}\right)\right]\end{array}\right)$ \\
3.262 & ethanol \\
5.993 & acetonitrile (eluent) \\
6.435 & n-propanol (internal standard) \\
8.582 & n-butanol \\
10.862 & 2-ethyl-1-butanol \\
11.397 & 1-hexanol
\end{tabular}

Figure S33. GC chromatogram and retention times of catalytic reaction table 2, entry 1 
Table 2, entry 2

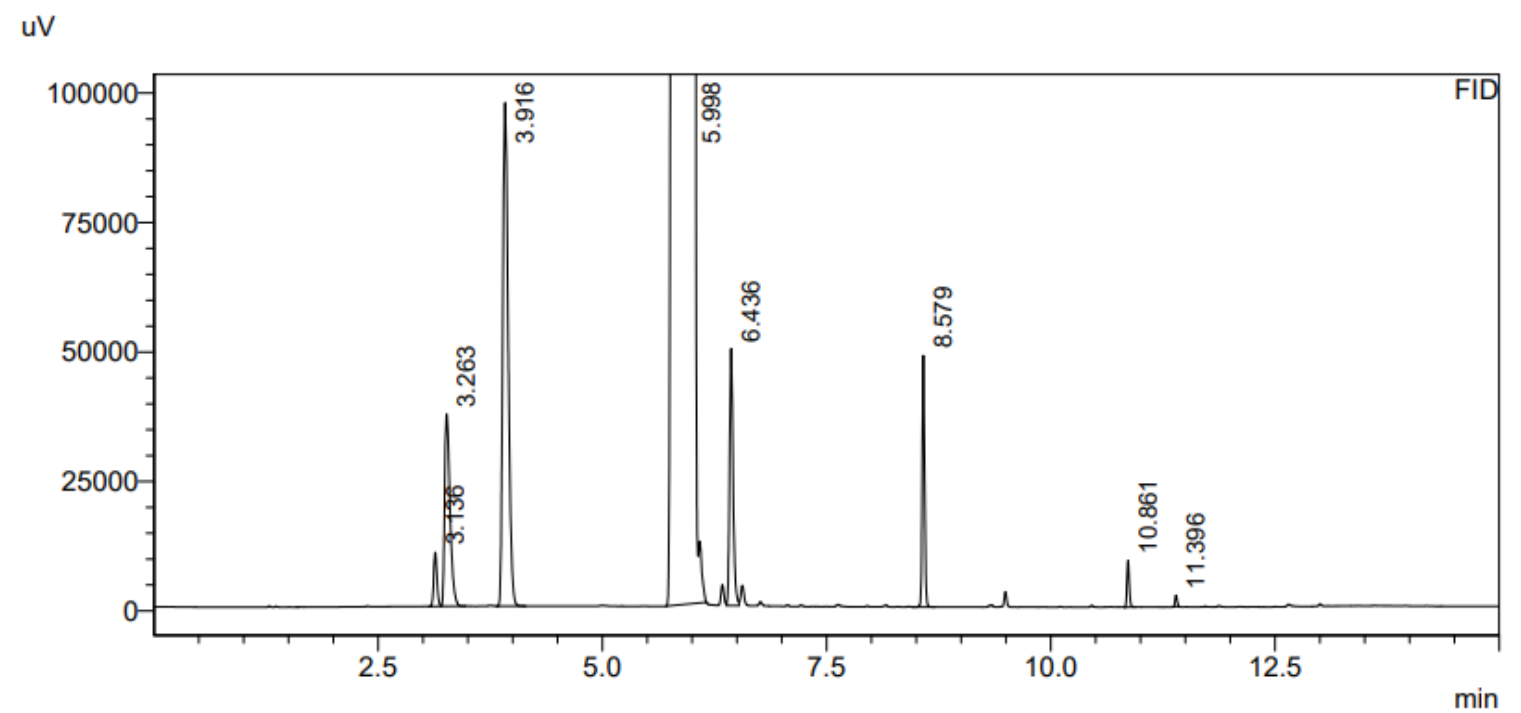

\begin{tabular}{cc} 
Retention Time & Compound \\
\hline 3.136 & impurity in eluent solvent \\
3.263 & methanol from NaOMe \\
3.916 & ethanol \\
5.998 & acetonitrile (eluent) \\
6.436 & $n$-propanol (internal standard) \\
8.579 & $n$-butanol \\
10.861 & 2-ethyl-1-butanol \\
11.396 & 1-hexanol
\end{tabular}

Figure S34. GC chromatogram and retention times of catalytic reaction table 2, entry 2 
Table 2, entry 3

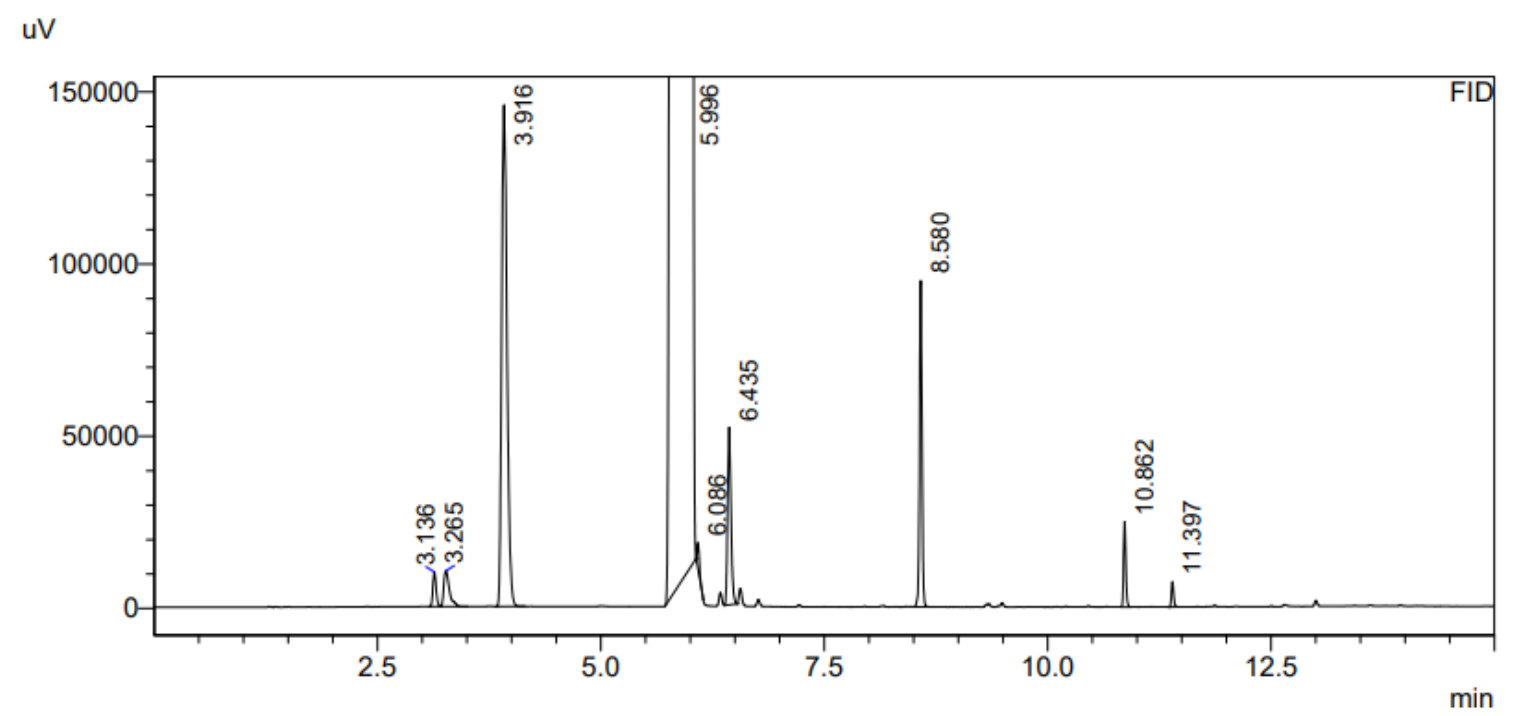

\begin{tabular}{cc} 
Retention Time & Compound \\
\hline 3.136 & $\left.\begin{array}{c}\text { impurity in eluent solvent } \\
\text { methanol (co-crystalized with } \\
\left.\left.\text { [Ru(bipy } \mathbf{O H}^{\mathbf{O H}}\right)\right]\end{array}\right)$ \\
3.265 & ethanol \\
5.996 & acetonitrile (eluent) \\
6.435 & n-propanol (internal standard) \\
8.580 & $n$-butanol \\
10.862 & 2-ethyl-1-butanol \\
11.397 & 1-hexanol
\end{tabular}

Figure S35. GC chromatogram and retention times of catalytic reaction table 2, entry 3 


\section{Table 2, entry 4}

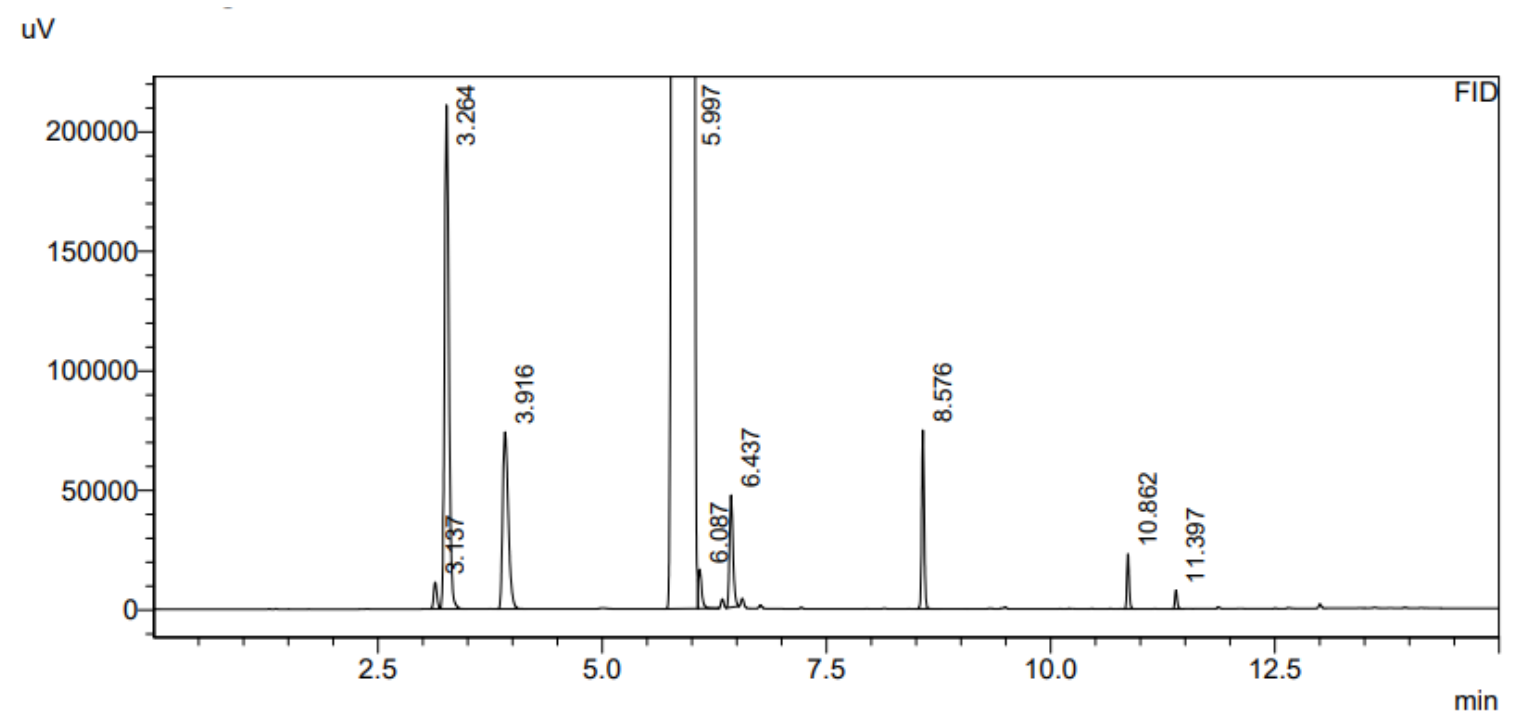

\begin{tabular}{cc} 
Retention Time & Compound \\
\hline 3.137 & impurity in eluent solvent \\
3.264 & tert-butyl alcohol from NaOtBu \\
3.916 & ethanol \\
5.997 & acetonitrile (eluent) \\
6.087 & unknown \\
6.437 & $n$-propanol (internal standard) \\
8.576 & $n$-butanol \\
10.862 & 2-ethyl-1-butanol \\
11.397 & 1-hexanol
\end{tabular}

Figure S36. GC chromatogram and retention times of catalytic reaction table 2, entry 4 


\section{Table 2, entry 5}

uV

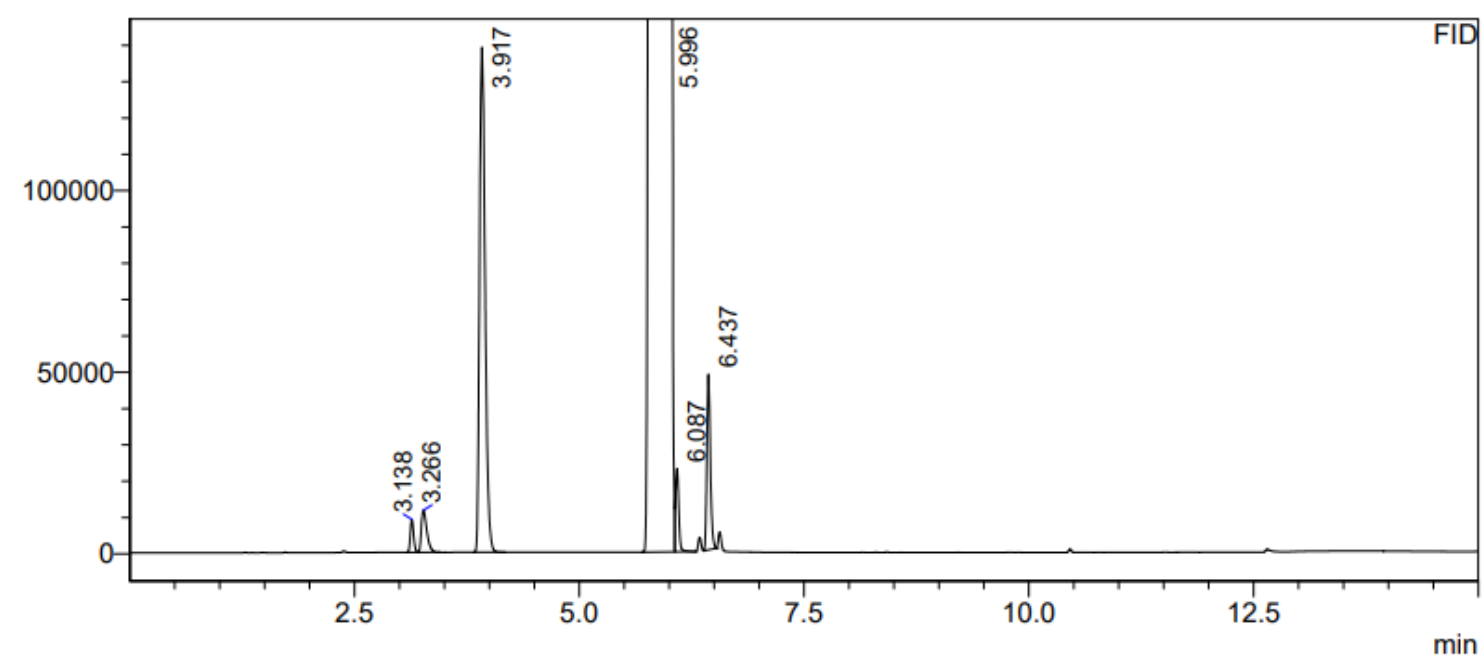

\begin{tabular}{cc} 
Retention Time & Compound \\
\hline 3.138 & impurity in eluent solvent \\
3.266 & methanol (co-crystalized with \\
& {$\left[\mathbf{R u}\left(\mathbf{b i p y} \mathbf{O H}^{\mathbf{H}}\right)\right]$ ) } \\
3.917 & ethanol \\
5.996 & acetonitrile (eluent) \\
6.087 & unknown \\
6.437 & $n$-propanol (internal standard)
\end{tabular}

Figure S37. GC chromatogram and retention times of catalytic reaction table 2, entry 5 
Table 2, entry 6

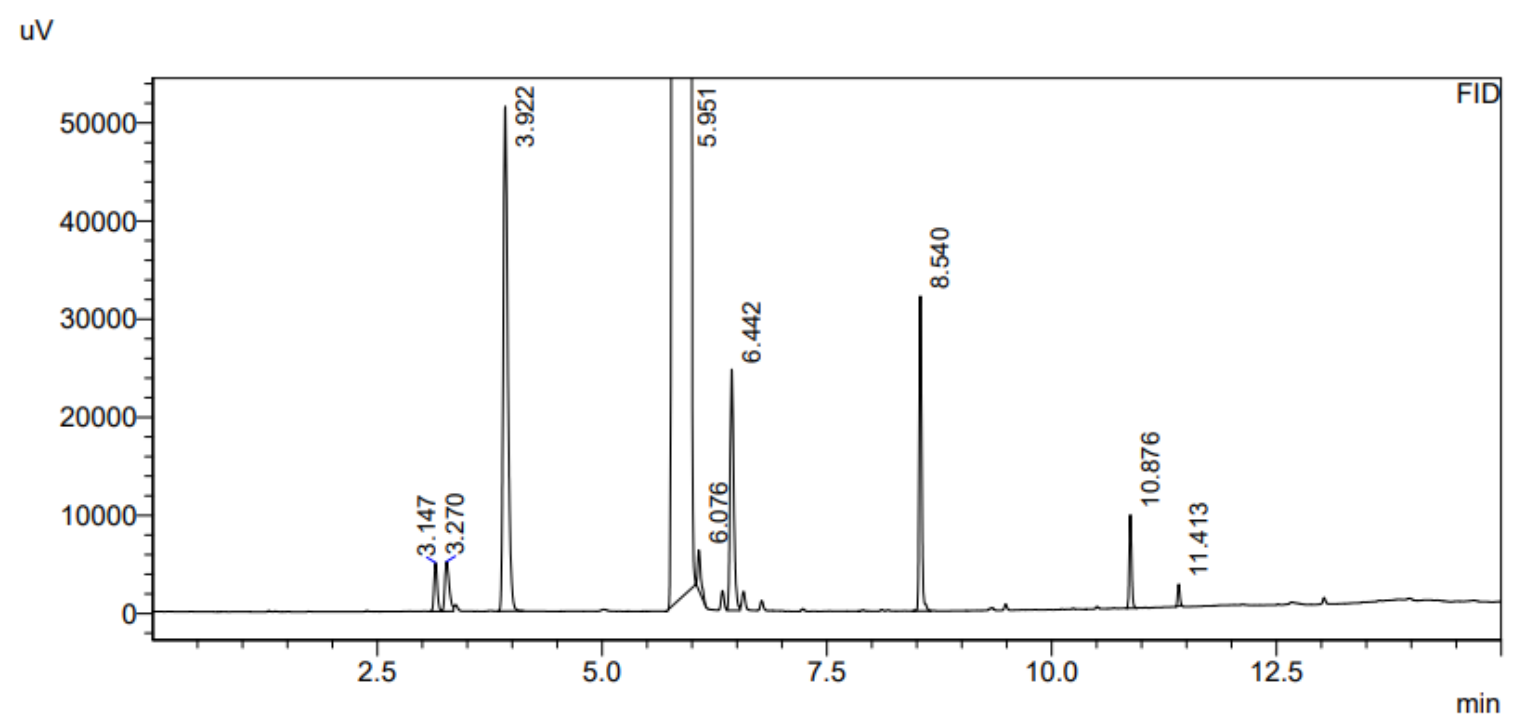

\begin{tabular}{|c|c|}
\hline Retention Time & Compound \\
\hline 3.147 & impurity in eluent solvent \\
\hline 3.270 & $\begin{array}{c}\text { methanol (co-crystalized with } \\
\left.\left[\mathbf{R u}\left(\mathbf{b i p y}^{\mathbf{O H}}\right)\right]\right)\end{array}$ \\
\hline 3.922 & ethanol \\
\hline 5.951 & acetonitrile (eluent) \\
\hline 6.078 & unknown \\
\hline 6.442 & $n$-propanol (internal standard) \\
\hline 8.540 & $n$-butanol \\
\hline 10.876 & 2-ethyl-1-butanol \\
\hline 11.413 & 1-hexanol \\
\hline
\end{tabular}

Figure S38. GC chromatogram and retention times of catalytic reaction table 2, entry 6 
Table 2, entry 7

uv

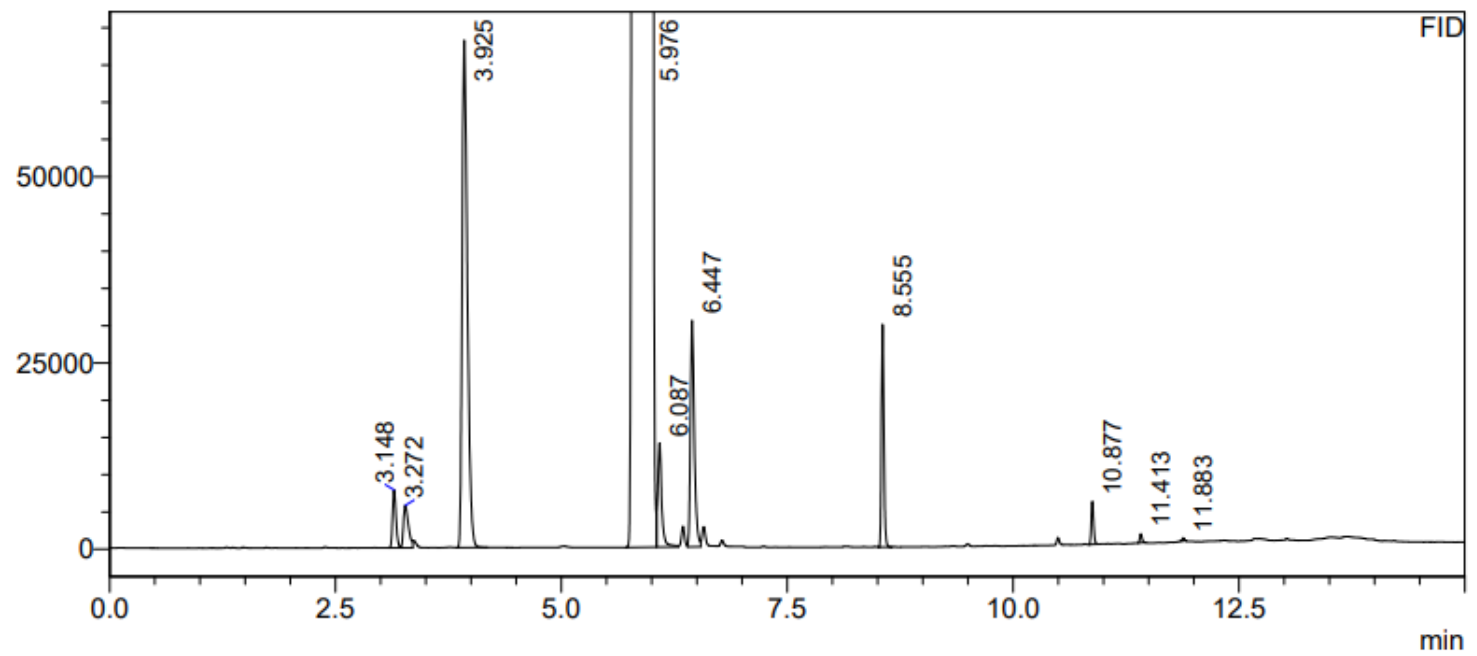

\begin{tabular}{cc} 
Retention Time & Compound \\
\hline 3.148 & impurity in eluent solvent \\
3.272 & $\left.\begin{array}{c}\text { methanol (co-crystalized with } \\
{\left[\mathbf{R u}\left(\mathbf{b i p y} \mathbf{O H}^{\mathbf{C}}\right)\right]}\end{array}\right)$ \\
& ethanol \\
3.925 & acetonitrile (eluent) \\
5.976 & unknown \\
6.087 & n-propanol (internal standard) \\
6.447 & n-butanol \\
8.555 & 2-ethyl-1-butanol \\
10.877 & 1-hexanol \\
11.413 & unknown \\
11.883 &
\end{tabular}

Figure S39. GC chromatogram and retention times of catalytic reaction table 2, entry 7 
Table 2, entry 8

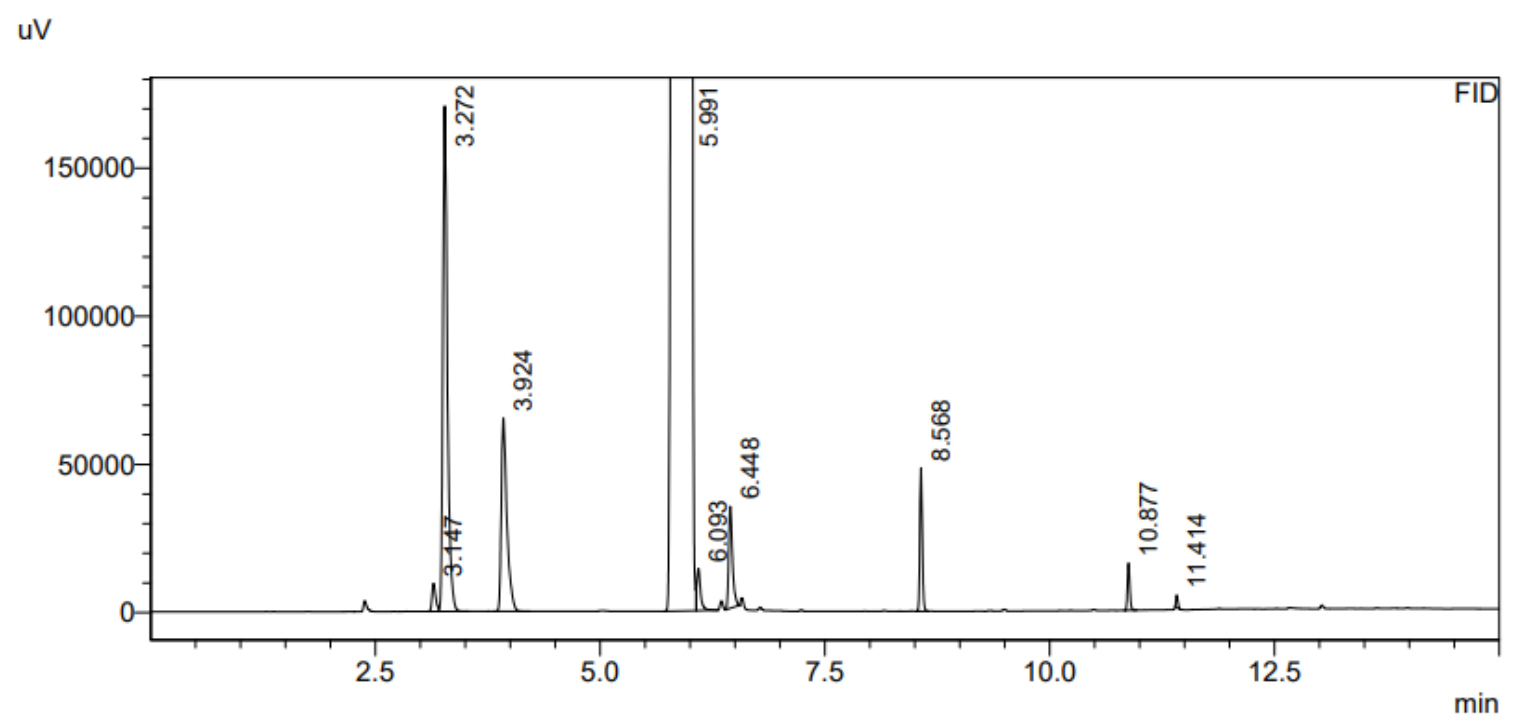

\begin{tabular}{cc} 
Retention Time & Compound \\
\hline 3.147 & impurity in eluent solvent \\
3.272 & tert-butyl alcohol from KOtBu \\
3.924 & ethanol \\
5.991 & acetonitrile (eluent) \\
6.093 & unknown \\
6.448 & $n$-propanol (internal standard) \\
8.568 & $n$-butanol \\
10.877 & 2-ethyl-1-butanol \\
11.414 & 1-hexanol
\end{tabular}

Figure S40. GC chromatogram and retention times of catalytic reaction table 2, entry 8 


\section{Table SIl, entry 1}

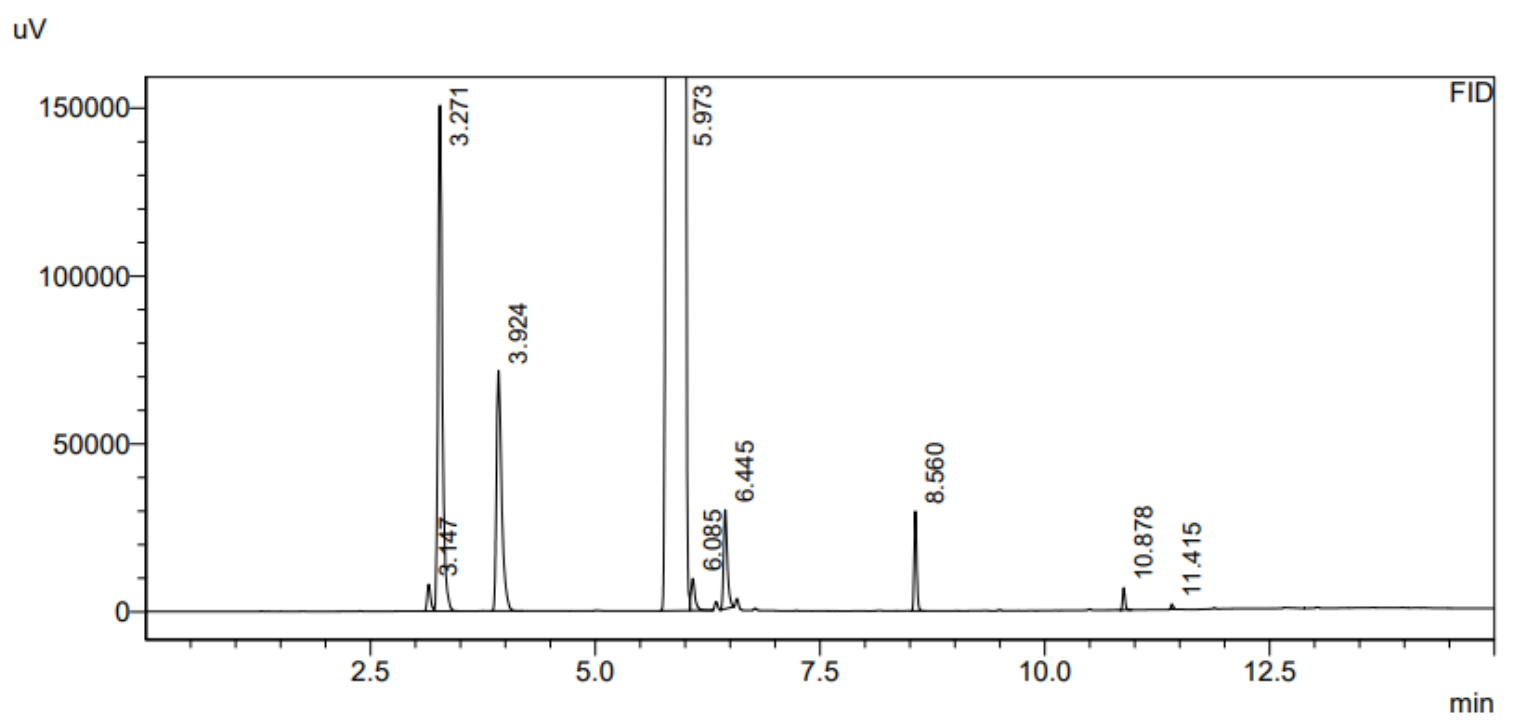

\begin{tabular}{cc} 
Retention Time & Compound \\
\hline 3.147 & impurity in eluent solvent \\
3.271 & tert-butyl alcohol from NaOtBu \\
3.924 & ethanol \\
5.973 & acetonitrile (eluent) \\
6.085 & unknown \\
6.445 & $n$-propanol (internal standard) \\
8.560 & $n$-butanol \\
10.878 & 2-ethyl-1-butanol \\
11.415 & 1-hexanol
\end{tabular}

Figure S41. GC chromatogram and retention times of catalytic reaction table S11, entry 1 


\section{Table S11, entry 2}

uV

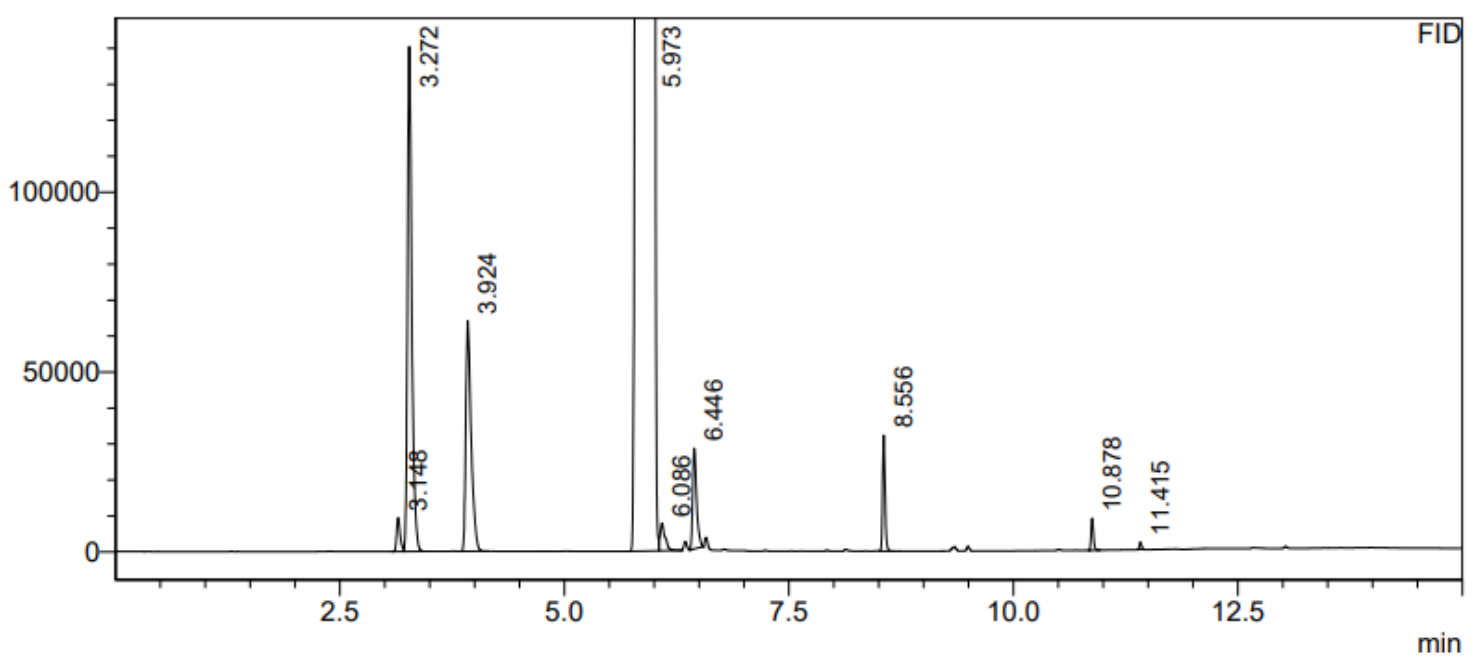

\begin{tabular}{cc} 
Retention Time & Compound \\
\hline 3.148 & impurity in eluent solvent \\
3.272 & tert-butyl alcohol from NaOtBu \\
3.924 & ethanol \\
5.973 & acetonitrile (eluent) \\
6.086 & unknown \\
6.446 & $n$-propanol (internal standard) \\
8.556 & n-butanol \\
10.878 & 2-ethyl-1-butanol \\
11.415 & 1-hexanol
\end{tabular}

Figure S42. GC chromatogram and retention times of catalytic reaction table S11, entry 2 


\section{Table 3, entry 1}

$\mathrm{uV}$

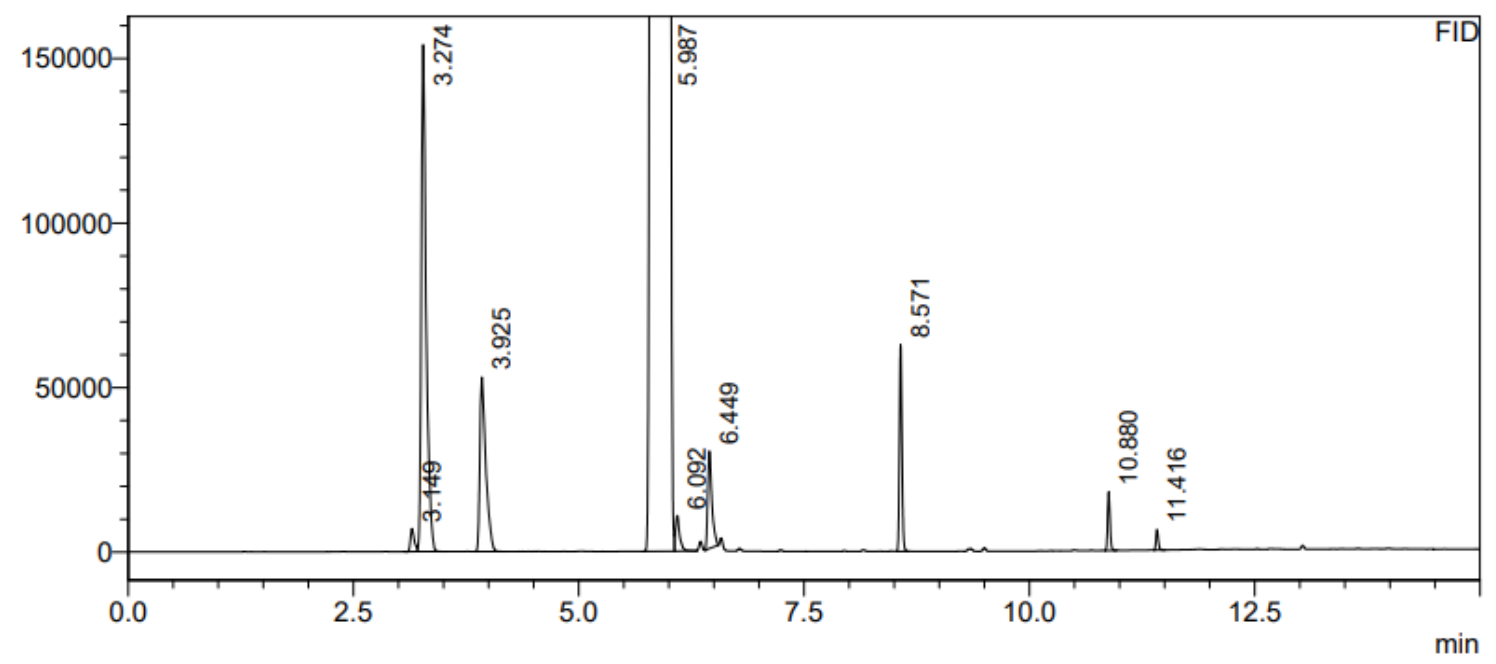

\begin{tabular}{cc} 
Retention Time & Compound \\
\hline 3.149 & impurity in eluent solvent \\
3.274 & tert-butyl alcohol from KOtBu \\
3.925 & ethanol \\
5.987 & acetonitrile (eluent) \\
6.092 & unknown \\
6.449 & $n$-propanol (internal standard) \\
8.571 & $n$-butanol \\
10.880 & 2-ethyl-1-butanol \\
11.416 & 1-hexanol
\end{tabular}

Figure S43. GC chromatogram and retention times of catalytic reaction table 3 , entry 1 
Table 3, entry 2

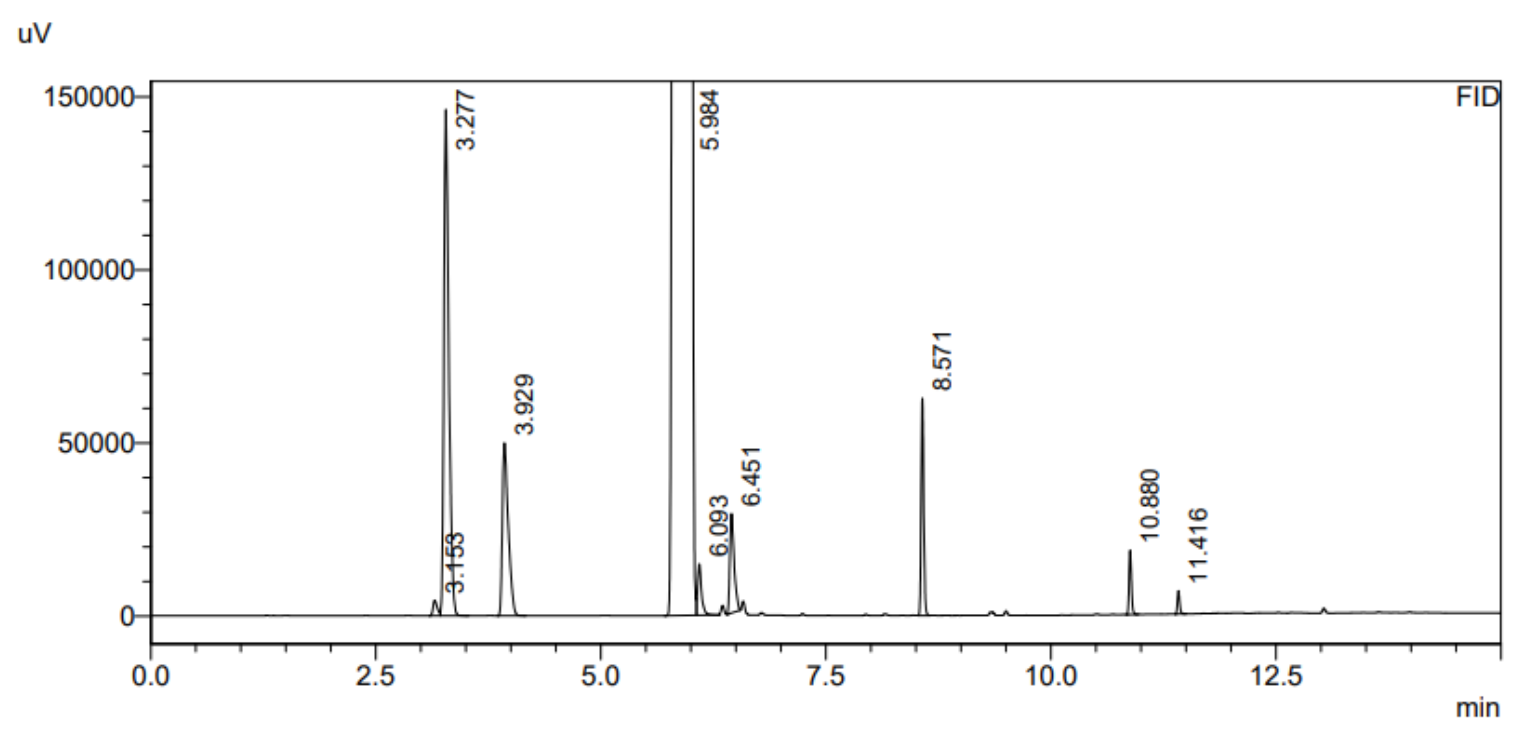

\begin{tabular}{cc} 
Retention Time & Compound \\
\hline 3.153 & impurity in eluent solvent \\
3.277 & tert-butyl alcohol from KOtBu \\
3.929 & ethanol \\
5.984 & acetonitrile (eluent) \\
6.093 & unknown \\
6.451 & $n$-propanol (internal standard) \\
8.571 & $n$-butanol \\
10.880 & 2-ethyl-1-butanol \\
11.416 & 1-hexanol
\end{tabular}

Figure S44. GC chromatogram and retention times of catalytic reaction table 3, entry 2 
Table 3, entry 3

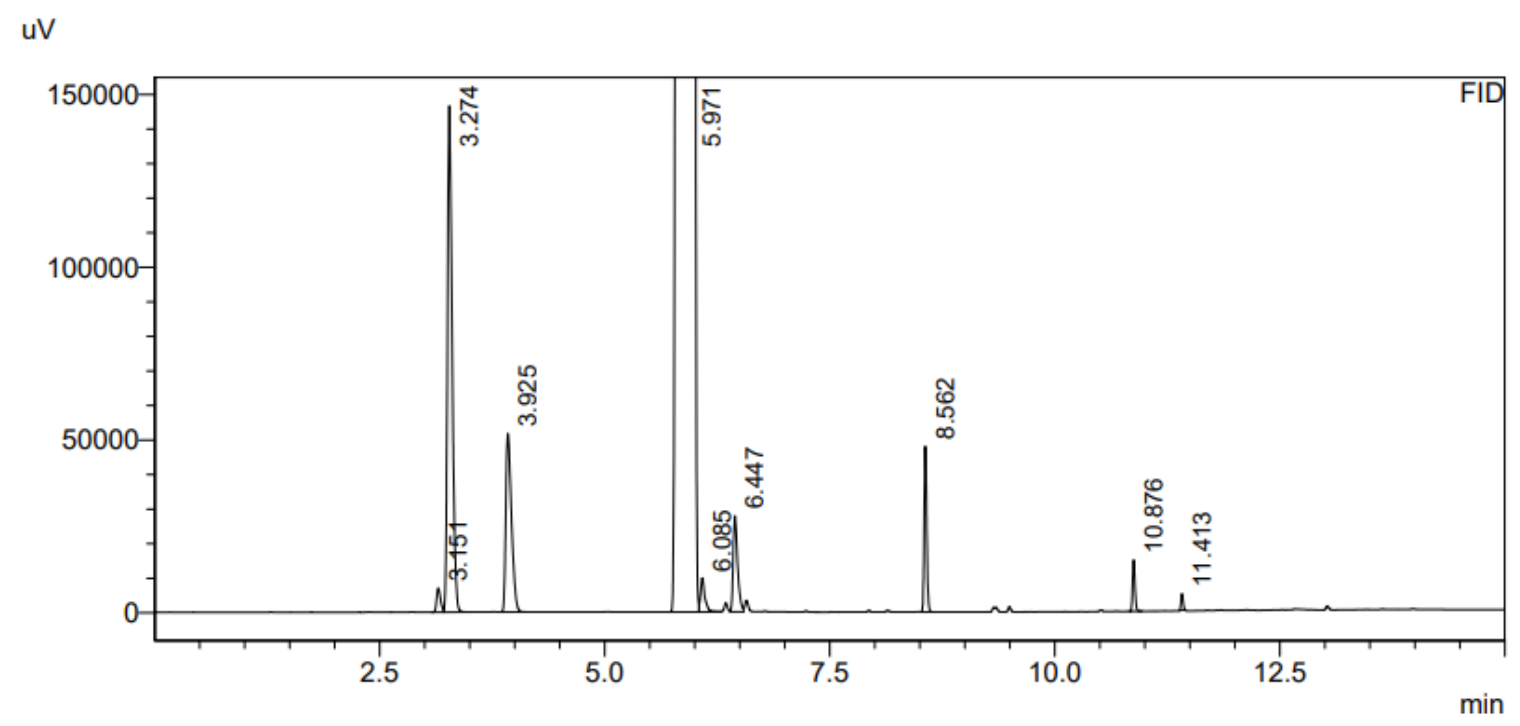

\begin{tabular}{cc} 
Retention Time & Compound \\
\hline 3.151 & impurity in eluent solvent \\
3.274 & tert-butyl alcohol from KOtBu \\
3.925 & ethanol \\
5.971 & acetonitrile (eluent) \\
6.085 & unknown \\
6.447 & $n$-propanol (internal standard) \\
8.562 & n-butanol \\
10.876 & 2-ethyl-1-butanol \\
11.413 & 1-hexanol
\end{tabular}

Figure S45. GC chromatogram and retention times of catalytic reaction table 3, entry 3 


\section{Table 3, entry 4}

$\mathrm{uV}$

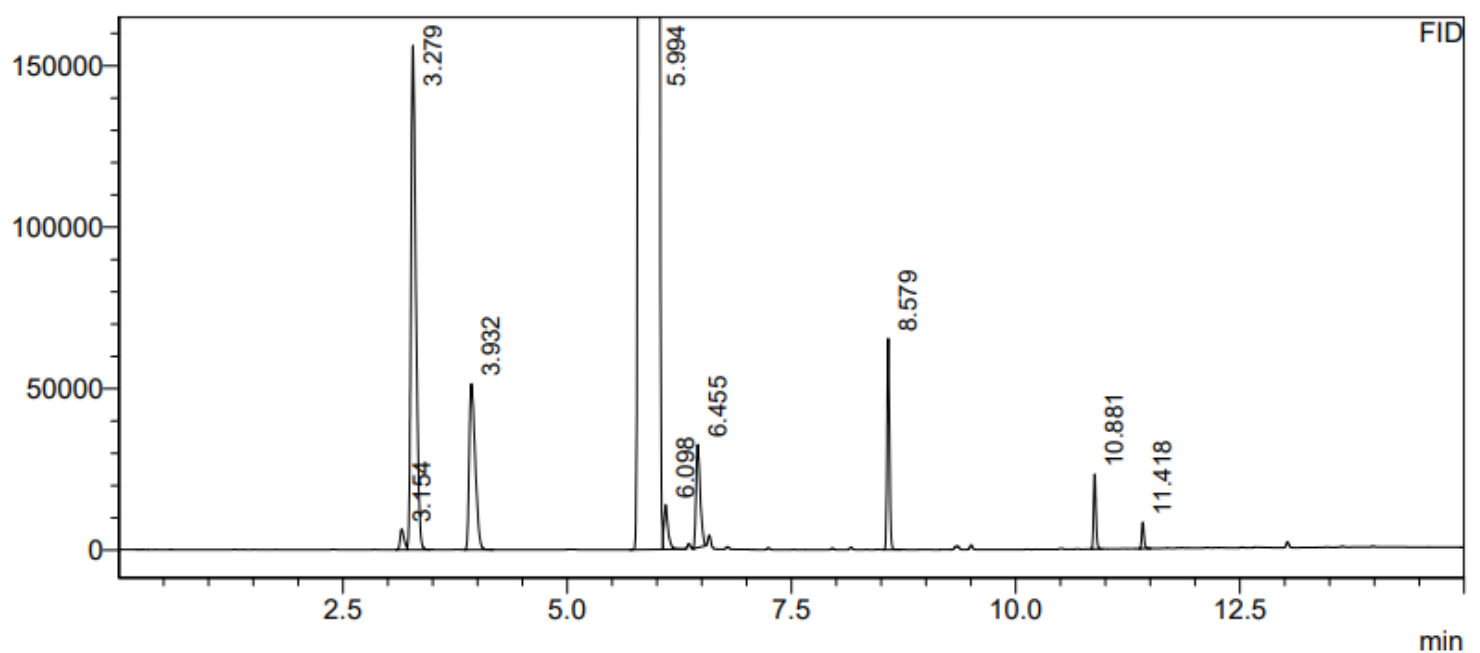

\begin{tabular}{cc} 
Retention Time & Compound \\
\hline 3.154 & impurity in eluent solvent \\
3.279 & tert-butyl alcohol from KOtBu \\
3.932 & ethanol \\
5.994 & acetonitrile (eluent) \\
6.098 & unknown \\
6.455 & $n$-propanol (internal standard) \\
8.579 & $n$-butanol \\
10.881 & 2-ethyl-1-butanol \\
11.418 & 1-hexanol
\end{tabular}

Figure S46. GC chromatogram and retention times of catalytic reaction table 3, entry 4 


\section{Table 3, entry 5}

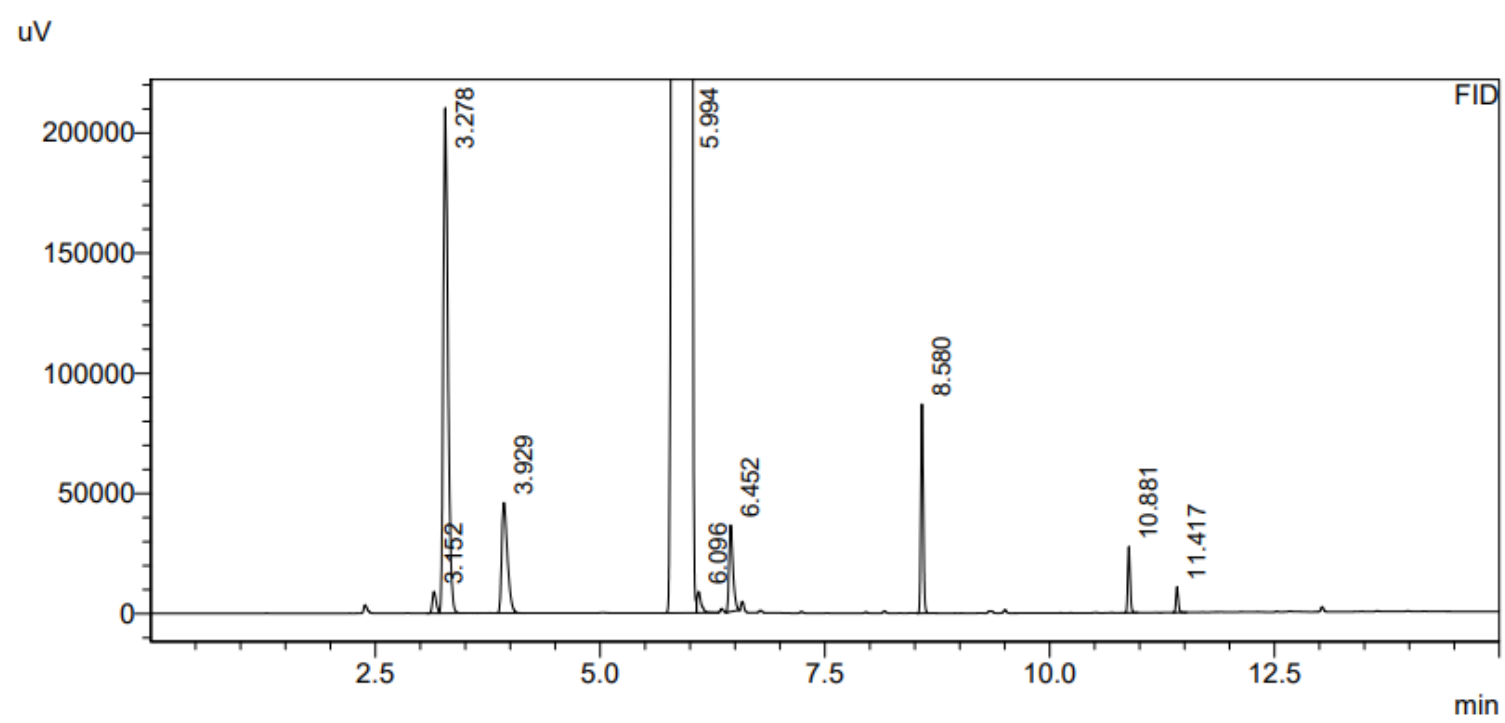

\begin{tabular}{cc} 
Retention Time & Compound \\
\hline 3.152 & impurity in eluent solvent \\
3.278 & tert-butyl alcohol from KOtBu \\
3.929 & ethanol \\
5.994 & acetonitrile (eluent) \\
6.096 & unknown \\
6.452 & $n$-propanol (internal standard) \\
8.580 & $n$-butanol \\
10.881 & 2-ethyl-1-butanol \\
11.417 & 1-hexanol
\end{tabular}

Figure S47. GC chromatogram and retention times of catalytic reaction table 3, entry 5 
Table 3, entry 6

uV

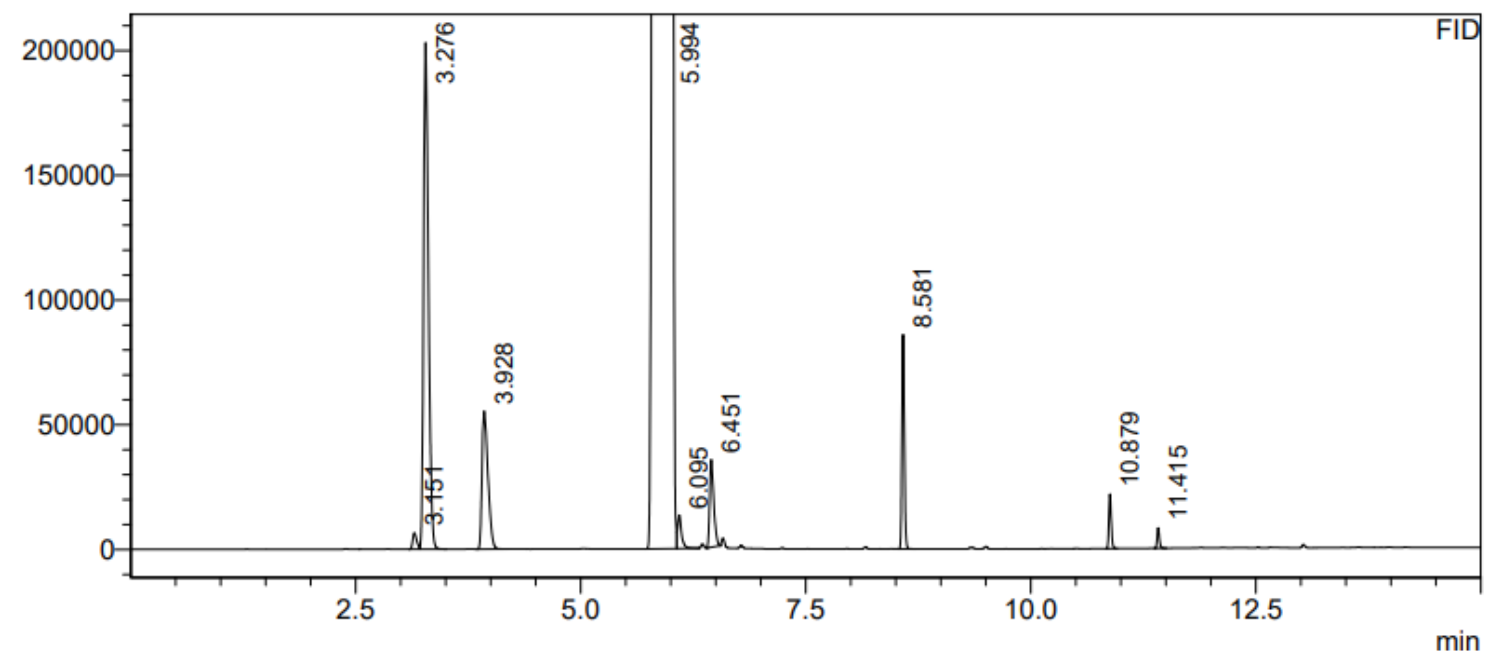

\begin{tabular}{cc} 
Retention Time & Compound \\
\hline 3.151 & impurity in eluent solvent \\
3.276 & tert-butyl alcohol from KOtBu \\
3.928 & ethanol \\
5.994 & acetonitrile (eluent) \\
6.095 & unknown \\
6.451 & $n$-propanol (internal standard) \\
8.581 & $n$-butanol \\
10.879 & 2-ethyl-1-butanol \\
11.415 & 1-hexanol
\end{tabular}

Figure S48. GC chromatogram and retention times of catalytic reaction table 3, entry 6 
Table 3, entry 7

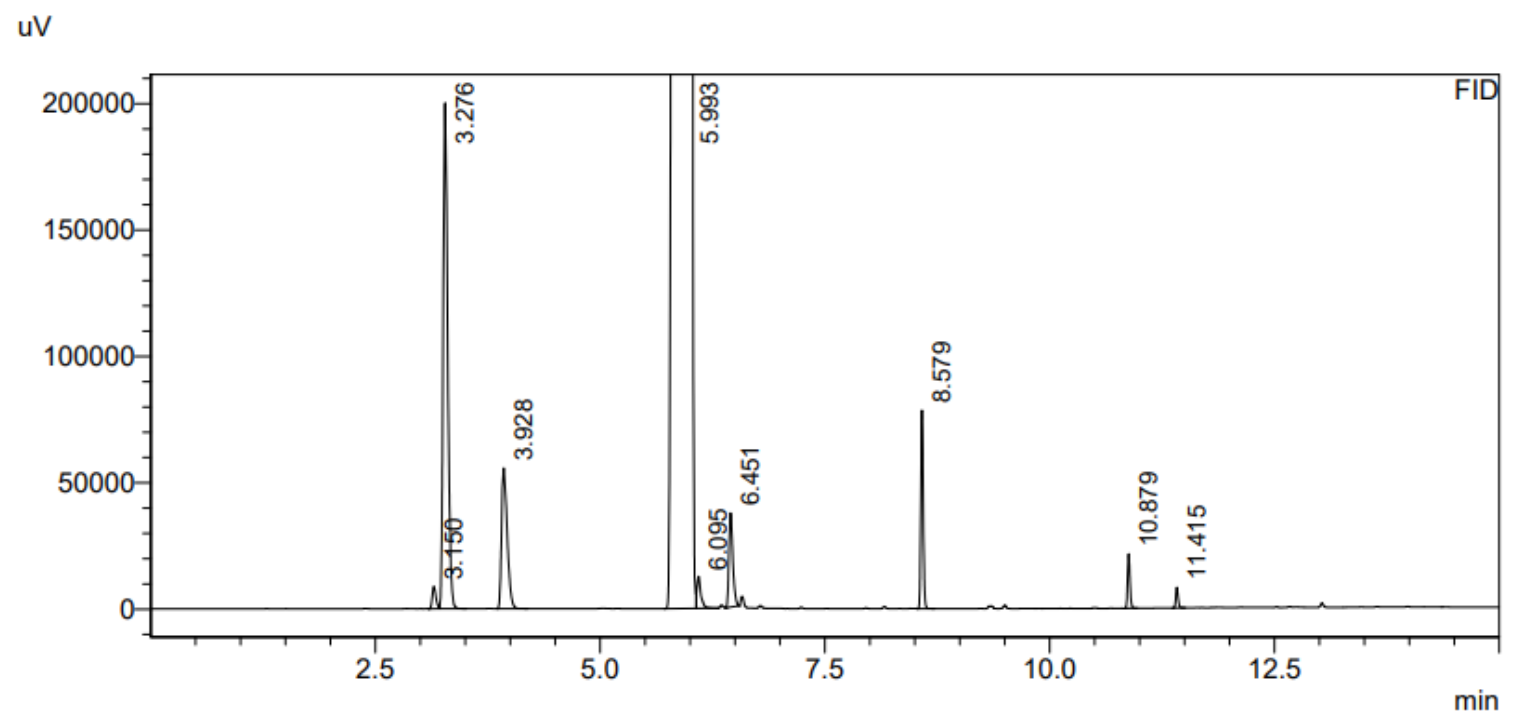

\begin{tabular}{cc} 
Retention Time & Compound \\
\hline 3.150 & impurity in eluent solvent \\
3.276 & tert-butyl alcohol from KOtBu \\
3.928 & ethanol \\
5.993 & acetonitrile (eluent) \\
6.095 & unknown \\
6.451 & $n$-propanol (internal standard) \\
8.579 & $n$-butanol \\
10.879 & 2-ethyl-1-butanol \\
11.415 & 1-hexanol
\end{tabular}

Figure S49. GC chromatogram and retention times of catalytic reaction table 3 , entry 7 


\section{Table 3, entry 8}

uV

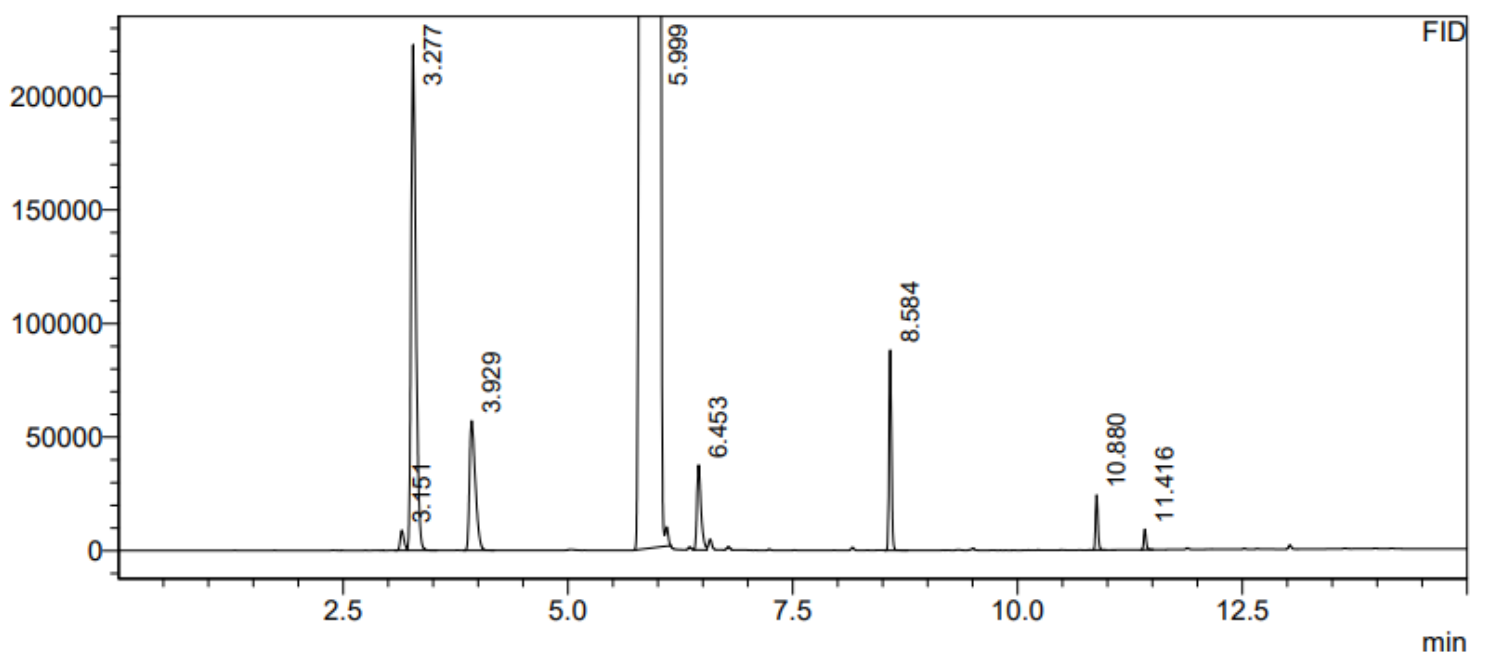

Retention Time

Compound

3.151

impurity in eluent solvent

3.277

3.929

5.999

tert-butyl alcohol from KOtBu

6.453

acetonitrile (eluent)

8.584

$n$-propanol (internal standard)

10.880

n-butanol

11.416

2-ethyl-1-butanol

1-hexanol

Figure S50. GC chromatogram and retention times of catalytic reaction table 3 , entry 8 
Table 3, entry 9

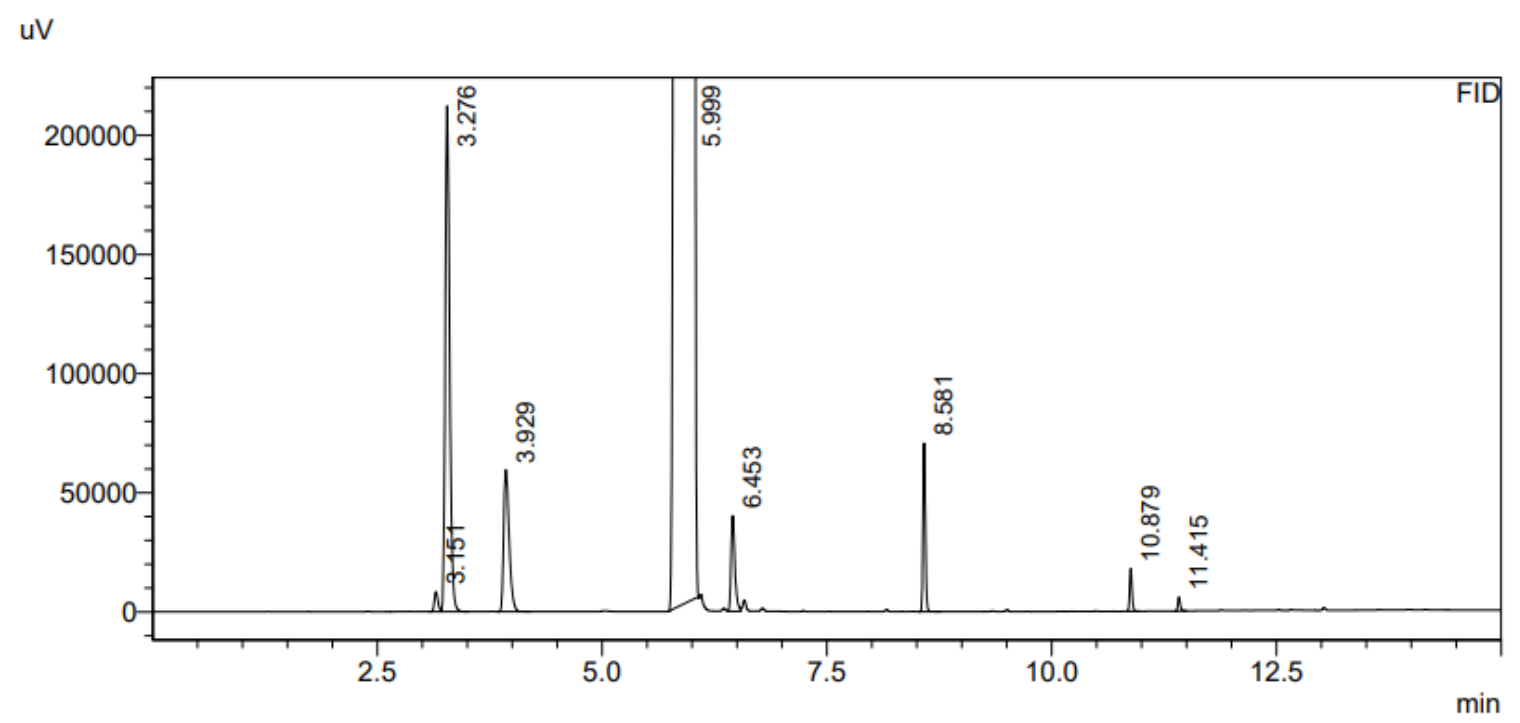

\begin{tabular}{cc} 
Retention Time & Compound \\
\hline 3.151 & impurity in eluent solvent \\
3.276 & tert-butyl alcohol from KOtBu \\
3.929 & ethanol \\
5.999 & acetonitrile (eluent) \\
6.453 & $n$-propanol (internal standard) \\
8.581 & $n$-butanol \\
10.879 & 2-ethyl-1-butanol \\
11.415 & 1-hexanol
\end{tabular}

Figure S51. GC chromatogram and retention times of catalytic reaction table 3, entry 9 
Table 3, entry 10

uV

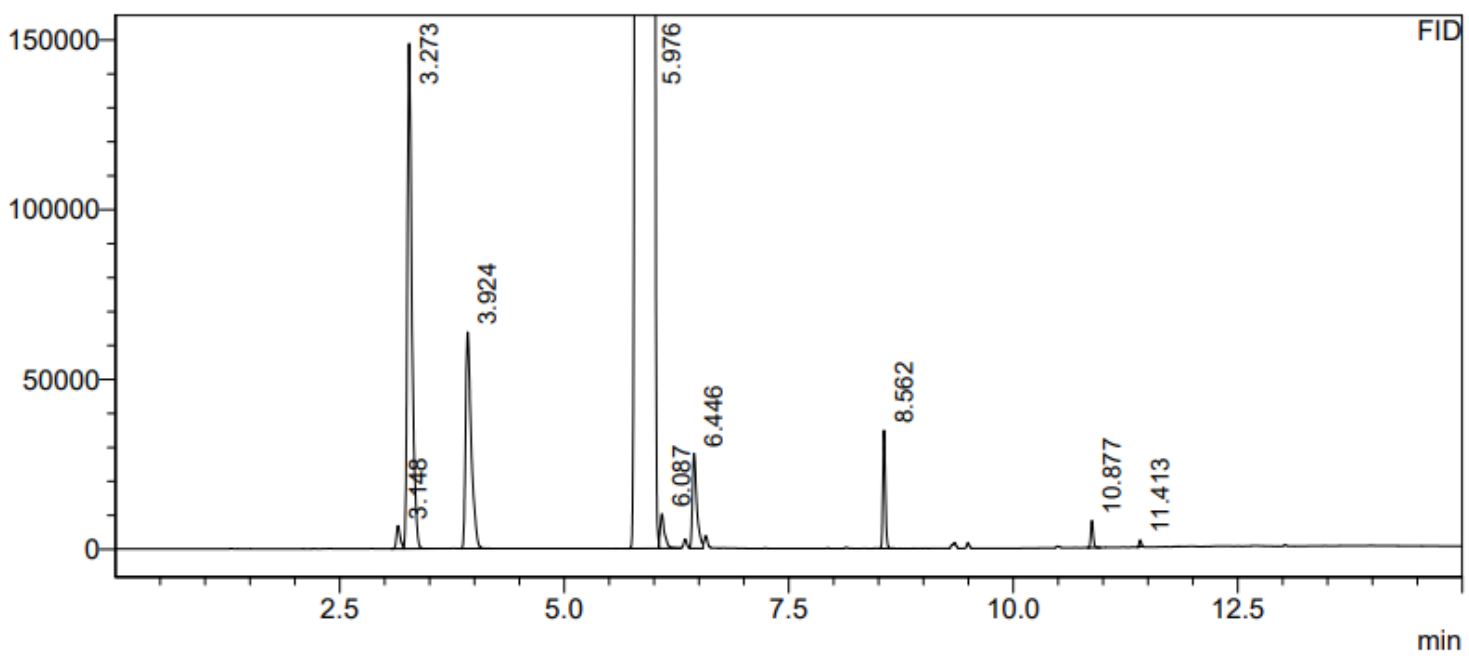

\begin{tabular}{cc} 
Retention Time & Compound \\
\hline 3.148 & impurity in eluent solvent \\
3.273 & tert-butyl alcohol from KOtBu \\
3.924 & ethanol \\
5.976 & acetonitrile (eluent) \\
6.087 & unknown \\
6.446 & $n$-propanol (internal standard) \\
8.562 & $n$-butanol \\
10.877 & 2-ethyl-1-butanol \\
11.413 & 1-hexanol
\end{tabular}

Figure S52. GC chromatogram and retention times of catalytic reaction table 3, entry 10 


\section{Table 3, entry 11}

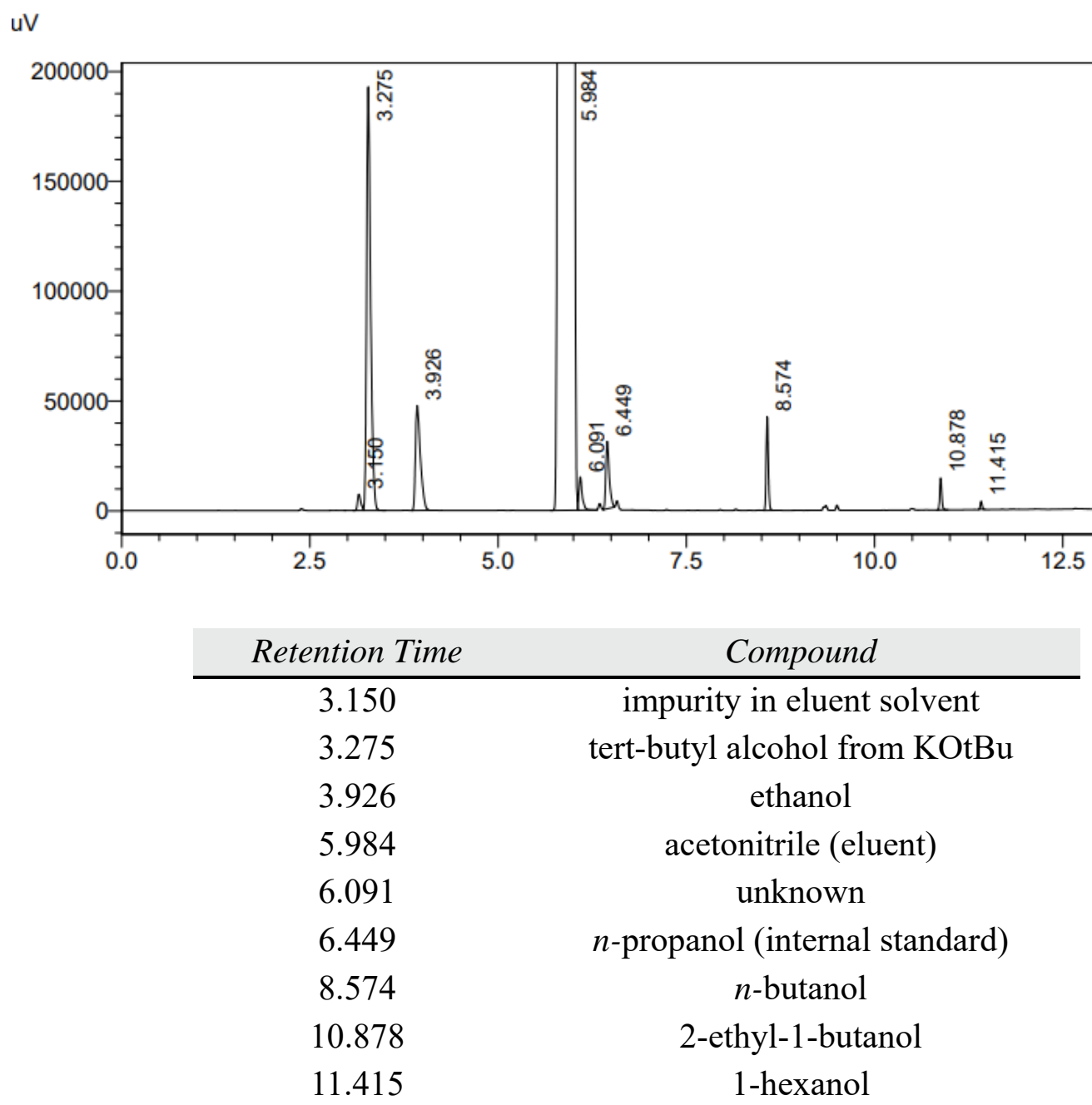

Figure S53. GC chromatogram and retention times of catalytic reaction table 3, entry 11 
Table 3, entry 12

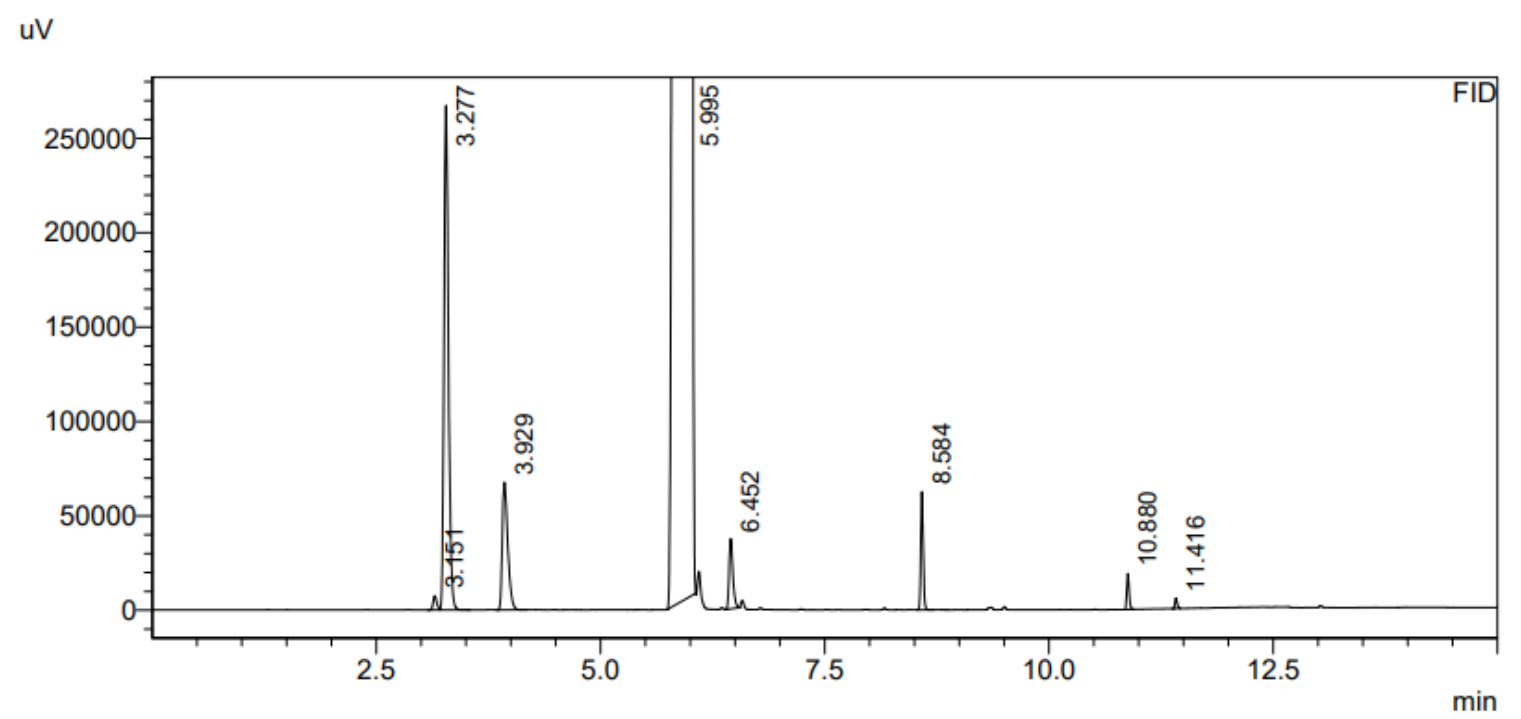

\begin{tabular}{cc} 
Retention Time & Compound \\
\hline 3.151 & impurity in eluent solvent \\
3.277 & tert-butyl alcohol from KOtBu \\
3.929 & ethanol \\
5.995 & acetonitrile (eluent) \\
6.452 & $n$-propanol (internal standard) \\
8.584 & n-butanol \\
10.880 & 2-ethyl-1-butanol \\
11.416 & 1-hexanol
\end{tabular}

Figure S54. GC chromatogram and retention times of catalytic reaction table 3, entry 12 
Table 3, entry 13

uV

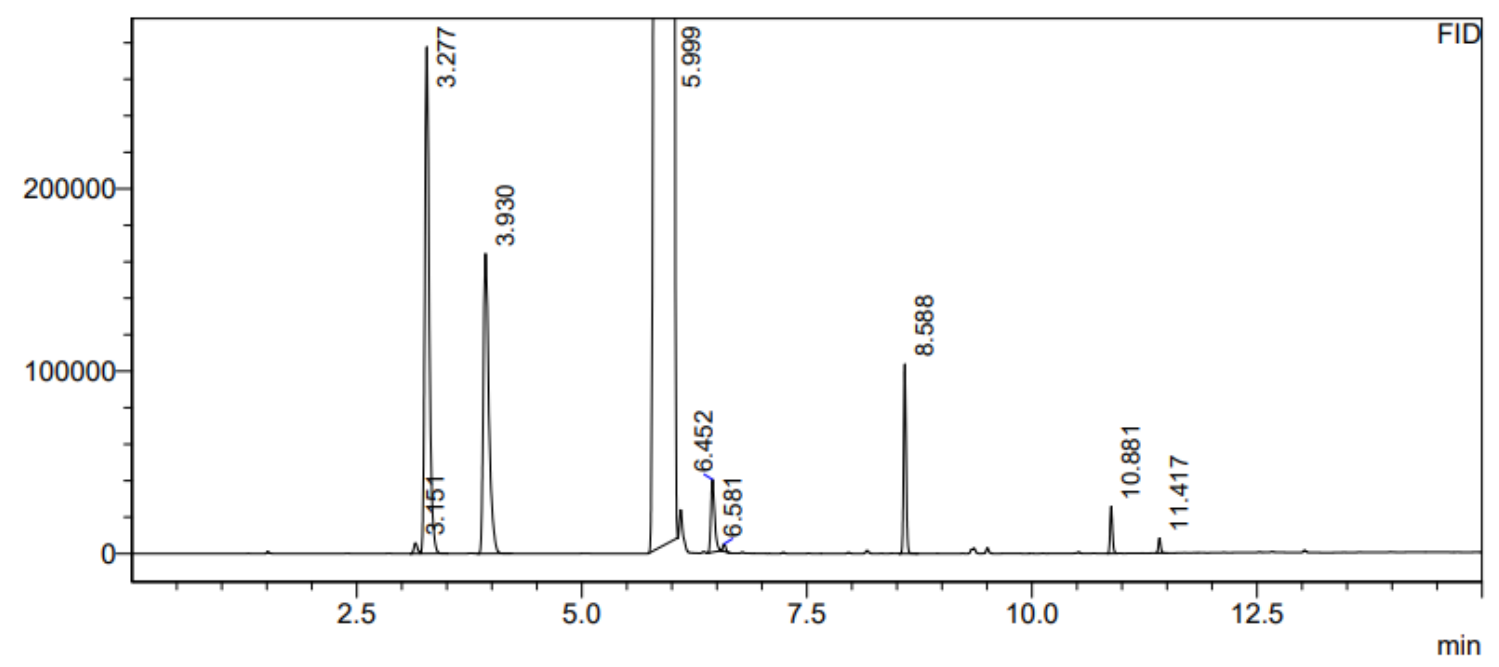

\begin{tabular}{cc} 
Retention Time & Compound \\
\hline 3.151 & impurity in eluent solvent \\
3.277 & tert-butyl alcohol from KOtBu \\
3.930 & ethanol \\
5.999 & acetonitrile (eluent) \\
6.452 & $n$-propanol (internal standard) \\
6.581 & unknown \\
8.588 & n-butanol \\
10.881 & 2-ethyl-1-butanol \\
11.417 & 1-hexanol
\end{tabular}

Figure S55. GC chromatogram and retention times of catalytic reaction table 3, entry 13 
Table 3, entry 14

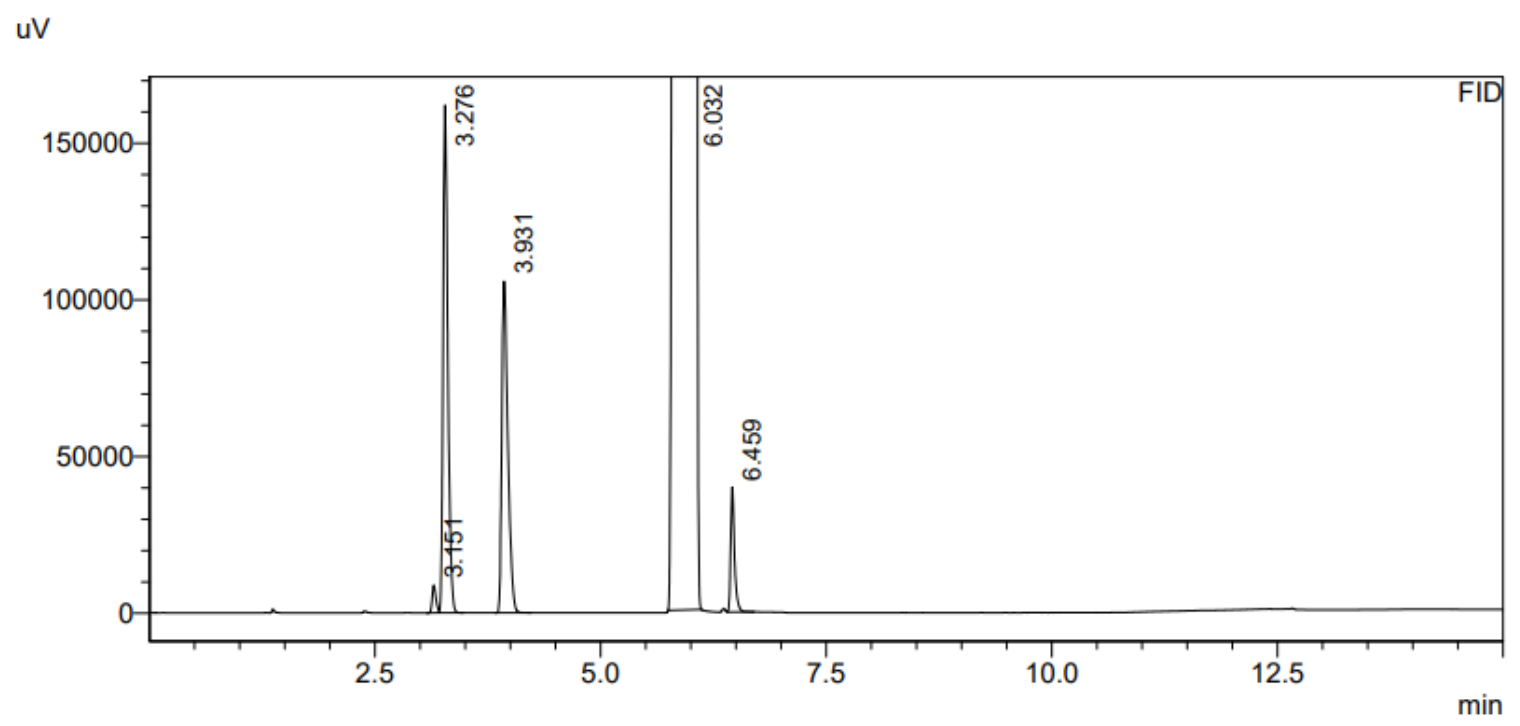

\begin{tabular}{cc} 
Retention Time & Compound \\
\hline 3.151 & impurity in eluent solvent \\
3.276 & tert-butyl alcohol from KOtBu \\
3.931 & ethanol \\
6.032 & acetonitrile (eluent) \\
6.459 & $n$-propanol (internal standard)
\end{tabular}

Figure S56. GC chromatogram and retention times of catalytic reaction table 3, entry 14 
Table 3, entry 15

uV

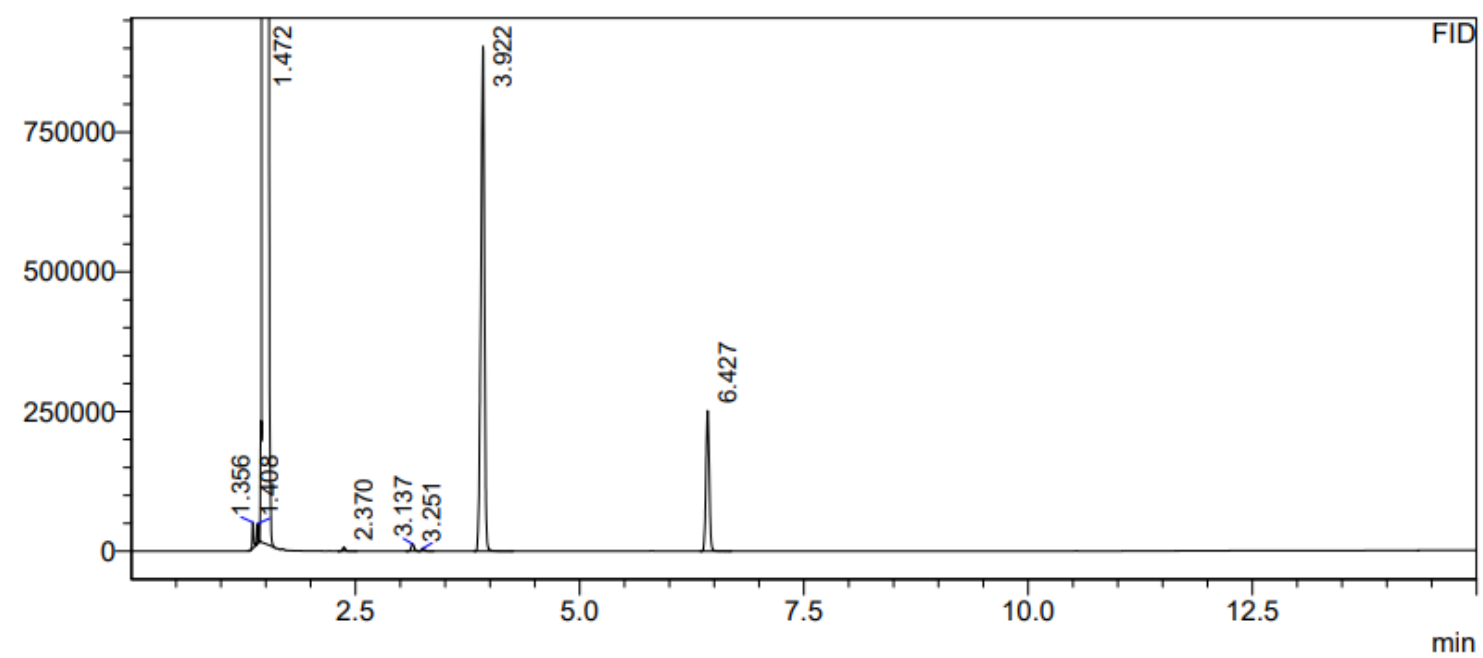

\begin{tabular}{cc} 
Retention Time & Compound \\
\hline 1.356 & impurity in eluent solvent \\
1.408 & impurity in eluent solvent \\
1.472 & diethyl ether \\
2.370 & unknown \\
3.137 & unknown \\
3.251 & unknown \\
3.922 & ethanol \\
6.427 & $n$-propanol (internal standard)
\end{tabular}

Figure S57. GC chromatogram and retention times of catalytic reaction table 3, entry 15 


\section{Catalytic reaction with sodium phenoxide}

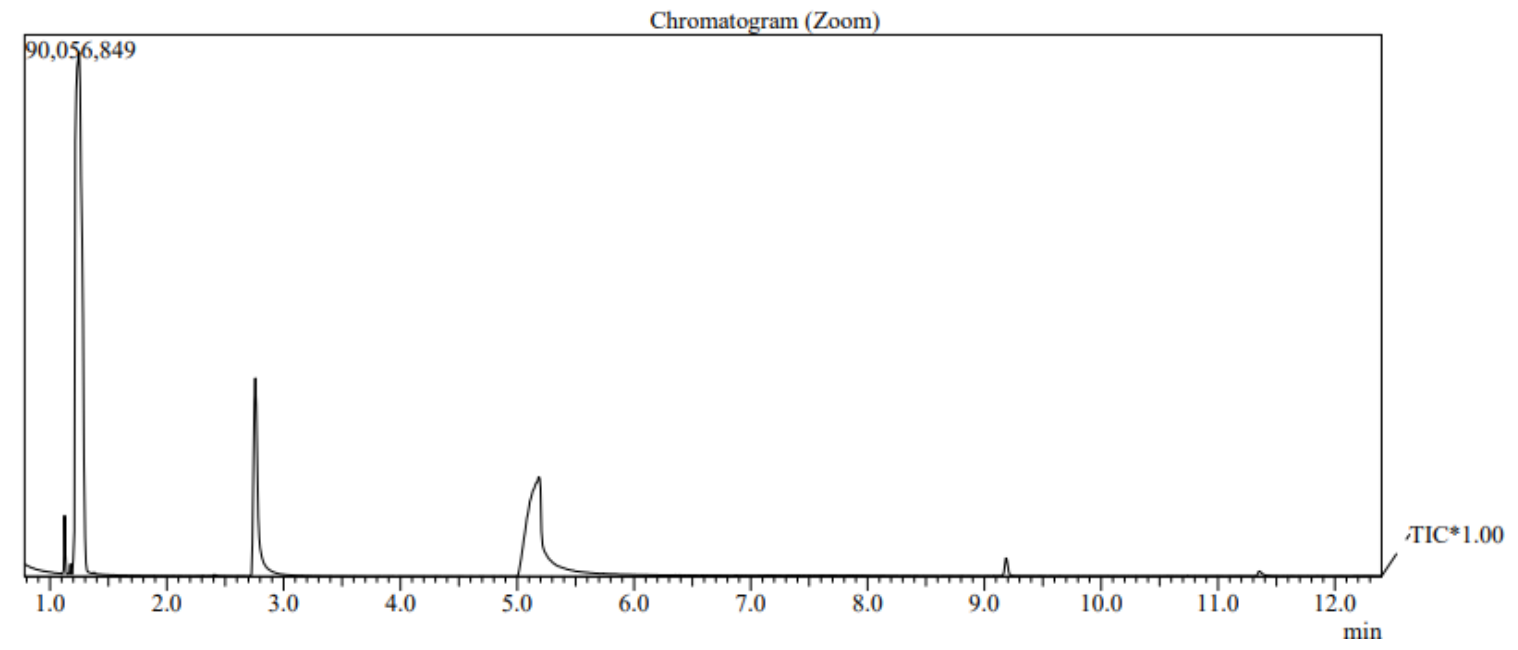

Line\#:1 R.Time:1.250(Scan\#:150)

MassPeaks: 190

250(150) BasePeak:30.85(11234618)

BG Mode:Averaged 1.192-1.342(143-161)

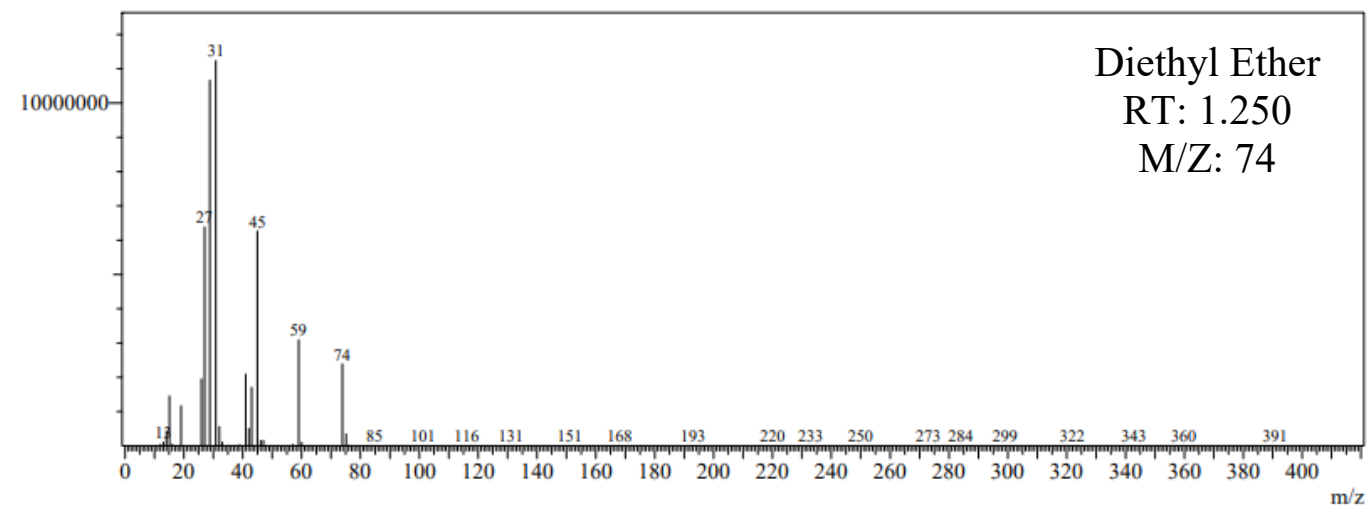

Line\#:1 R.Time:2.758(Scan\#:331)

MassPeaks: 276

RawMode:Single 2.758(331) BasePeak:31.05(9446314)

BG Mode:Averaged 2.608-3.050(313-366)

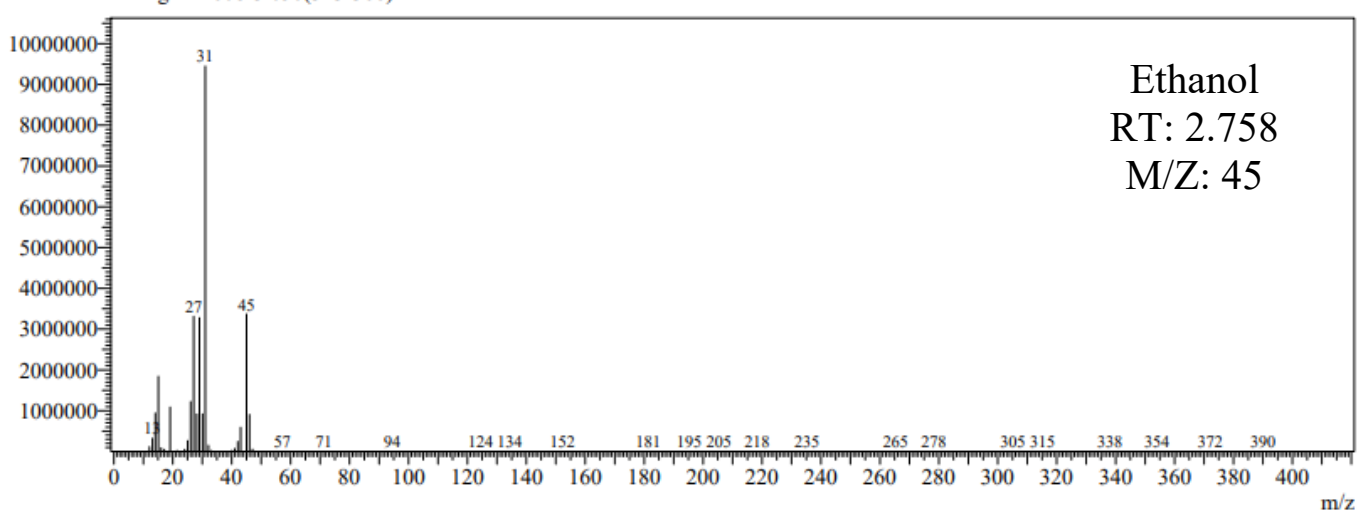



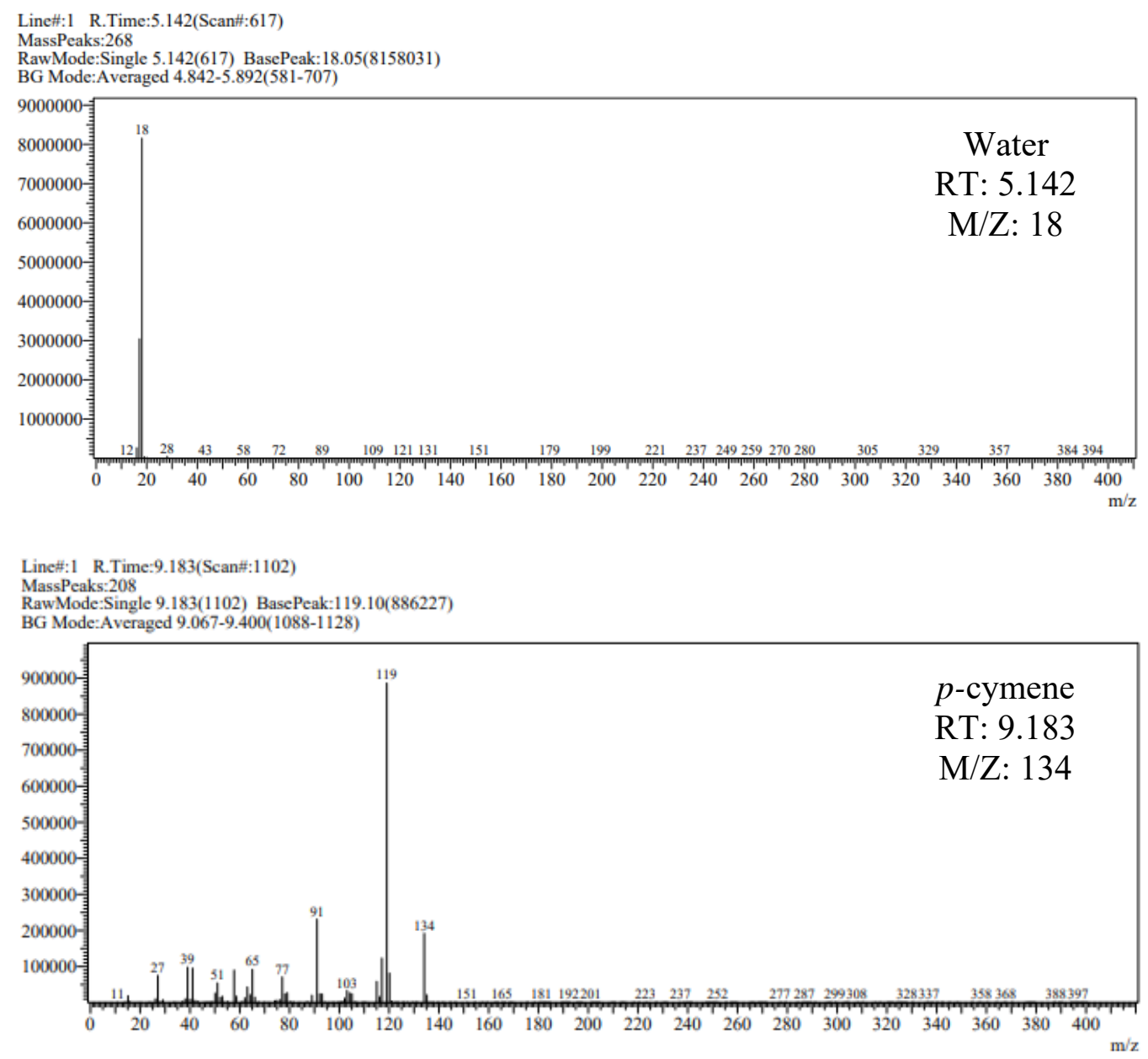

Figure S58. GC-MS chromatogram of catalytic reaction with sodium phenoxide 


\section{Catalytic reaction with DBU}

uV

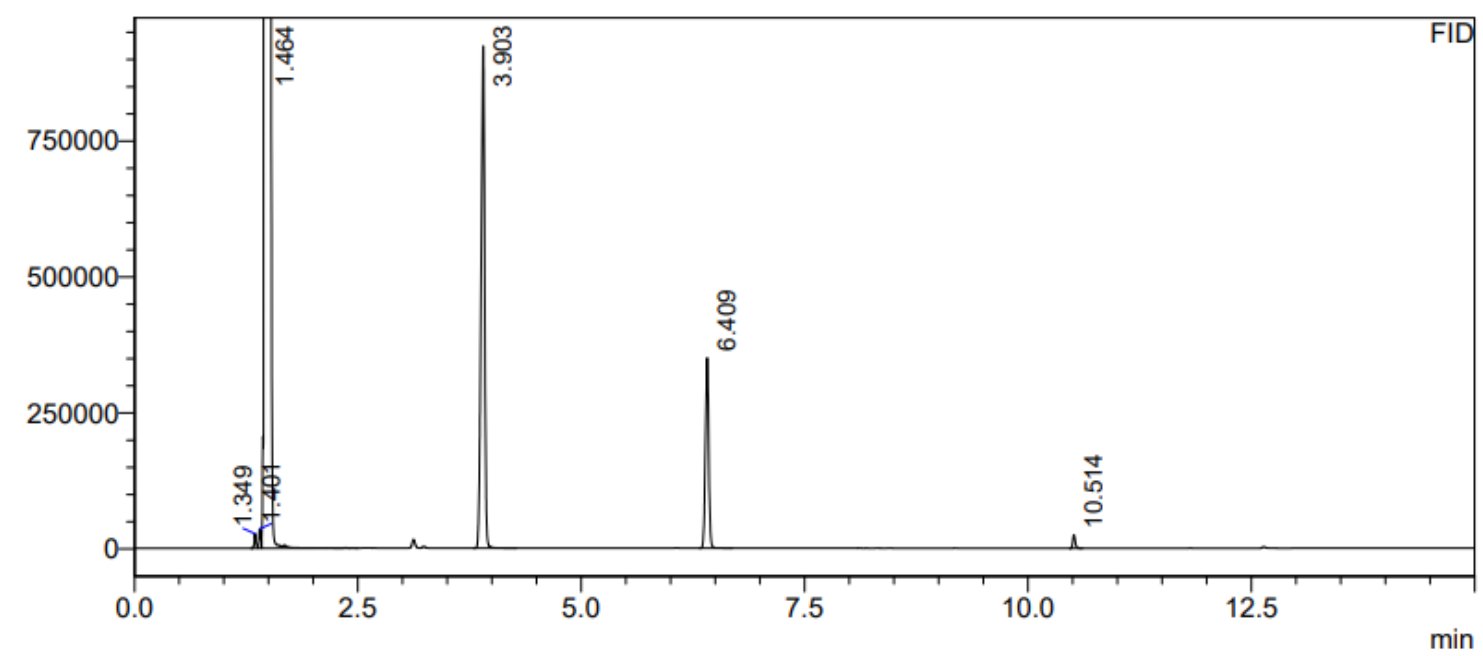

\begin{tabular}{cc} 
Retention Time & Compound \\
\hline 1.349 & impurity in eluent solvent \\
1.401 & impurity in eluent solvent \\
1.464 & Diethyl ether \\
3.903 & ethanol \\
6.409 & $n$-propanol (internal standard) \\
10.514 & $p$-cymene
\end{tabular}

Figure S59. GC-MS chromatogram of catalytic reaction with DBU 


\section{Catalytic reaction with Hunig's base}

uV

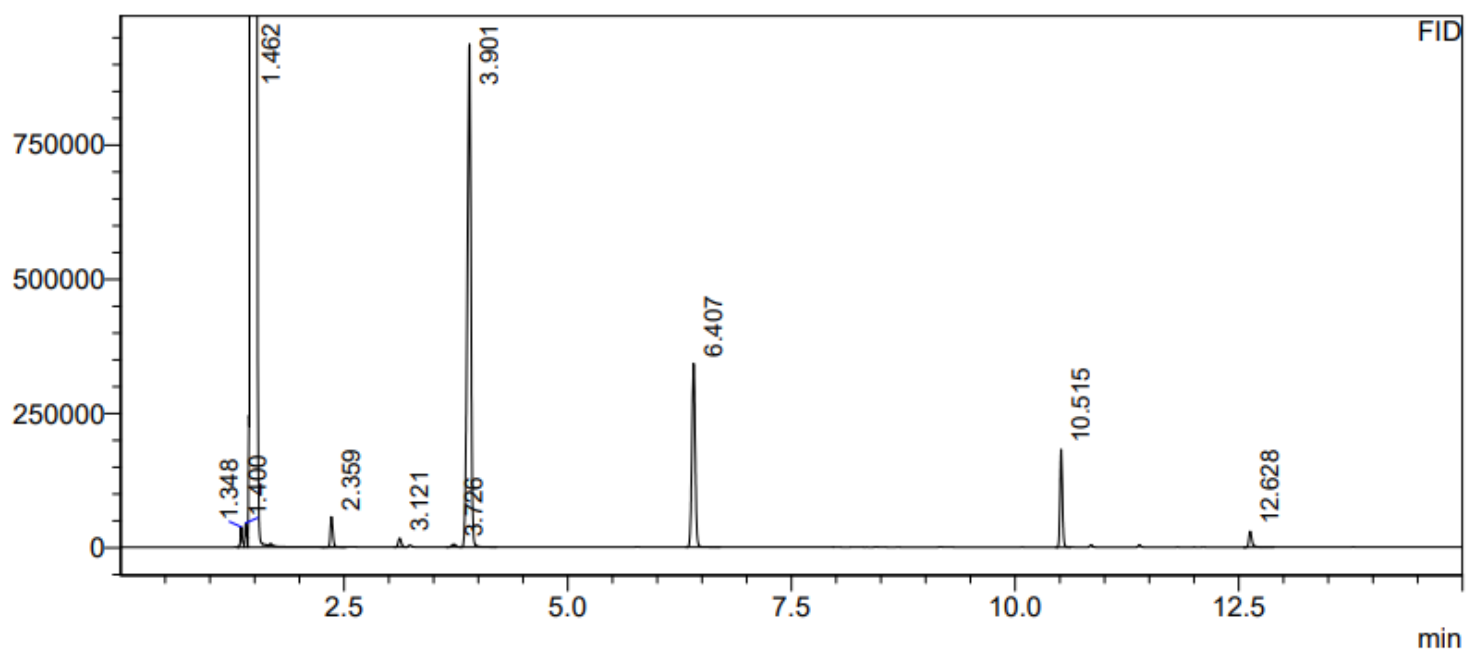

\begin{tabular}{cc} 
Retention Time & Compound \\
\hline 1.348 & impurity in eluent solvent \\
1.400 & impurity in eluent solvent \\
1.462 & Diethyl ether \\
2.359 & unknown \\
3.121 & unknown \\
3.901 & ethanol \\
6.407 & n-propanol (internal standard) \\
10.515 & p-cymene \\
12.628 & unknown
\end{tabular}

Figure S60. GC-MS chromatogram of catalytic reaction with Hunig's base 


\section{Catalytic reaction with triethyl amine}

uV

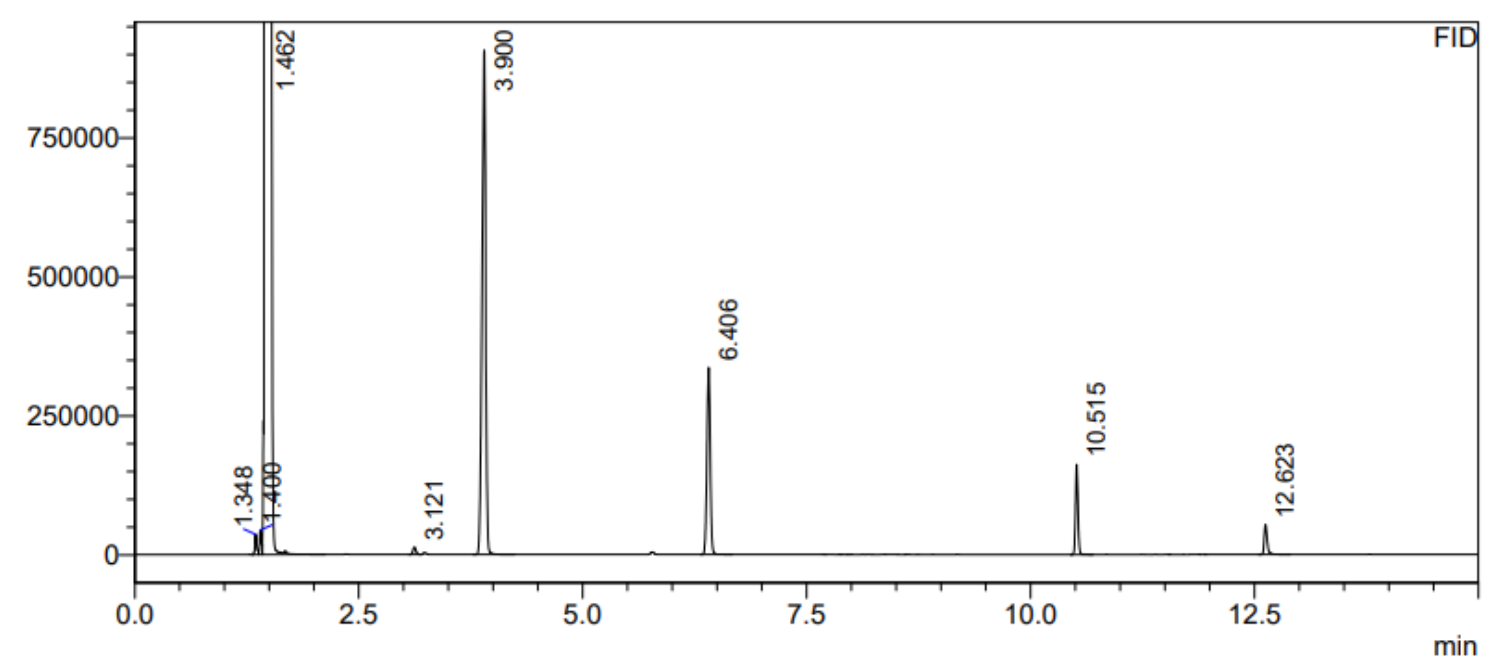

\begin{tabular}{cc} 
Retention Time & Compound \\
\hline 1.348 & impurity in eluent solvent \\
1.400 & impurity in eluent solvent \\
1.462 & Diethyl ether \\
3.121 & unknown \\
3.900 & ethanol \\
6.406 & n-propanol (internal standard) \\
10.515 & p-cymene \\
12.623 & unknown
\end{tabular}

Figure S61. GC-MS chromatogram of catalytic reaction with triethyl amine 


\section{S8. IR Data for white solid (potassium silicate)}

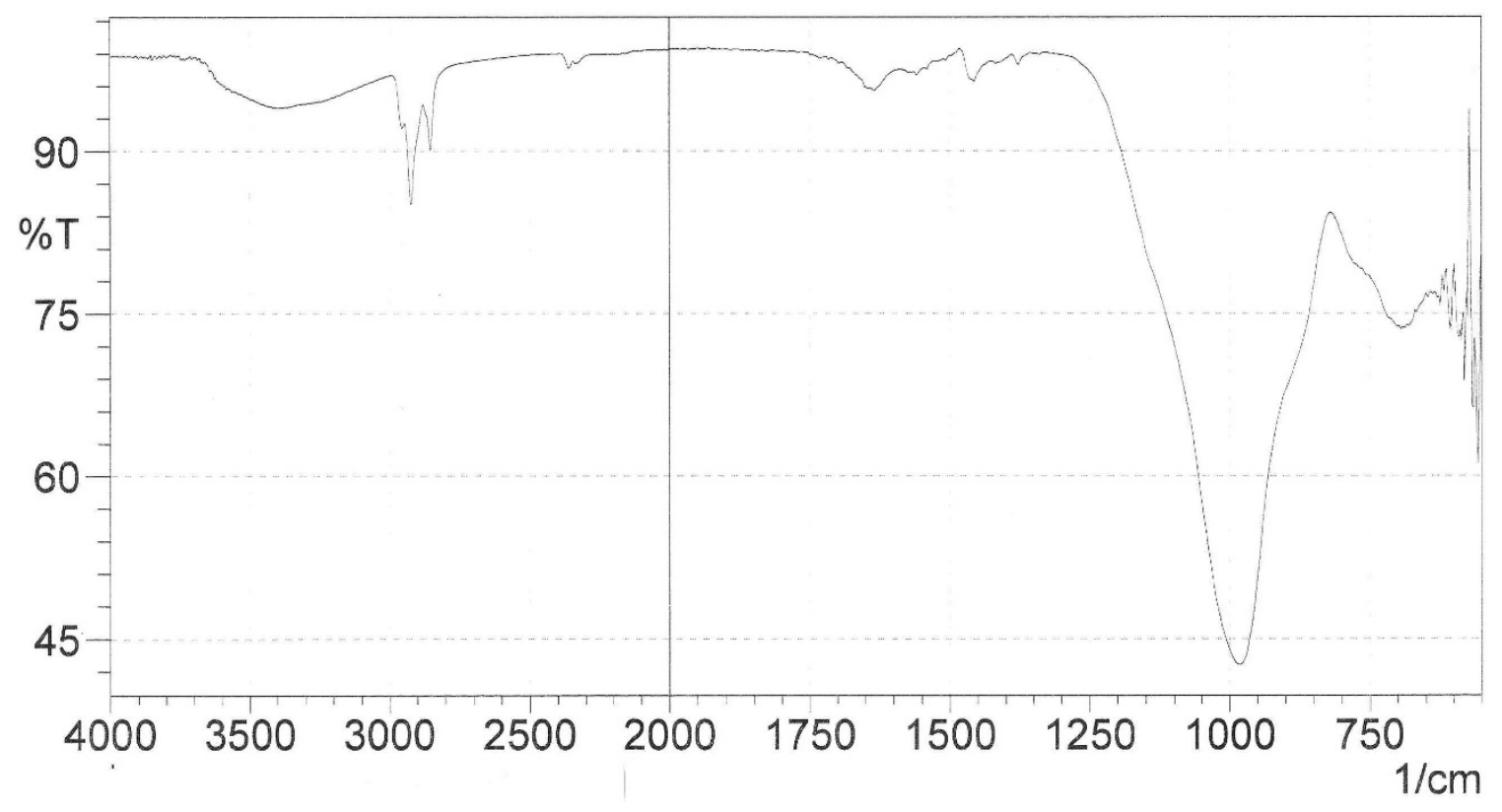

\section{S9. Examination of aqueous phase of the reaction}

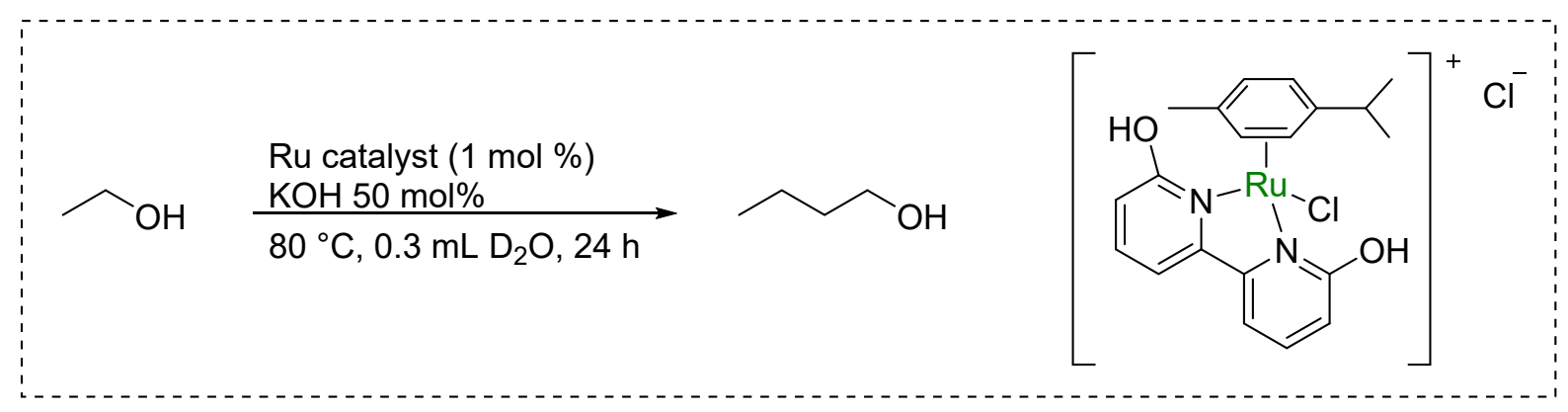

The reaction was carried out using ethanol ( $1 \mathrm{mmol}, 1$ equiv), $\mathrm{KOH}$ ( $50 \mathrm{~mol} \%$ ), Ru catalyst (1 mol \%) and $0.3 \mathrm{~mL} \mathrm{D}_{2} \mathrm{O}$. After $24 \mathrm{~h}$ at $80{ }^{\circ} \mathrm{C}, 0.2 \mathrm{~mL}$ of $10 \% \mathrm{HCl}$ was added and the reaction was filtered through a glass fiber filter. An additional $0.1 \mathrm{~mL}$ of acid was added after filtration. The $\mathrm{pH}$ was determined to be $\mathrm{pH} 2$ and the organics were extracted with 5 $\times 1 \mathrm{~mL}$ diethyl ether. $10 \mu \mathrm{L}$ of 1 - propanol was added to the diethyl ether extractions and the reaction was examined by GC. A ${ }^{1} \mathrm{H}$ NMR spectra was obtained of the aqueous layer with acetonitrile added as an internal standard. No acetate was observed. 


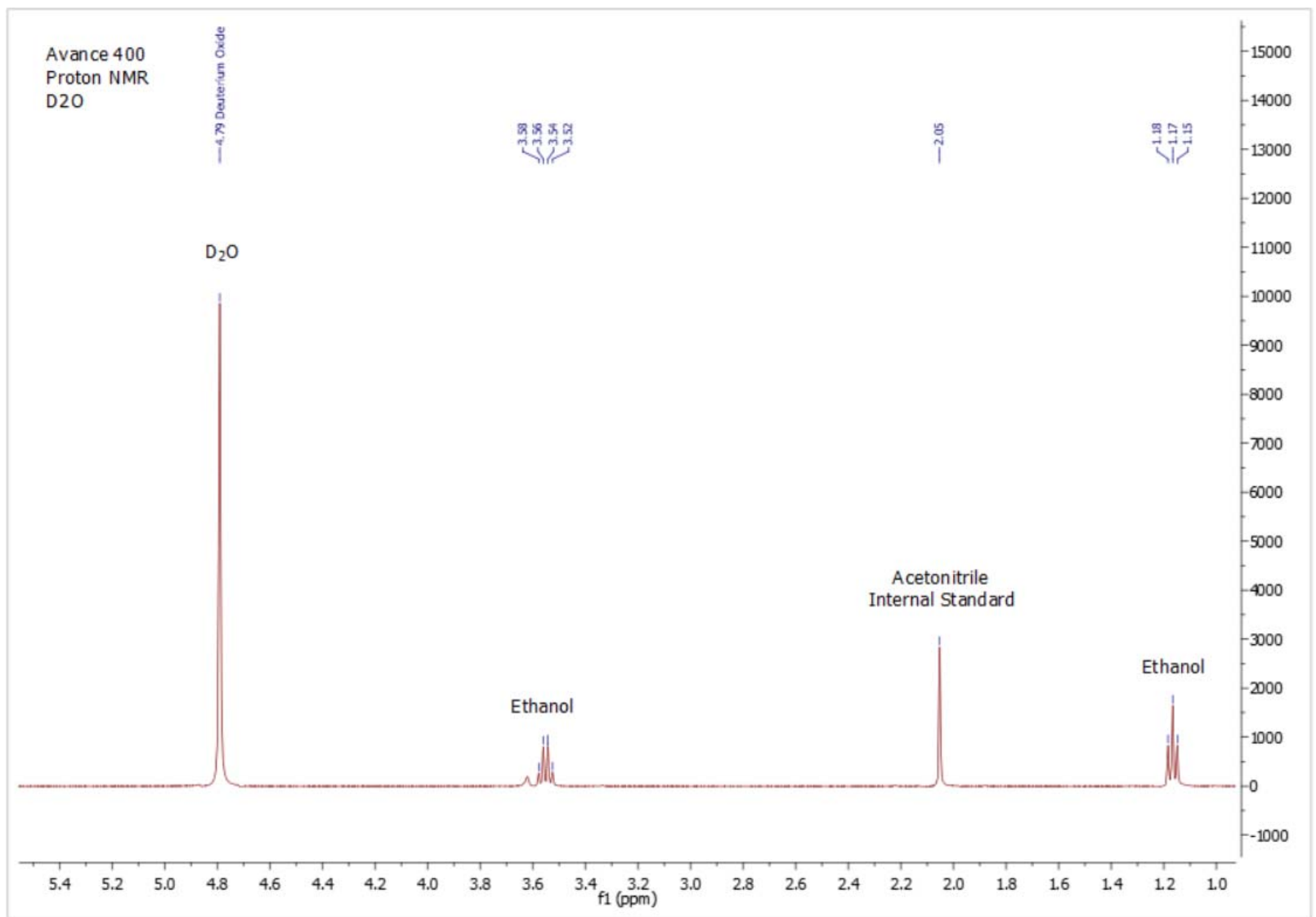

Figure S62. ${ }^{1} \mathrm{H}$ NMR spectra of aqueous phase of standard reaction. Acetic acid is not seen at $\delta 2.08$. Acetonitrile was added as an internal standard $(\delta 2.06)$.

\section{References}

${ }^{1}$ Nieto, I.; Livings, M. S.; Sacci, J. B.; Reuther, L. E.; Zeller, M.; Papish, E. T. Transfer Hydrogenation in Water via a Ruthenium Catalyst with OH Groups near the Metal Center on a Bipy Scaffold. Organometallics 2011, 30, 6339-6342. 